\title{
GLOBAL DNA METHYLATION ANALYSIS IN RELAPSED PRE-B CELL ACUTE LYMPHOBLASTIC LEUKEMIA
}

A Dissertation
presented to
the Faculty of the Graduate School
at the University of Missouri-Columbia
In Partial Fulfillment
of the Requirements for the Degree
Doctor of Philosophy
Alexei Jay Stuckel
Dr. Jeffrey Bryan, Dissertation Supervisor

May 2019 
(C) Copyright by Alexei Jay Stuckel 2019

All Rights Reserved 
The undersigned, appointed by the dean of the Graduate School,

have examined the Dissertation entitled

GLOBAL DNA METHYLATION ANALYSIS IN RELAPSED PRE-B CELL ACUTE LYMPHOBLASTIC LEUKEMIA

Presented by Alexei Jay Stuckel

A candidate for the degree of

Doctor of Philosophy

And hereby certify that, in their opinion, it is worthy of acceptance.

\begin{tabular}{c}
\hline Jeffrey N. Bryan \\
\hline Senthil R. Kumar \\
\hline Dmitriy Shin \\
\hline Trupti Joshi \\
\hline Bimal K. Ray
\end{tabular}




\section{DEDICATION}

This work is dedicated to my parents, Jay \& Christine Stuckel. I would also like to dedicate this work to former committee member, colleague, and friend Jerry Arthur who passed away last year. 


\section{ACKNOWLEDGMENTS}

I would first like to acknowledge my previous advisor Dr. Kristen Taylor, current advisor Dr. Jeffrey Bryan and my co-advisor Dr. Dmitriy Shin for their guidance and patience throughout this research project. I was able to gain knowledge, research passion and complete this project with their expertise and encouragement. Thank you for being positive and for helping me along the way. I would also like to thank my degree committee members Dr. Bimal Ray, Dr. Trupti Joshi, and Dr. Senthil Kumar for their advice and guidance in this endeavor.

I would like to thank Dr. Gerald Arthur, Dr. J. Wade Davis, Dr. Benjamin T. Levinson, and Dr. Andi Dhroso for helping me to develop bioinformatics skill necessary to complete this project and degree. In addition I would like to thank Jennifer Schnabel for her expertise in experimental design and general wisdom. Thanks to the members of the Taylor and Bryan Lab, specifically Olha Kholod, Clayton Del Pico, Dr. Shirley Chu, and Emily Shank for providing there free time to help my projects come to fruition. I have truly enjoyed every day because of the great people I've met throughout graduate school.

Finally, I would like to thank my parents, my girlfriend Kayla Kilpatrick, and other family members for always supporting me. I could not have done any of this work without their support, love and encouragement. 


\section{TABLE OF CONTENTS}

ACKNOWLEDGMENTS......................................................

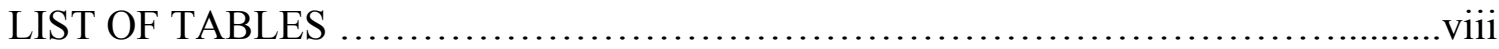

LIST OF FIGURES...........................................................

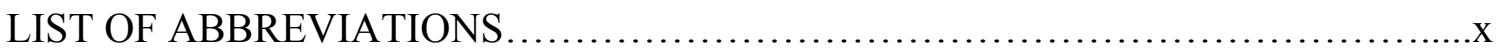

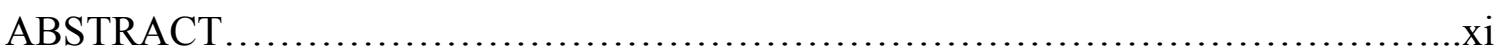

$\begin{array}{ll}\text { Chapter } & \text { Page }\end{array}$

CHAPTER 1: BACKGROUND ...............................................

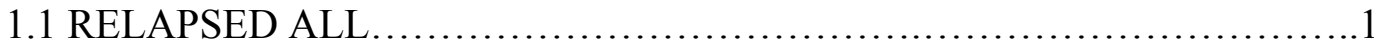

1.1.1 Future treatment of relapsed ALL...............................2

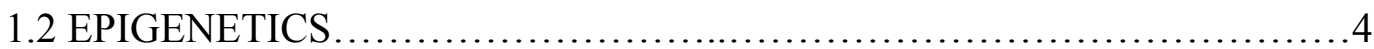

1.2.1 DNA methylation..........................................4

1.2.2 DNA methylation in cancer...............................6

1.3 DNA METHYLATION METHODS...................................8

1.4 DNA METHYLATION BIOMARKERS IN CANCER.....................9

1.4.1 DNA methylation relapse-associated biomarkers in ALL............10

1.4.2 DNA methylation based cytogenetic subtyping in ALL.............14

1.4.3 DNA methylation in the context of minimal residual disease

$(\mathrm{MRD})$ in ALL............................................... 18

1.4.4 Differential DNA methylation and gene expression provides

insight into gene-targeted therapy at relapse $\ldots \ldots \ldots \ldots \ldots \ldots \ldots \ldots \ldots . \ldots . \ldots . \ldots 23$

\subsection{DNA METHYLATION INHIBITORS IN RELAPSED ALL}

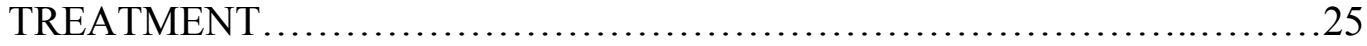




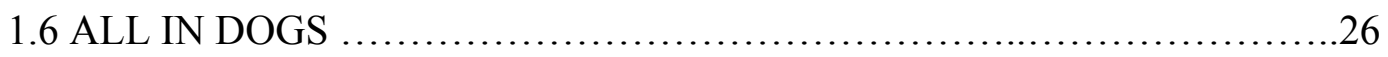

1.6.1 DNA methylation in dog ALL................................27

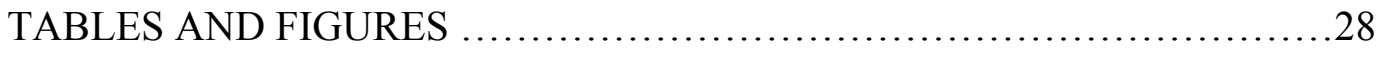

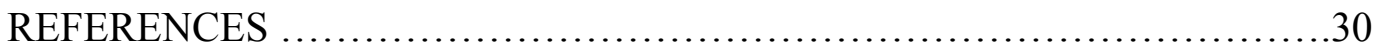

CHAPTER 2: METHYLOME ANALYSIS OF RELAPSED PEDIATRIC PRE-B

ACUTE LYMPHOBLASTIC LEUKEMIA ...................................... 45

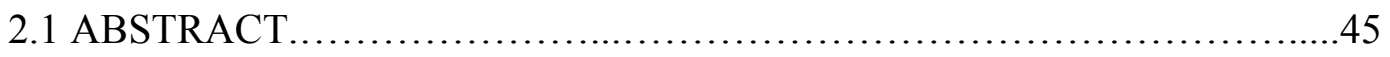

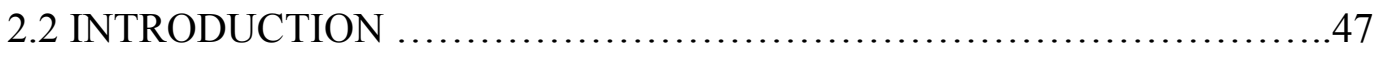

2.3 MATERIALS AND METHODS...........................................48

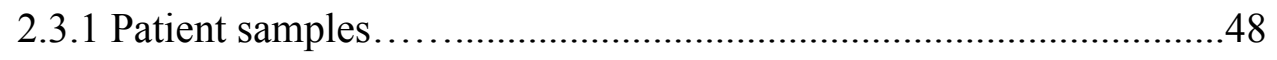

2.3.2 Genomic DNA isolation and MIRA-seq profile construction........49

2.3.3 Sequence processing and annotation of patient sample libraries.....51

2.3.4 Identifying DMRs between diagnosis and relapse patients..........51

2.3.5 Identifying common DMRs between diagnosis and relapse

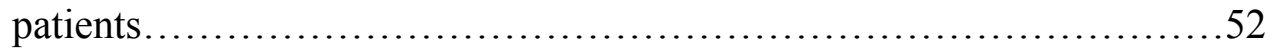

2.3.6 mirPath $\mathrm{v} 3$ software analysis..................................53

2.3.7 Identification of enriched biological processes of hypomethylated protein-coding genes..................................................

2.3.8 In silico analysis of 38 hypermethylated regions at relapse..........53

2.3.9 Identification of relapse associated regions in patients at original

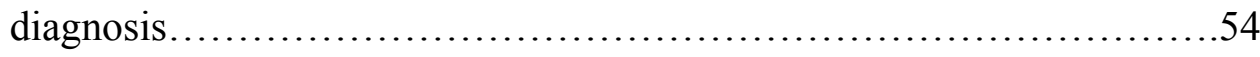

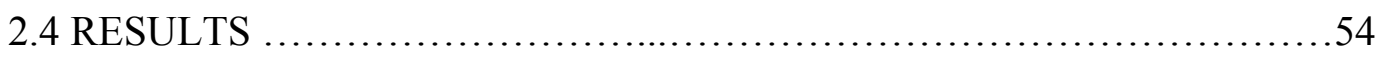

2.4.1 Patients with ALL lose methylation at relapse......................54 
2.4.2 Identification of DMRs present at diagnosis and relapse....

2.4.3 Identification of relapse associated DMRs present at diagnosis......58

2.5 DISCUSSION .59

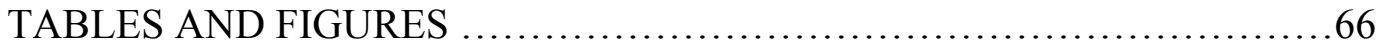

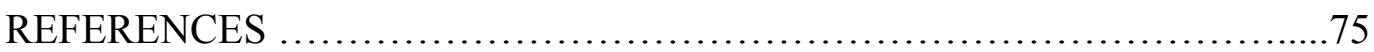

\section{CHAPTER 3: COMPARATIVE METHYLOME ANALYSIS IN CANINE AND}

HUMAN ACUTE LEUKMEIA............................................... 81

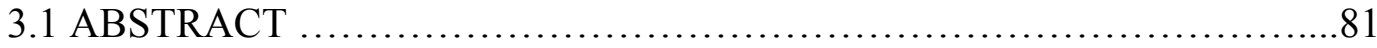

3.2 INTRODUCTION ................................................ 82

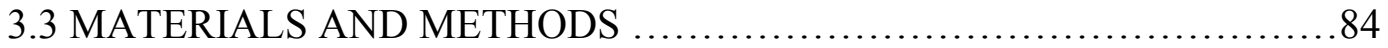

3.3.1 Patient samples.............................................. 84

3.3.2 Genomic DNA isolation and MIRA-seq construction from patient sample....................................................85

3.3.3 Sequence processing and peak identification of dog

MIRA-seq libraries...........................................87

3.3.4 Identifying DMRs between cAL and healthy dog..............87

3.3.5 Custom annotation of genomic coordinates in canine (canfam3)...88

3.3.6 Comparative DNA methylation analysis in human and dog and bedGraph illustration..........................................89

3.3.7 Identifying conserved intergenic sequences with aberrant methylation between human ALL and canine AL.....................90

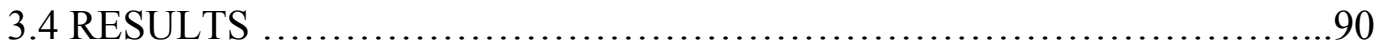

3.4.1 DNA methylation peak analysis in canine AL .......................90

3.4.2 Predominate hypermethylation in canine AL...........................91 
3.4.3 Comparative DNA methylation analysis in canine AL and human ALL.....92

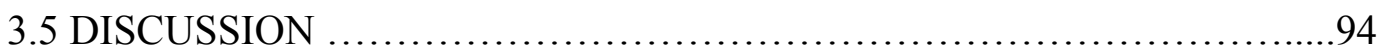

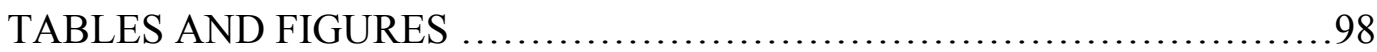

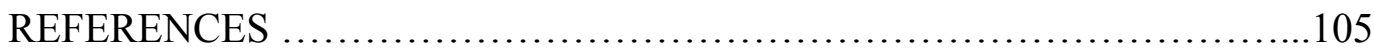

CHAPTER 4: RELAPSE ASSOCIATED BIOMARKERS IN ACUTE

\section{LYMPHOBLASTIC}

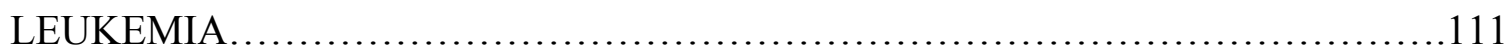

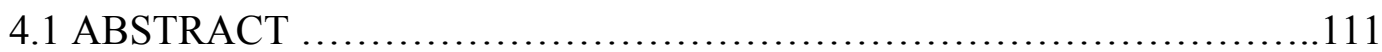

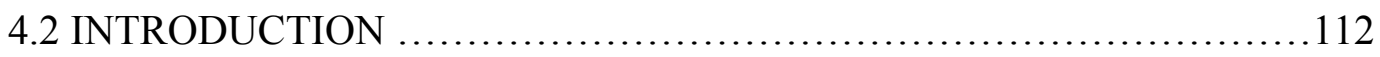

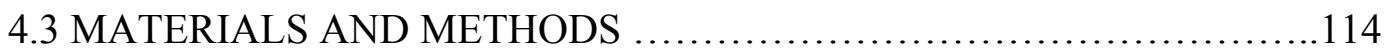

4.3.1 Patient samples ........................................114

4.3.2 Genomic DNA isolation and pyrosequencing experimentation....114

4.3.3 Statistical analysis of pyrosequencing results.................115

4.3.4 Determining 38 loci of interest for pyrosequencing analysis......115

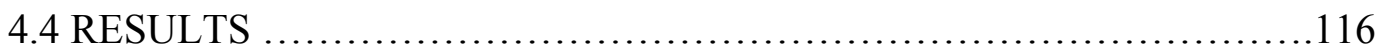

4.4.1 38 loci are associated with relapse outcome in ALL patients........116

4.4.2 CpG sites are hypermethylated in ALL patients who relapsed

compared to ALL patients who did not relapse.......................117

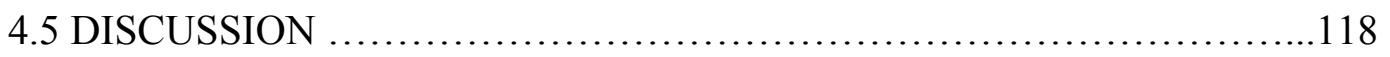

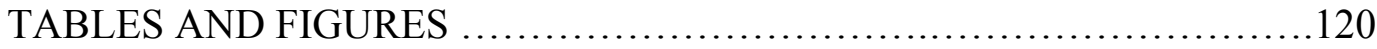

REFERENCES ................................................... 124

CHAPTER 5: SUMMARY AND FUTURE DIRECTIONS .......................127 


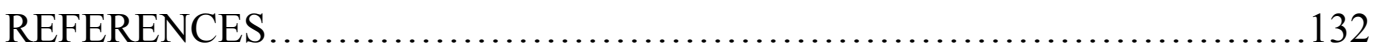

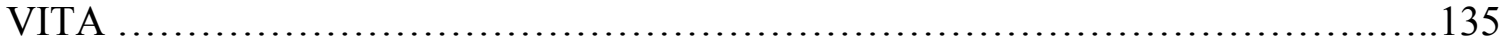




\section{LIST OF TABLES}

Table

Page

1.1: Cancer associated promoter-hypermethylated genes..........................28

1.2: Cytogenetic risk stratification of ALL ....................................28

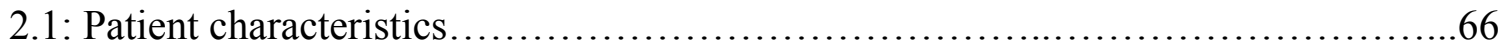

2.2: Genes with oncogenic potential that were hypomethylated in pediatric ALL

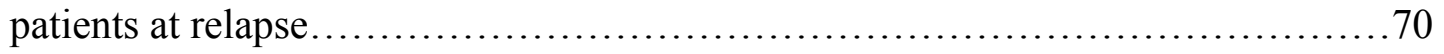

2.3: Hypermethylated DMR in pediatric patients with ALL at relapse.................71

2.4: Classification of genes associated with aberrant methylation at diagnosis and

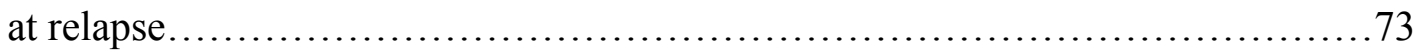

3.1: Clinical characteristics of 4 dogs diagnosed with acute leukemia..................98

3.2: Classification of genes associated with 5 ' regulatory hypermethylation in cAL....101

3.3: Downregulated genes in human ALL accompanied with 5' hypermethylation in canine and human leukemia............................................. 102

4.1: Patient characteristics (II) .......................................... 120

4.2: Primer sequences.................................................. 121 


\section{LIST OF FIGURES}

Figure Page

1.1: Venn diagram of upregulated genes at relapse that correlated with promoter

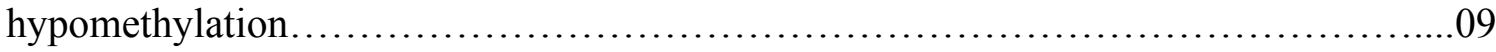

2.1: Genomic distribution of DMR that were hypomethylated in pediatric ALL patients at relapse...................................................67

2.2: BedGraphs illustrating read count differences between diagnosis and relapse (I)....68

2.3: BedGraphs illustrating read count differences between diagnosis and relapse (II)...69

2.4: Hypermethylated DMRs present in pediatric patients with ALL at diagnosis and

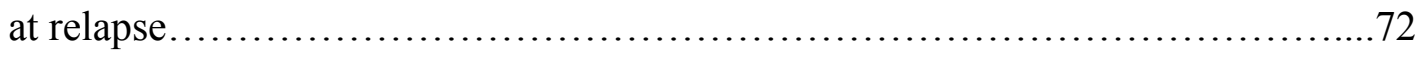

2.5: Differentially methylated loci between patients that went on to relapse and those who did not relapse................................................. 74

3.1: Genomic distribution of methylation peaks in canine........................ 99

3.2: Genomic distribution of DMRs in acute leukemia dogs........................100

3.3: BedGraph illustrations of read distributions of genes in human ALL and cAL.....103

3.4: Sequence alignment of hypermethylated locus found in human and canine........104

4.1: Venn diagram of 38 statistically significant loci based on odds ratio..............121

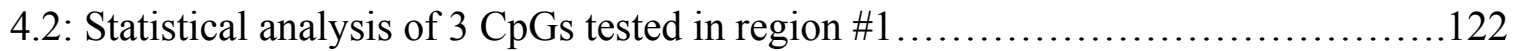

4.3: Line graph representing \% methylation of 3 CpGs observed in ALL patients.......123 


\section{LIST OF ABBREVIATIONS}

$\mathrm{ALL}=$ Acute lymphoblastic leukemia

$\mathrm{cAL}=$ canine acute leukemia

$\mathrm{CD}=$ Cluster of differentiation

$\mathrm{CpG}=\mathrm{CG}$ dinucleotide

$\mathrm{CGI}=\mathrm{CpG}$ island

$\mathrm{DMR}=$ Differentially methylated region

$\mathrm{DNMT}=\mathrm{DNA}$ methyltransferase

$\mathrm{FDR}=$ False discovery rate

$\mathrm{HCB}=$ Human umbilical cord blood

H3K 4me1= Histone H3 lysine 4 monomethylation

$\mathrm{H} 3 \mathrm{~K} 27 \mathrm{ac}=$ Histone $\mathrm{H} 3$ lysine 27 acetylation

$\mathrm{MBD}=$ Methyl $\mathrm{CpG}$ binding domains

MIRA-seq= Methylated $\mathrm{CpG}$ island recovery assay (MIRA) followed by next generation sequencing

$\operatorname{miRNA}=$ Micro-RNA

Pre-B $=$ Precursor B-cell

$\mathrm{TF}=$ Transcription factor 


\begin{abstract}
Reliable biomarkers for relapsed acute lymphoblastic leukemia are scarce. Currently, minimal residual disease (MRD) is the best method in predicting a relapse event, but is invasive to the patient. In addition, high quantity amount of cells are needed for flow-MRD and PCR-MRD requires stable IG-TCR rearrangements. An alternative MRD strategy may involve DNA based technologies involving mass spectrometry that have the potential to monitor the progression of ALL. There are also many recurrent karyotypes that stratify patients into either low-standard risk or high-risk of relapsing. However, many patients with favorable karyotypes (e.g. highhyperdiploidy, ETV6/RUNX1) still experience one or more relapse events. DNA methylation has the potential to serve as a biomarker throughout the course of the disease in several aspects. DNA methylation associated microarrays have demonstrated the ability to stratify patients into their recurrent cytogenetic subtype. Further, Others have identified CpG loci that have the potential to stratify patients at diagnosis that are at risk of relapsing. This dissertation identified differential DNA methylation between matched diagnosis and relapsed patients by creating a methylome profile (MIRA-seq) for each patient. We are the first to report global hypomethylation that occurs at relapse, predominately within retrotransposable elements. In addition, genes that exhibited 5' regulatory aberrant methylation from diagnosis to relapse were identified. Some of the genes harboring epigenetic lesions may be considered an "epidriver" of ALL. A "driver" mutation can be defined as a mutation that can directly or indirectly offer a Darwinian advantage in terms of growth for leukemic blasts. The "epi" component refers to the nature of the mutation as epigenetic in origin and in the context of this study is synonymous with deviant or aberrant methylation. Further, our MIRA-seq study in canine acute leukemia observed epigenetic lesions of epidriver genes that were also present at
\end{abstract}


diagnosis and relapse in human ALL. Lastly, MIRA-seq profiles from ALL patients at diagnosis who either did or did not go on to relapse were compared against each other in order to identify individual CpGs using pyrosequencing that were associated with relapse (prognostic). These combined efforts were done with the foresight of identifying potential novel targets that exist as epidrivers of ALL or loci that hold prognostic power at diagnosis. This dissertation builds upon others who have previously identified relapse-associated biomarkers with implications of improved patient care and risk stratification. 


\section{CHAPTER 1: BACKGROUND}

\subsection{RELAPSED ALL}

Acute lymphoblastic leukemia (ALL) is a heterogeneous disease that accounts for $25 \%$ of all childhood cancers and constitutes approximately $72 \%$ of childhood leukemia. Each year, around 4,900 children are diagnosed with ALL with a peak incidence occurring between 2 and 5 years of age. With an optimistic $90 \%$ cure rate at diagnosis, the outlook for relapsed ALL patients is dismal and accounts for more deaths than any other childhood cancer. Relapse events can be attributed to a number of factors, including incorrect risk stratification of patients at diagnosis and/or after initial treatment. This can result in high-risk patients subjected to treatment under low to standard risk protocols or low to standard risk patients treated under a more potent and potentially fatal regimen. In addition, there is a lack of risk stratification power for patients at relapse who are also subjected to limited treatment options. ALL treatment protocols for low to standard risk patients at diagnosis primarily consist of 3 phases (induction, consolidation, and maintenance). High-risk candidates determined at either diagnosis or after initial treatment, undergo additional treatment phases (interim maintenance and delayed intensification phase) with added chemo agents coupled with increased dosage. ${ }^{1}$

Current prognostic factors used to stratify patients into risk groups at diagnosis and/or after induction treatment combine the utility of clinical and genetic features. These include a patient's age, white blood cell count (WBC), gender, 
race, immunophenotype, and cytogenetic subtype. Specifically, age and leukocyte count are independent predictors of prognosis, where a linear relationship exists between leukocyte number and outcome. ${ }^{1}$ In addition, karyotyping is a crucial determinant factor of prognosis and treatment response. However, several limitations of karyotyping exist, resulting in false patient subtypes. Minimal residual disease (MRD) diagnostics occur after initial induction treatment and remain the gold standard in terms of the most reliable prognostic factor for an ALL patient relapsing. Studies have determined that post induction treatment days 33 and 78 offered the most reliable and valuable prognostic knowledge. $^{2}$

\subsubsection{Future treatment of relapsed ALL}

In the case of a bone marrow relapse, chemotherapy and hematopoietic stem cell transplantation (HSCT) remain the two primary forms of treatment. ${ }^{1}$ Complete remission can be attained for the majority of relapsed ALL patients where treatment may remain consistent as before or additional drugs may be added such as anthracycline derivatives like daunorubicin or mitoxantrone. Moreover, HSCT is widely considered a last resort option for relapse patients having a positive minimal residual disease (MRD+) outcome after chemotherapy treatment. Central nervous system (CNS) relapse constitutes less than $10 \%$ of relapsed ALL patients, where $90 \%$ will experience CNS remission. ${ }^{3}$ Successful treatment of CNS relapse includes cranial radiotherapy (CRT) coupled with intrathecal (IT) treatment of either methotrexate or triple IT (methotrexate, 
hydrocortisone, cytarabine). Testicular relapse has decreased from around 10$15 \%$ to around $2 \%$ currently. Testicular relapse is frequently associated with systemic relapse, therefore chemotherapy intensification and testicular irradiation are the primary treatment options with an event free survival (EFS) $>90 \%$ for ALL patients with late testicular relapse. ${ }^{4}$

Promising new chemotherapy and immunotherapy options are on the horizon for relapse patients. This includes the proteasome inhibitor bortezomib which has shown promising results for relapsed ALL patients in phase I and II trial studies. ${ }^{5}$ In addition, monoclonal antibodies (mAB) conjugated with chemo agents or immunotoxins (ricin) have demonstrated efficacy when administered alongside conventional therapy. These mABs would target antigens displayed on leukemic blasts of B-cells, which would include CD19, CD20, and CD22. Immunotherapeutic approaches include novel drugs that can bind B cell and T cell antibodies which enables T-effector cells to come within proximity of leukemic blasts, termed bispecific T-cell engaging antibodies (BITEs). ${ }^{6}$ In addition, the highly anticipated CAR T-cell therapy has shown promising results in phase I/II trials of relapsed ALL patients. This process involves extracting and then adding an artificial receptor to a patient's $T$ cells that are genetically programmed to bind leukemic blasts, thereby promoting other T cells to eliminate blasts at the site. ${ }^{7,8}$ 


\subsection{EPIGENETICS}

Conrad Waddington termed the word "epigenetics" in 1942 where he defined it as "the branch of biology which studies the casual interactions between genes and their products, which bring the phenotype into being." $\mathrm{A}$ modernized definition may describe 'epigenetics' as the study of mitotically or meiotically heritable changes in gene expression that do not involve a change in DNA sequence. Mechanisms by which epigenetic regulation occurs include: Methylation of cytosines in DNA, post-transcriptional modification of histones (changes in chromatin conformation), microRNA (miRNA) and long non-coding RNAs (IncRNA) targeted interaction and subsequent degradation of mRNA transcripts. Epigenetic regulations like DNA methylation and histone modifications play a pivotal role in all cellular differentiation events that start as early as the blastocyst stage in human development and in later somatic events that include lymphopoiesis and B cell maturation.

\subsubsection{DNA methylation}

DNA methylation is a well-studied epigenetic phenomenon that is primarily associated with an addition of a methyl group onto the $5^{\prime}$ carbon of cytosine in the context of 5'CpG'3 dinucleotide sequence. The main players involved in DNA methylation include molecules that add the methyl group to DNA termed DNA methyltransferases (DNMTs), where S-adenosyl-L-methionine (SAM) donates the methyl group in an enzymatic fashion. In mammals, there are four 
highly conserved DNA methyltransferases (DNMT1, DNMT3A, DNMT3B, DNMT3L). ${ }^{10}$ Three of the four DNMTs are biologically active, whereas DNMT3L is not and facilitates the catalytic activity of DNMT3A and DNMT3B. DNMT1 is considered a maintenance methyltransferase that is highly expressed during $\mathrm{S}$ phase of the cell cycle. During DNA replication, DNMT1 faithfully lays down methylation within naked $\mathrm{CpG}$ sites of the newly synthesized DNA strand that maintains the methylation pattern of the original strand in a palindromic likefashion. The DNMTs involved in de novo methylation include DNMT3A and DNMT3B. This form of methylation is essential in establishing genomic imprinting in embryonic development where mutagenic defects of DNMT3A and DNMT3B result in latent death. ${ }^{11}$ In contrast, DNMT3L mutations shown in mice can be non-lethal, but have been shown to impede normal spermatogenesis in males and leads to loss of imprinting in females; therefore contributing to infertility. ${ }^{12}$

The function of DNA methylation pertains to several essential molecular and biological processes. One prime example relates to embryonic development in which waves of non-random demethylation and remethylation dynamics occur within differentiating primordial germ cells. ${ }^{11}$ Moreover, genomic imprinting occurs during this process through methylation-mediated gene silencing within the maternal or paternal allele. This results in monoallelic expression of signal transducer molecules like insulin-like growth factor 2 (IGF2) or tumor suppressor genes (DIRAS3). ${ }^{13,14}$ In humans there is also cross talk between DNA 
methylation and histone regulation mediated by methyl-CpG-binding proteins (MBD1, MBD2, MBD3, MBD4, MECP2). Primarily, MBD proteins facilitate chromatin conformation by mobilizing components of molecules such as Mi-2NuRD complex involved in histone deacetylation (chromatin condensation) leading to gene repression for example. ${ }^{15}$ Another example of an MBD derived process lays with the function of MBD4. MBD4 has demonstrated mismatch repair ability as a DNA glycoslyase by removing aberrant thymine or uracil nucleotides from individual CpG sites. ${ }^{16}$ Other related processes involving DNA methylation include random $\mathrm{X}$ chromosome inactivation in females, promotermediated silencing of tissue specific genes, and overall genomic stability and protection against foreign molecules.

\subsubsection{DNA methylation in cancer}

Aberrant DNA methylation is found in most cancers, especially human leukemia. Many of the differentially methylated regions (DMRs) occur within a CpG island context. A CpG island can be described as a region that is at least $200 \mathrm{bp}$ with a $60 \%$ CpG observed-to-expected ratio. ${ }^{17}$ The majority of genes $(70 \%)$ in humans, especially housekeeping genes that harbor CpG islands in their promoter and 5' region, remain unmethylated in healthy individuals. ${ }^{18}$ Some oncogenes are an exception to this observation and their malignant phenotype kept at bay due to promoter methylation-mediated silencing. A common observation in cancer is DNA hypermethylation within $\mathrm{CpG}$ islands of gene promoters that can lead to silencing of tumor suppressor, DNA mismatch/repair, apoptotic, miRNAs, and cell 
cycle related genes (Table 1.1). ${ }^{19-36}$ In conjunction with targeted promoter hypermethlyation, global hypomethylation is also a trend that contributes to genomic instability, resulting in activation of retrotransposable and other repetitive elements or loss of genomic imprinting. In addition, promoter hypomethylation has shown to lead to oncogenic activation. For instance, upregulation of oncogenes such as PARP1 and FEN1 has been correlated with promoter hypomethylation in various cancers. ${ }^{37,38}$

The mechanism(s) that characterizes aberrant methylation in cancer remains poorly understood. However, there is increasing evidence that supports the notion of mechanistic passive demethylation that can occur after many DNA replications and therefore may contribute to the global loss of methylation displayed in cancer. ${ }^{39}$ In addition, the molecular players themselves that are involved in adding and removing DNA methylation can be compromised due to single nucleotide polymorphisms (SNPs). For example, our study detected decreased expression of TET proteins in ALL patients at diagnosis against healthy patients. ${ }^{29}$ TET proteins are considered the "guardians of CpG islands" as they remove aberrant $\mathrm{CpG}$ methylation within promoter sequences. ${ }^{40}$ Therefore, one may infer that the promoter hypermethylation signature is irreversible and unchecked, allowing for continued methylation to occur throughout the progression of some ALL individuals. Misregulation of DNA methyltransferases has also been identified in several cancers. Moreover, around $1 / 5^{\text {th }}$ of AML patients had accumulated somatic mutations of DNMT3A, 
which serves as another example of how epigenetic lesions may manifest on a genome-wide scale. ${ }^{41}$

\subsection{DNA METHYLATION METHODS}

Several techniques exist to study DNA methylation in a research and clinical based setting. Next-generation sequencing has broadened the utility of these techniques, which has incorporated a strong statistical/bioinformatics backbone to handle the high-throughput data generated. A widely used category of analyzing DNA methylation includes a bisulfite chemical conversion of DNA, which converts only unmethylated cytosines into uracils. This differentiation step is used for many downstream techniques that include combined bisulfite restriction digest analysis (COBRA), methylation specific PCR (MSP), MassARRAY EpiTYPER, microarray probe analysis (450K or $850 \mathrm{~K}$ ), pyrosequencing, and whole genome (WGSBS) or reduced representation (RRBS) bisulfite sequencing. Another category is not dependent upon chemical treatment of genomic DNA, but utilizes antibodies that bind 5-methylcytosine (MeDIP-seq) or methyl binding domain proteins (MIRA-seq/MBD-seq). The other category independent of bisulfite conversion includes Hpall enrichment by ligation-mediated PCR (HELP-seq) and methylation sensitive cut counting (MSCC) that use restriction enzyme digestion specific to methylated CpG sites. Bisulfite sequencing is considered the gold standard for methylation analysis as it provides individual $\mathrm{CpG}$ resolution and superior coverage to alternative methods. However, bisulfite sequencing is very expensive and unrealistic in studies 
analyzing hundreds of patient samples in the interest of finding clinical significance. Therefore, affinity based assays (single-end) are monetarily attractive and can provide 25bp-100bp read count resolution for each CpG island, including many low $\mathrm{CpG}$ density regions containing at least 2 methylated CpGs within close proximinty. ${ }^{42}$

\subsection{DNA METHYLATION BIOMARKERS IN CANCER}

The sensitivity and reliability of DNA methylation based assays are attractive methods within a clinical setting as demonstrated by identifying chemo-resistant patients through analyzing the methylation status of $M G M T$ and other genes. In addition, DNA methylation remains an attractive biomarker option in a clinical based setting for several reasons. One pertains to the robust nature of DNA methylation, which can be stored for long periods of time as shown in formalinfixed paraffin-embedded (FFPE) samples. ${ }^{43}$

DNA repair gene $0^{6}$-methylguanine-DNA methyltransferase $(M G M T)$ is a prime example of a DNA methylation based biomarker; one of the first DNA methylation predictive biomarkers identified. It is well established that gliomablastoma patients fare better with Temozolomide (TMZ) when the promoter of MGMT is methylated and silenced. The hypothesis is that the absence of promoter methylation within MGMT leads to protein expression, thereby counteracting the chemotherapy effect of (TMZ) by removing alkyl adducts, resulting in chemoresistant malignant cells. Multiple studies have concluded that the promoter 
methylation status of $M G M T$ is a predictive biomarker of patient response to alkylating agent-based chemotherapy. ${ }^{19,44,45}$ One study found that $95 \%$ of longterm survivor (>30 months) patients with glioblastoma had MGMT promoter methylation, while only $36 \%$ of patients with a shorter survival harbored MGMT promoter methylation. ${ }^{44}$ Interestingly, one study's model suggests that after cell division, Temozolomide itself may have an inhibitory effect on maintaining the methylation status of $M G M T^{46}$

Importantly, what could result from the DNA methylation studies of MGMT are potential changes in risk stratification and therapeutic strategies. For instance, recruitment of high risk glioblastoma patients for Phase II clinical trials from MD Anderson Cancer site are currently underway and estimated to be completed by June 2021 [NCT02717962]. This is a biomarker driven study assessing high-risk glioma patients classified as MGMT promoter unmethylated using an alternative drug. These patients will be tested using an alternative chemotherapy agent to alkylating agent Temozolomide, called VAL-083 or dianhydrogalactitol (DAG). Other examples of genes considered as promoter-hypermethlyation derived putative biomarkers include SEPT9 in colorectal cancer, GSTP1 in prostate cancer, and $M L H 1$ in endometrial cancer. ${ }^{47-49}$

\subsubsection{DNA methylation relapse-associated biomarkers in ALL}

Multiple studies have identified a panel or individual CpG sites that are associated with relapse or poorer overall survival in ALL. For example, Borssen 
and others identified a panel comprised of thousands of $\mathrm{CpGs}$ that could further stratify T-ALL patients based on a CpG island methylator phenotype (CIMP) profile, where patients exhibiting less methylation within the CpG panel (CIMP-) fare poorly compared against individuals with a more methylated profile $(\mathrm{CIMP}+)^{50}$ Their later study examined 601 pre-B ALL patients at diagnosis and assigned each patient into CIMP+ or CIMP-. ${ }^{51}$ The CIMP+ cohort had a higher overall 5-year survival compared to CIMP-patients at diagnosis and at relapse, but was not a predictive indicator of relapse. This suggests a difference in treatment response at relapse between CIMP+ and CIMP- profiled patients. Importantly, CIMP status could stratify relapsed patients classified as and treated under the standard-intermediate risk protocol at diagnosis, where $69 \%$ survival was observed in CIMP+ patients compared to $45 \%$ in CIMP- patients. In the high-risk cohort, survival difference was even more pronounced $(\mathrm{CIMP}+=56 \%)$ $($ CIMP- $=21 \%)$. Given that survival after relapse remains poor, this study demonstrates that even after relapse, CIMP profiling may be able to identify chemo-resistant individuals. This knowledge may provide clinicians the foresight needed to anticipate and strategize for additional relapse events.

Past studies have also identified aberrant DNA methylation of specific loci within genes of patients at diagnosis that correlated with relapse. One study identified CpG sites that were also patient subtype specific, where the methylation intensity of individuals associated with relapse closely resembles healthy CD34+ and CD19+ stem-like cells. For example, Nordlund and colleagues identified 46 
individual CpGs from 15 genes that corresponded with relapse among patients belonging to 3 different cytogenetic subtypes of ALL (ETV6/RUNX1, MLL/11q23, BCR/ABL1). ${ }^{52}$ The study highlighted 15 individual $\mathrm{CpG}$ from three genes, where patients displaying the phenotype of high levels of methylation corresponded with a lesser likelihood of relapsing compared to patients of the same subtype exhibiting low levels of methylation. Similarly, another study found a different set of relapse associated CpG sites, where patients belonging to one of ten genetic subtypes and also displayed low levels of methylation in 21 out of $22 \mathrm{CpG}$ sites were at greater risk of relapsing than those with a high methylation status. ${ }^{53}$ The baseline methylation level for the given CpG sites in healthy control cells was not given in that study so a comparison could not be made to investigate whether or not the methylation pattern of the patients at higher risk of relapsing resembled healthy control cells as in Nordlund et al. ${ }^{52}$ Further, none of the CpG sites listed in the previously described studies were differentially methylated between ALL and healthy pre-B cells in our study. ${ }^{29}$

The notion of $\mathrm{CpGs}$ displaying a stem-like methylation pattern is also consistent with Sandoval et al, where the methylation status of 20,661 individual CpG sites separated patients into two ALL groups at diagnosis (ALL-1, ALL-2), where the ALL-2 cohort correlated with a higher risk of relapse $(p<0.01) .{ }^{54}$ Interestingly, all healthy control patients clustered with the ALL-2 group and shared a similar methylation pattern, where the majority of the $\mathrm{CpG}$ sites were lowly methylated in both groups. This is in contrast to the ALL-1 cohort, where 17,182 CpGs out of 
20,661 were hypermethylated compared to ALL-2. This suggests that the previous studies may have identified regions where differential methylation between healthy controls is indeed a negative indicator of relapse.

These potential biomarkers differ from our regions of interest, which were predicated upon patients exhibiting hypermethylation at diagnosis, who later went on to relapse, compared to healthy patients. Similarly, another study found a correlation between the hypermethylated status of $31 \mathrm{CpG}$ sites within the 5' regulatory $\mathrm{CpG}$ island of $\mathrm{PCDH} 17$ and an increase risk of relapse and mortality $(P=0.001, P=0.017)$ based on the notion of also displaying differential methylation against healthy control cells. ${ }^{55}$ The study compared the methylation pattern of three cadherin genes: $C D H 1, P C D H 8$, and $P C D H 17$ and concluded that only $P C D H 17$ remained unmethylated among all ten control samples. This may also be supported by our data, where a $1.6 \mathrm{~kb}$ hypermethylated region spanning the 5' regulatory region of the PCDH17's CpG island at diagnosis and relapse was differentially methylated against pre-B control samples. In summary the previously described biomarker related studies have demonstrated the potential utility of DNA methylation as a risk stratification tool using either 1) a panel of CpGs (CIMP status) 2) individual CpGs that (a) resemble a control stemlike methylation pattern or (b) are differentially methylated against healthy control samples. 


\subsubsection{DNA methylation based cytogenetic subtyping in ALL}

Cytogenetic subtyping is essential for stratifying ALL patients into low-standard and high-risk groups prior to treatment (Table 1.2) ${ }^{56}$ As for childhood ALL, there have been multiple studies that have tested the utility of DNA methylation as an alternative molecular tool to karyotyping that can identify patients with various cytogenetic subtypes of ALL. Identifying a CpG panel in ALL patients may provide an additional safety net to act alongside standard karyotyping methods such as G-banding analysis and metaphase fluorescent in situ hybridization (FISH). This would also compensate for patients that are incorrectly karyotyped prior to treatment. For example, high-risk dic(9;20) ALL patients have been shown to escape G-band detection at diagnosis and some ALL patients labeled as having a normal karyotype in accordance to conventional karyotyping, did in fact harbor chromosomal abnormalities when tested using microarray $\mathrm{CGH}$ technology. ${ }^{57}$

Multiple studies have conducted large-scale methylation analyses utilizing the Illumina 450k BeadChip array in an attempt to identify a panel of individual CpGs that sorts patients into their respective cytogenetic subtype. The latest study (Nordlund et al.) produced an accurate DNA methylation panel of $246 \mathrm{CpG}$ sites that stratified patients into recurrent subtypes of ALL with high accuracy. ${ }^{58}$ The subtypes of ALL patients included T-ALL, high-hyperdiploidy $(\mathrm{HeH})$, ETV6/RUNX1, MLL, TCF3/PBX1, dic(9:20)+, BCR/ABL1, and iAMP21. The DNA 
methylation panel was able to correctly assign $91 \%$ of patients $(n=546)$ into their respective subtype as well as an additional $92 \%$ of newly diagnosed patients $(n=39)$ in a blinded manner. This particular CpG panel has a high percentage of patient subtype accuracy from a large number of patient samples and should be considered for clinical use.

Interestingly, the panel was able to place around $47 \%$ of patients $(n=105)$ with non-recurrent karyotypes into typical recurrent karyotypes, termed like-subtype. Patients placed into their like-subtypes had similar cytogenetic characteristics. For example, patients carrying 48-49 chromosomes, including those with Down's syndrome were assigned into the high-hyperdiploidy $(\mathrm{HeH})$ subtype due to the similarity in methylation pattern. Moreover, the $\mathrm{CpG}$ panel grouped patients with RUNX1/ASXL1, ETV6/CBX3, and ETV6/AK125726 fusion genes into the ETV6/RUNX1 subtype. These observations bring up a key limitation for exclusively using a $\mathrm{CpG}$ derived panel for identifying patient subtypes. Due to the existence of like-subtypes, a clinician may not assume a patient's karyotype using the $\mathrm{CpG}$ panel alone. For instance, if a patient's $\mathrm{CpG}$ profile placed them into the recurrent ETV6/RUNX1 subtype, there is still the possibility (low) of a patient possessing a different gene fusion partner of ETV6 or RUNX1. Further, the risk factor pertaining to like-subtypes is not fully understood because of their infrequency in ALL. 
Previous studies have attempted to subtype patients using DNA methylation based technology, but were not as accurate in doing so. However, they were important precursor studies that lead to the Nordlund study that identified bonafide CpG markers with the ability to differentiate ALL patients based on many cytogenetic subtypes. For example, Milani et al. subjected a list of 300 different $\mathrm{CpG}$ sites to unsupervised hierarchical clustering in an attempt to stratify patients ( $n=401$ ) into their respective cytogenetic subtype: T-ALL, ETV6/RUNX1, MLL, TCF3/PBX1, HeH, BCR/ABL1, dic(9;20), iAMP21, hypodiploidy, and normal karyotype. ${ }^{53}$ Clustering analysis was able to differentiated pre-B ALL from TALL. However, many of the pre-B cell patient subtypes were scattered, where 7 out of $9 \operatorname{dic}(9,20)$ and 4 out of 6 iAMP21 patients clustered with other subtypes. The reason for the inaccurate clustering of patient subtypes may be attributed to the fact that the $300 \mathrm{CpG}$ sites used to cluster patients were predetermined based on their association with genes displaying imbalanced allele-specific expression (ASE) coupled with having a high standard deviation cutoff $(>0.16){ }^{59}$ Two other previous studies stratifying patients based on genetic subtypes had comparable results to Milani et al. in that they too found individual $\mathrm{CpGs}$ that clustered ALL patients into their distinct genetic subtype with similar accuracy. ${ }^{60,61}$

Interestingly, when identifying common individual CpGs to cluster patients into genetic subtypes from all four studies, only Nordlund et al. and Busche et al. shared 4 CpG sites in genes: E2F6 (TSS), ZDHHC3 (5'UTR), CBFA2T3 
(5'UTR; Intron), and DSC3 (TSS). Importantly, these individual CpG sites served as classifiers for patients harboring the ETV6/RUNX1 translocation in both studies and were hypomethylated compared to the other genetic subtypes. This observation is supported by the fact that both studies were able to cluster ETV6/RUNX1 carrying patients with high accuracy [Nordlund et al. (158/161 patients) 98\%] [Busche et al. (12/13 patients) 92\%]. Therefore these CpGs are sufficient classifiers for patients with ETV6/RUNX1 translocation and may also identify genes of potential functional interest related to ETV6/RUNX1 translocation.

The differentiating factor between past microarray studies and the most recent study (Nordlund et al) ${ }^{58}$ is the influence of informatics and statistical modeling that contributed to identifying robust classifiers from microarray data. Nordlund et al. took a predictive modeling approach using the nearest shrunken centroid (NSC) method to identify consensus CpG sites that accurately identified different patient genetic subtypes. With a total of $\sim 28$ million $\mathrm{CpGs}$ in the human genome, one could imagine an even more robust and accurate $\mathrm{CpG}$ panel of up to $\sim 99 \%$ accuracy using the latest $850 \mathrm{~K}$ microarray platform or even whole genome bisulfite sequencing with decreasing costs of sequencing in the near future. 


\subsubsection{DNA methylation in the context of minimal residual disease (MRD) in}

ALL

There are several challenges facing the instrumentation of MRD measurement.

For example, flow cytometry MRD is the preferred method of choice in the United

States and while this approach is relatively quick and inexpensive, achieving optimal sensitivity of leukemia cell detection $\leq 1$ in 10,000 (MRD-negative) is less than perfect and a critical limitation for monitoring ALL. Further, MRD requires bone marrow aspiration, which is invasive and incredibly painful to the patient. In addition, the minimum cell requirement is demanding $\left(\geq 2 \times 10^{6}\right)$ to even consider reaching a sensitivity of around $10^{-4} .{ }^{62}$ Thus, new and resourceful biomarkers are needed to aid in the improvement of risk stratification before and during the induction phase of treatment.

MRD remains the most important prognostic factor in terms of the likelihood of a relapse event in ALL. However, the two standard measurements of MRD (flowcytometry) and (Ig-TCR rearrangement PCR) have specific constraints that limit it's applicability in ALL patients. For example, measuring MRD by amplification of IG-TR gene rearrangements has been shown to be unstable in many patients during disease progression. ${ }^{63,64}$ The EuroFlow 8-color antibody panel approach in ALL patients has a sensitivity now comparable to the Ig-TCR method with a limit of detection of $\left(10^{-5}\right)$ and is faster and a more standardized method against conventional flow-cytometry. ${ }^{65}$ However, very large quantities of cells are still needed $\left(>4 \times 10^{-6}\right)$ to complement the accuracy of the EuroFlow and still require 
the painful and invasive nature of bone marrow aspirations. Therefore, patients would benefit from other MRD based methods such as DNA methylation.

A DNA methylation based method could be a future viable option that could aid clinical institutions both financially and in time management. Several studies have addressed this vision, first by comparing DNA methylation differences between diagnosis and a combination of both remission (post-induction treatment) and healthy samples from the same patient. The initial objective was to find a DNA methylation signature that could distinguish between leukemic and non-leukemia samples. Hence, identifying suitable and stable loci that could be used for diagnostic purposes and disease monitoring.

For instance, Nordlund et al. identified 28 differentially methylated probes from 24 genes, while Wong et al. identified 15 separate probes in the promoter region of 15 genes that clearly distinguished between the diagnosis and remission stages of ALL and were predominately hypermethylated at diagnosis; independent of recurrent karyotypes conditions. ${ }^{66,67}$ Findings from Wong et al. was consistent with the increased methylation observed in our study which found that 13 of the 15 gene promoters (FOXE3, TLX3, C1orf76, FBXO39, MYOD1, GUCY1A2, PKDREJ, PNMA2, PPARG, PRLHR, PTPRZ1, SCRN1, SOX17) that were represented by the 15 probes, correlated with hypermethylation within 19 ALL patients compared to 10 healthy donor patients. ${ }^{29}$ Only 3 promoters $(D B C 1$, EYA4, MYO3A) among the 24 genes identified in Nordlund et al. were also 
hypermethylated in ALL from our study ${ }^{29}$ Chatterton and colleagues went on to analyze the methylation status of $103 \mathrm{CpG}$ sites within the 15 probes using the SEQUENOM EpiTYPER. ${ }^{68}$ The methylation pattern for the 103 CpG sites was predominately hypermethylated in the leukemic group compared to the remission and control groups. Approximately $91 \%$ of the ALL patients (77/85) were correctly assigned into their respective leukemic or remission/control group. The remaining misclassified patients $(8 / 85)$ were those with hypodiploidy status.

The same study also addressed the potential of DNA methylation used in disease monitoring using mass spectrometry. The methylation status of CpG 17 within TLX3 was the focal point in comparing the sensitivity of the EpiTYPER and methyISABER chemistry in bone marrow patient samples from induction treatment through remission. The study found the primer extension technique of methyISABER having superior sensitivity over the EpiTYPER method in regards to detecting copies of methylated TLX3 (10 in 100,000 total). A methylation extension (ME) threshold $>0.30$ (corresponding with $>10$ in 100,000 copies) was used to determine a positive residual presence of disease. This cutoff detected 2 out of the 3 patients at remission that would eventually have an early relapse event, but did not detect late relapse patients $(n=2)$ at remission. Even though this assay did not detect patients that relapsed later, one could infer that patients presenting ME $>0.30$ at remission would have a poorer prognosis. Moreover, a reduction of ME in all 10 patients can be seen throughout the course of treatment into remission, which provides a sense of disease monitoring in its infancy. 
Consequently, this may allow for intervention and changes in therapy regimen for patients unresponsive to treatment.

This study would have been more impactful if they demonstrated that their methyISABER technique was as effective and sensitive in peripheral blood samples. Thus, entertaining the future direction of MRD as a noninvasive and accurate form of disease monitoring in patients throughout treatment. For example, Flow-MRD has been tested in peripheral blood samples of ALL patients. The study found that detection of MRD+ within the bone marrow was not as powerful alone in predicting relapse as detection of MRD+ within peripheral blood as well. ${ }^{62}$ Moreover, DNA quantity requirements for mass spectrometry based methods are significantly lower than flow cytometry, therefore peripheral blood should provide an adequate quantity of DNA for the methyISABER method. Molecular techniques that incorporate mass spectrometry based instruments may be considered among next generation biomarker applications that could monitor patients throughout treatment in a less laborious manner. Currently, the EpiTYPER assay is the method of choice in detecting methylation levels of $M G M T$ in phase II clinical trials for relapsed or refractory small cell lung cancer patients [NCT01638546]. One limitation for mass spectrometry based methods includes the nature of polymorphisms present within the sequence of interest, resulting in a shift in the spectrum, which could lead to false results or interpretations. There is also a concern that DNA 
fragment masses $<1700$ Da may interrupt optimal calibration of the mass spectrometry appliance. ${ }^{69}$

Another group demonstrated the ability to reach sensitivity comparable to the latest advancements of flow-MRD of up to $10^{-6}$ (1 leukemic cell in 1,000,000 healthy background blood cells) using methylation sensitive enzyme restriction PCR (MSR-PCR) within the CpG island of $D L C-1 .^{70}$ The principal of this method relies on methylation sensitive enzymes prior to PCR, which are unable to cleave methylated CpG sites. PCR products can be visualized on an agarose gel from primers designed for methylated sequences exhibited in the promoter of $D L C-1$ of ALL patients. However, unmethylated sequences within that region from healthy patients, would succumb to fragmentation, thus no PCR product would be seen. In order to reach a $10^{-6}$ sensitivity mark, a second primer set was designed for the previously amplified product of $D L C-1$ (nested PCR). Like Wong et al, this study was also able to monitor disease progression using a different marker (DLC-1) in 4 ALL patients from both bone marrow aspirates and peripheral blood that was concordant with pathological examination, flowcytometry, and clinical information.

The previously described studies have demonstrated the ability to monitor patient MRD using a DNA methylation based assay and have provided hope for a potentially new and innovative approach to MRD tracking for ALL patients in the future. Nonetheless, the stability in detecting a specific marker (e.g. TLX3 and 
$D L C$-1) for ALL patient monitoring remains a crucial limitation in both studies. For example, the MSR-PCR technique was only able to detect the presence DLC-1 in 16/29 (55\%) bone marrow samples and 15/28 (54\%) peripheral blood samples. ${ }^{70}$ As for $T L X 3$, detection of CpG site 17 was not evaluated in any other patient cohort besides the 10 patients that were used for MRD tracking. ${ }^{68}$ One might suspect a similar detection rate in a larger sample size as observed in patients tracked using the DLC-1 marker. This notion may be supported by the several false negatives identified in $11 \%$ (10/95) of ALL patients that were incorrectly categorized into the clear bone marrow group predicated on 19 individual CpG sites from TLX3 to quantitatively distinguish between ALL and healthy patients (i.e. between diseased and clear bone marrow) by mass spectrometry. Therefore, it is reasonable to assume that the detection rate may dramatically decrease when using only 1 of 19 CpG sites in TLX3 (CpG 17) for patient MRD monitoring.

\subsubsection{Differential DNA methylation and gene expression provides insight into gene-targeted therapy at relapse}

Novel targeted therapies are needed to help to decrease the fatality rate of relapse patients. Patients that relapse have a poor chance in survival and unfortunately, treatment outcomes have not significantly improved over the past few decades. Combining the power of gene expression and DNA methylation studies between diagnosis and relapse patients may identify potential novel targets. Hence, the selection process should also include targeting genes that 
are also epigenetically altered at relapse by aberrant DNA methylation events that leads to gene misregulation, termed epidriver genes.

Contrary to previous studies, our MIRA-seq results demonstrated an overwhelming pattern of hypomethylation that occurs at relapse compared to 10 matched diagnosis patients. Hogan et al. and Nordlund et al. identified a combined total of 109 genes, while our study classified 2,777 genes exhibiting hypomethylation within the promoter, 5' UTR, or first exon regulatory region at relapse. ${ }^{52,71}$ Commonalities of hypomethylation between all 3 studies were sparse, where only 10 genes overlapped from no more than two of the studies. Interestingly, our set of hypomethylated genes included potential oncogenes involved in promoting DNA replication, MAP-kinase or Wnt/ $\beta$-catenin signaling pathways. Hence, hypomethylation may result in the upregulation of oncogenes that contribute to leukemogenesis that may also serve as novel therapeutic targets for relapsed ALL in the future.

Three separate studies have evaluated gene expression differences between diagnosis and relapse matched patient samples using microarray technology $(n=3)$ as well as a meta-analysis study that synthesized the data from those studies in order to identify a consensus set of differentially expressed genes. ${ }^{71-74}$ Our hypomethylated list of genes correlated with genes upregulated from the previous studies suggests there may be potential relapse-specific oncogene targets. When overlapping genes that were upregulated in each of the 4 studies 
and were concomitant with hypomethylation at relapse from our study, a sum of 215 genes were found to be upregulated and hypomethylated in our relapse cohort (Figure 1.1). Strikingly, TOP2A was the only gene that correlated with hypomethylation in our study and was upregulated in each study previously reported. It therefore stands out as a potential candidate for targeted therapy. TOP2A is a topoisomerase gene involved in transcription and DNA replication. Further, overexpression of TOP2A has been correlated with several malignancies, including adrenocortical carcinoma (ACC) and prostate cancer. ${ }^{75}$ In addition, knockdown (siRNA) of TOP2A in ACC cell lines significantly reduced proliferation, suggesting that $T O P 2 A$ may play a role in oncogenesis and warrants further investigation in relapsed ALL. ${ }^{76}$

\subsection{DNA METHYLATION INHIBITORS IN RELAPSED ALL TREATMENT}

Aberrant DNA methylation has been identified at relapse in two separate $450 \mathrm{~K}$ microarray studies that found predominate increases of methylation at relapse ${ }^{52,71}$ Hogan and colleagues identified target genes of interest that was epigenetically misregulated, which lead to subsequent studies administering demethylating agent (5-aza-2'-deoxycytidine/decitabine) to relapsed ALL patients. Decitabine is a cytidine analog that is incorporated into DNA, resulting in a DNA methyltransferases-cytidine analog irreversible covalent bond. First, several potential tumor suppressors exhibiting hypermethylation at relapse were found. This observation led to the hypothesis that decitabine would induce expression of previously methylated and silenced tumor suppressor genes, 
thereby promoting leukemic cells to undergo apoptosis. In vitro studies administering decitabine to leukemic cell lines, resulted in demethylation and upregulation of several tumor suppressor genes previously identified at relapse $(P T P R O, C O L 6 A 2, C D K N 2 A) .{ }^{77}$ Furthermore, cell viability assays on primary patient samples demonstrated decitabine's ability to induce chemosensitivity, warranting a clinical study using decitabine coupled with vorinostat (histone deacetylase inhibitor). The pilot study revealed encouraging results in relapsed patients with a $50 \%(n=8)$ complete remission rate, where every patient that underwent complete remission became MRD-negative [NCT00882206]. However, when decitabine and vorinostat were tested in a larger cohort $(n=23)$, the study was terminated due to drug toxicity, where $18 / 23$ patients died [NCT01483690]. The authors concluded that a future study with modulations to therapeutic dosage would be conducted. Thus, clinical use of decitabine in relapsed ALL treatment is unlikely in the near future.

\subsection{ALL IN DOGS}

The manifestation of ALL in dogs is the result of malignant hematopoietic progenitors accumulating in the bone marrow. Unfortunately, ALL diagnosis in dogs is fatal due to poor response to treatment and a general lack of clinical insight partially attributed to the scarcity of large sample size studies. In a review of 50 cases of $A L L$, only a few patients survived longer than six months and none reached the one-year milestone. ${ }^{78}$ Another study assessing 30 dogs with ALL found an average of 4-months' survival. ${ }^{79}$ The induction treatment in dogs is 
analogous to human ALL, where vincristine, prednisone, and anthracyclines are the primary frontline chemoagents used. There is a large difference in remission rate between the two species, however. Induction treatment in humans results in over $90 \%$ of ALL patients to experience complete remission. This number is drastically smaller in dogs, where one study found only $23 / 36$ dogs achieved either partial or complete remission. ${ }^{78}$ B-cell origin predominates in human ALL, however the true prevalence of B or T-cell origin in dogs is conflicting. Based on immunophenotyping ALL, dogs with B-cell origin typically display CD20, CD21, and/or CD79a, whereas T-cell origin show CD3, CD4 or CD8 antigens on their cell surface ${ }^{80}$ In addition, there is speculation that CD34+ may be a negative prognostic marker in B-cell origin in dog, as evidence of correlation between CD34+ and poorer prognosis has been observed. For example, one study found $76 \%$ of patients expressed CD34. ${ }^{81}$

\subsubsection{DNA methylation in canine ALL}

In the context of $\mathrm{CpG}$ islands, the genetic makeup is quite different between human and dog. Although, the dog genome has approximately 1 billion fewer bps compared to human ( 3.4 billion bps), they have over 20,000 more CpG islands. ${ }^{82}$ Interestingly, there are fewer promoter-associated CpG islands in dogs than human. However, the methylation landscape of dog ALL is currently unknown. There is evidence that promoter hypomethylation may be associated with chemoresistance as demonstrated in canine lymphoid cell lines. Smallwood and colleagues found increased resistance to L-asparaginase that was 
associated with and could be induced by demethylating the promoter of asparagine synthetase (ASNS) via 5-azacytidine treatment. ${ }^{83}$ In canine AML, one study quantitated methylation levels using a 5'mC ELISA assay and found higher methylation-heterogeneity in AML samples. ${ }^{84}$ Because the DNA methylation pattern is subtype (cytogenetic) specific in human acute leukemia, this observation is likely attributed to the various cytogenetic lesions that exists in canine AML. For instance, BCR-ABL translocation has also been reported in canine acute leukemia. ${ }^{85}$ Unfortunately, there is insufficient amount of cytogenetic data for dogs due to the laborious and extremely difficult task of karyotyping 76 acrocentric autosomal chromosomes of similar shape.

\begin{tabular}{|c|c|c|}
\hline Gene Name & Methylation status & Cancer type \\
\hline MGMT & Hypermethylation & Glioblastoma $^{19}$ \\
\hline MLH1 & Hypermethylation & Colorectal $^{20}$ \\
\hline GSTP1 & Hypermethylation & Prostate $^{21}$ \\
\hline SEPT9 & Hypermethylation & Head and neck $^{22}$ \\
\hline BRCA1 & Hypermethylation & Breast $^{23}$ \\
\hline ATM & Hypermethylation & Breast cancer $^{24}$ \\
\hline NEIL1 & Hypermethylation & Head and neck $^{25}$ \\
\hline LIG4 & Hypermethylation & Colorectal $^{26}$ \\
\hline FANCB & Hypermethylation & Head and neck $^{27}$ \\
\hline PTPRO & Hypermethylation & Acute leukemia \\
\hline MCOLN2 & Hypermethylation & Acute leukemia \\
\hline miR-9-1 & Hypermethylation & Head and neck $^{30}$ \\
\hline miR-34a & Hypermethylation & Colorectal $^{31}$ \\
\hline miR-130b & Hypermethylation & Ovarian $^{32}$ \\
\hline miR-124-2 & Hypermethylation & Breast $^{33}$ \\
\hline p16 & Hypermethylation & Acute leukemia $^{34}$ \\
\hline p15 & Hypermethylation & Acute leukemia $^{34}$ \\
\hline CDH1 & Hypermethylation & Cervical $^{35}$ \\
\hline p14 & Hypermethylation & Esophageal $^{36}$ \\
\hline$R B$ & Hypermethylation & Retinoblastoma $^{34}$ \\
\hline
\end{tabular}

Table 1.1 Cancer associated promoter-hypermethylated genes

\begin{tabular}{|c|c|}
\hline \multicolumn{2}{|c|}{ Cytogenetic risk stratification of ALL } \\
\hline Low-standard risk & High risk \\
\hline Hyperdiploidy & Hypodiploidy \\
\hline High-hyperdiploidy & BCR-ABL1 \\
\hline ETV6-RUNX1 & MLL rearrangement \\
\hline PBX1-TCF3 & IAMP21 \\
\hline Normal/diploidy & dic(9;20) \\
\hline & T-ALL \\
\hline
\end{tabular}

Table 1.2 


\section{Staal et al. Hogan et al.}

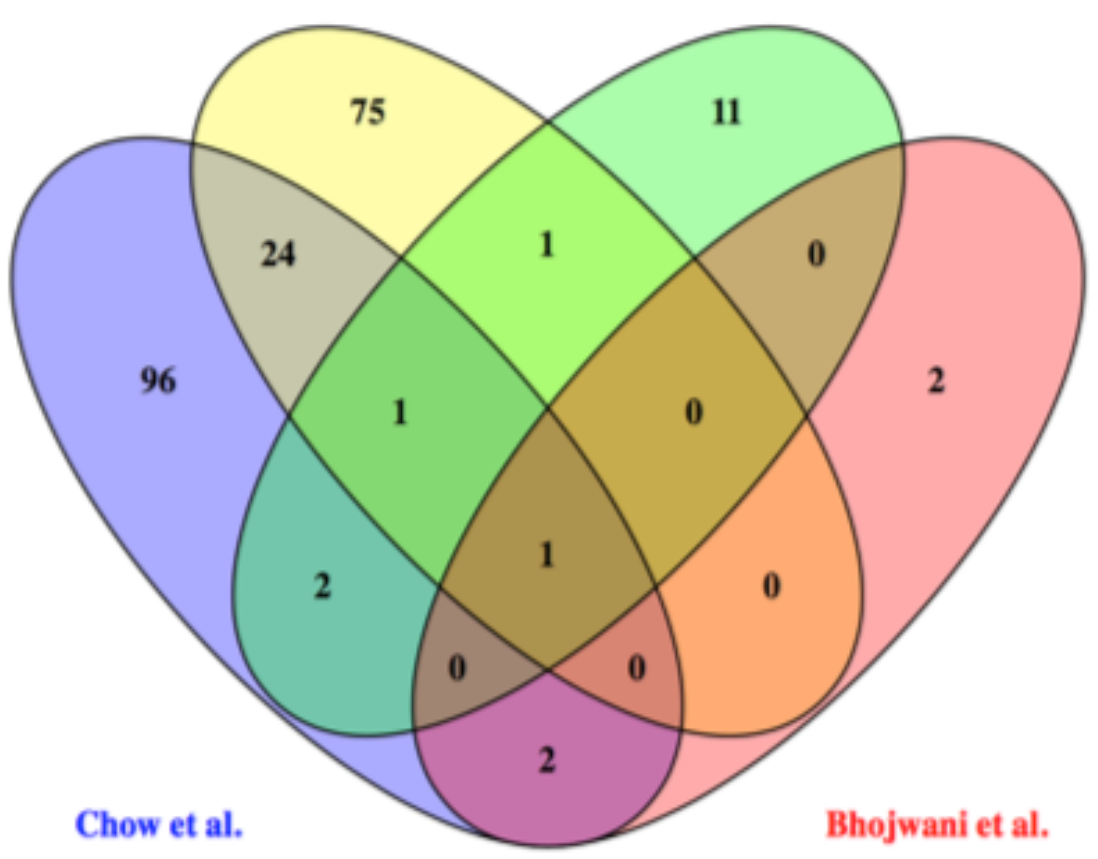

Figure 1.1 Venn diagram containing genes that were upregulated at relapse in each of the four studies that also correlated with promoter hypomethylation at relapse in our study. 


\section{REFERENCES}

1. Principles and Practice of Pediatric Oncology, $7^{\text {th }}$ : Phillip Pizzo, MD, David Poplack, MD, Lippincott Williams \& Wilkins, 2016

2. van Dongen JJ, Seriu T, Panzer-Grümayer ER, Biondi A, PongersWillemse MJ, Corral L, Stolz F, Schrappe M, Masera G, Kamps WA, Gadner H. Prognostic value of minimal residual disease in acute lymphoblastic leukaemia in childhood. The Lancet. 1998 Nov 28;352(9142):1731-8

3. Pui C H, Campana D, and Pei D et al.: Treating childhood acute lymphoblastic leukemia without cranial irradiation. $N$ Engl $J$ Med 2009; 360: 2730-2741.

4. Tallen G, Ratei R, and Mann G et al.: Long-term outcome in children with relapsed acute lymphoblastic leukemia after time-point and site-of-relapse stratification and intensified short-course multidrug chemotherapy: results of trial ALL-REZ BFM 90. J Clin Oncol 2010; 28: 2339-2347.

5. Du X L and Chen Q.: Recent advancements of bortezomib in acute lymphocytic leukemia treatment. Acta Haematol 2013; 129: 207-214.

6. Topp M S, Gokbuget N, and Zugmaier G et al.: Long-term follow-up of hematologic relapse-free survival in a phase 2 study of blinatumomab in patients with MRD in B-lineage ALL. Blood 2012; 120: 5185-5187.

7. Grupp S A, Kalos M, and Barrett D et al.: Chimeric antigen receptormodified T cells for acute lymphoid leukemia. N Engl J Med 2013; 368: 1509-1518. 
8. Maus M V, Grupp S A, and Porter D L et al.: Antibody-modified T cells: CARs take the front seat for hematologic malignancies. Blood 2014; 123: 2625-2635.

9. C. H. Waddington; The Epigenotype, International Journal of Epidemiology 2012; 1: 10-13.

10. Li E. Chromatin modification and epigenetic reprogramming in mammalian development. Nat Rev Genet. 2002 Sep;3(9):662-73.

11. Delaval K, Feil R. Epigenetic regulation of mammalian genomic imprinting. Curr Opin Genet Dev. 2004 Apr;14(2):188-95.

12. Hata K, Okano M, Lei H, Li E. Dnmt3L cooperates with the Dnmt3 family of de novo DNA methyltransferases to establish maternal imprints in mice. Development. 2002 Apr;129(8):1983-93.

13. Waterland RA, Lin JR, Smith CA, Jirtle RL. Post-weaning diet affects genomic imprinting at the insulin-like growth factor 2 (lgf2) locus. Human molecular genetics. 2006 Jan 18;15(5):705-16.

14. Niemczyk M, Ito Y, Huddleston J, Git A, Abu-Amero S, Caldas C, Moore GE, Stojic L, Murrell A. Imprinted chromatin around DIRAS3 regulates alternative splicing of GNG12-AS1, a long noncoding RNA. The American Journal of Human Genetics. 2013 Aug 8;93(2):224-35.

15. Wade PA, Gegonne A, Jones PL, Ballestar E, Aubry F, Wolffe AP. Mi-2 complex couples DNA methylation to chromatin remodelling and histone deacetylation. Nat Genet. 1999 Sep;23(1):62-6. 
16. Hendrich B, Hardeland U, Ng HH, Jiricny J, Bird A. The thymine glycosylase MBD4 can bind to the product of deamination at methylated CpG sites. Nature. 1999 Sep 16;401(6750):301-4.

17. Fatemi M, Pao MM, Jeong S, Gal-Yam EN, Egger G, Weisenberger DJ, Jones PA. Footprinting of mammalian promoters: use of a CpG DNA methyltransferase revealing nucleosome positions at a single molecule level. Nucleic acids research. 2005 Jan 1;33(20):e176-.

18. Saxonov S, Berg P, Brutlag DL. A genome-wide analysis of CpG dinucleotides in the human genome distinguishes two distinct classes of promoters. Proceedings of the National Academy of Sciences. 2006 Jan 31;103(5):1412-7.

19. Hegi ME, Diserens AC, Gorlia T, Hamou MF, De Tribolet N, Weller M, Kros JM, Hainfellner JA, Mason W, Mariani L, Bromberg JE. MGMT gene silencing and benefit from temozolomide in glioblastoma. New England Journal of Medicine. 2005 Mar 10;352(10):997-1003.

20. Gausachs M, Mur P, Corral J, Pineda M, González S, Benito L, Menéndez M, Espinàs JA, Brunet J, Iniesta MD, Gruber SB. MLH1 promoter hypermethylation in the analytical algorithm of Lynch syndrome: a costeffectiveness study. European Journal of Human Genetics. 2012 Jul;20(7):762 .

21. Maldonado L, Brait M, Loyo M, Sullenberger L, Wang K, Peskoe SB, Rosenbaum E, Howard R, Toubaji A, Albadine R, Netto GJ. GSTP1 
promoter methylation is associated with recurrence in early stage prostate cancer. The Journal of urology. 2014 Nov;192(5):1542-8.

22. Schröck A, Leisse A, de Vos L, Gevensleben H, Dröge F, Franzen A, Wachendörfer M, Schröck F, Ellinger J, Teschke M, Wilhelm-Buchstab T. Free-circulating methylated DNA in blood for diagnosis, staging, prognosis, and monitoring of head and neck squamous cell carcinoma patients: an observational prospective cohort study. Clinical chemistry. 2017 Jul 1;63(7):1288-96.

23. Nindrea RD, Harahap WA, Aryandono T, Lazuardi L. Association of BRCA1 Promoter methylation with breast cancer in Asia: a meta-analysis. Asian Pacific journal of cancer prevention: APJCP. 2018;19(4):885.

24. Begam N, Jamil K, Raju SG. Promoter hypermethylation of the ATM gene as a novel biomarker for breast cancer. Asian Pacific journal of cancer prevention: APJCP. 2017;18(11):3003.

25. Chaisaingmongkol J, Popanda O, Warta R, Dyckhoff G, Herpel E, Geiselhart L, Claus R, Lasitschka F, Campos B, Oakes CC, Bermejo JL. Epigenetic screen of human DNA repair genes identifies aberrant promoter methylation of NEIL1 in head and neck squamous cell carcinoma. Oncogene. 2012 Dec;31(49):5108.

26. Kuhmann C, Li C, Kloor M, Salou M, Weigel C, Schmidt CR, Ng LW, Tsui WW, Leung SY, Yuen ST, Becker N. Altered regulation of DNA ligase IV activity by aberrant promoter DNA methylation and gene amplification in 
colorectal cancer. Human molecular genetics. 2013 Nov 26;23(8):204354.

27. Smith IM, Mithani SK, Mydlarz WK, Chang SS, Califano JA. Inactivation of the tumor suppressor genes causing the hereditary syndromes predisposing to head and neck cancer via promoter hypermethylation in sporadic head and neck cancers. ORL. 2010;72(1):44-50.

28. Stevenson WS, Best OG, Przybylla A, Chen Q, Singh N, Koleth M, Pierce S, Kennedy T, Tong W, Kuang SQ, Garcia-Manero G. DNA methylation of membrane-bound tyrosine phosphatase genes in acute lymphoblastic leukaemia. Leukemia. 2014 Apr;28(4):787.

29. Almamun M, Levinson BT, van Swaay AC, Johnson NT, McKay SD, Arthur GL, Davis JW, Taylor KH. Integrated methylome and transcriptome analysis reveals novel regulatory elements in pediatric acute lymphoblastic leukemia. Epigenetics. 2015 Sep 2;10(9):882-90.

30. Minor J, Wang X, Zhang F, Song J, Jimeno A, Wang XJ, Lu X, Gross N, Kulesz-Martin M, Wang D, Lu SL. Methylation of microRNA-9 is a specific and sensitive biomarker for oral and oropharyngeal squamous cell carcinomas. Oral oncology. 2012 Jan 1;48(1):73-8.

31. Siemens H, Neumann J, Jackstadt R, Mansmann U, Horst D, Kirchner T, Hermeking $\mathrm{H}$. Detection of miR-34a promoter methylation in combination with elevated expression of $\mathrm{c}-M e t$ and $\beta$-catenin predicts distant metastasis of colon cancer. Clinical cancer research. 2013 Feb $1 ; 19(3): 710-20$. 
32. Yang C, Cai J, Wang Q, Tang H, Cao J, Wu L, Wang Z. Epigenetic silencing of miR-130b in ovarian cancer promotes the development of multidrug resistance by targeting colony-stimulating factor 1. Gynecologic oncology. 2012 Feb 1;124(2):325-34.

33. Oltra SS, Peña-Chilet M, Vidal-Tomas V, Flower K, Martinez MT, Alonso E, Burgues O, Lluch A, Flanagan JM, Ribas G. Methylation deregulation of miRNA promoters identifies miR124-2 as a survival biomarker in Breast Cancer in very young women. Scientific reports. 2018 Sep 26;8(1):14373.

34. Guo SX, Taki T, Ohnishi H, Piao HY, Tabuchi K, Bessho F, Hanada R, Yanagisawa M, Hayashi Y. Hypermethylation of $\mathrm{p} 16$ and $\mathrm{p} 15$ genes and RB protein expression in acute leukemia. Leukemia research. 2000 Jan 1;24(1):39-46 .

35. Holubeková V, Mendelová A, Grendár M, Meršaková S, Kapustová I, Jašek K, Vaňochová A, Danko J, Lasabová Z. Methylation pattern of $\mathrm{CDH} 1$ promoter and its association with $\mathrm{CDH} 1$ gene expression in cytological cervical specimens. Oncology letters. 2016 Oct 1;12(4):261321.

36. Herrera-Goepfert R, Oñate-Ocaña LF, Mosqueda-Vargas JL, Herrera LA, Castro C, Mendoza J, González-Barrios R. Methylation of DAPK and THBS1 genes in esophageal gastric-type columnar metaplasia. World journal of gastroenterology. 2016 May 14;22(18):4567. 
37. Bi FF, Li D, Yang Q. Hypomethylation of ETS transcription factor binding sites and upregulation of PARP1 expression in endometrial cancer. BioMed research international. 2013;2013.

38. Singh P, Yang M, Dai H, Yu D, Huang Q, Tan W, Kernstine KH, Lin D, Shen B. Overexpression and hypomethylation of flap endonuclease 1 gene in breast and other cancers. Molecular Cancer Research. 2008 Nov 1;6(11):1710-7.

39. Kohli RM, Zhang Y. TET enzymes, TDG and the dynamics of DNA demethylation. Nature. 2013 Oct;502(7472):472.

40. Williams K, Christensen J, Helin K. DNA methylation: TET proteinsguardians of CpG islands?. EMBO reports. 2012 Jan 1;13(1):28-35.

41. Ley TJ, Ding L, Walter MJ, McLellan MD, Lamprecht T, Larson DE, Kandoth C, Payton JE, Baty J, Welch J, Harris CC. DNMT3A mutations in acute myeloid leukemia. New England Journal of Medicine. 2010 Dec 16;363(25):2424-33.

42. Benjamin AL, Green BB, Crooker BA, McKay SD, Kerr DE. Differential responsiveness of Holstein and Angus dermal fibroblasts to LPS challenge occurs without major differences in the methylome. BMC genomics. 2016 Dec;17(1):258.

43. Pikor LA, Enfield KS, Cameron H, Lam WL. DNA extraction from paraffin embedded material for genetic and epigenetic analyses. JoVE (Journal of Visualized Experiments). 2011 Mar 26(49):e2763. 
44. Smrdel U, Popovic M, Zwitter M, Bostjancic E, Zupan A, Kovac V, Glavac D, Bokal D, Jerebic J. Long-term survival in glioblastoma: methyl guanine methyl transferase (MGMT) promoter methylation as independent favourable prognostic factor. Radiology and oncology. 2016 Dec 1;50(4):394-401.

45. Binabaj MM, Bahrami A, ShahidSales S, Joodi M, Joudi Mashhad M, Hassanian SM, Anvari K, Avan A. The prognostic value of MGMT promoter methylation in glioblastoma: A meta-analysis of clinical trials. Journal of cellular physiology. 2018 Jan;233(1):378-86.

46. Storey K, Leder K, Hawkins-Daarud A, Swanson K, Ahmed AU, Rockne RC, Foo J. Glioblastoma recurrence and the role of MGMT promoter methylation. bioRxiv. 2018 Jan 1:317636.

47. Grützmann R, Molnar B, Pilarsky C, Habermann JK, Schlag PM, Saeger HD, Miehlke S, Stolz T, Model F, Roblick UJ, Bruch HP, Koch R, Liebenberg V, Devos T, Song X, Day RH, Sledziewski AZ, Lofton-Day C. Sensitive detection of colorectal cancer in peripheral blood by septin 9 DNA methylation assay. PLoS One. 2008;3(11):e3759.

48. Harden SV, Guo Z, Epstein JI, Sidransky D. Quantitative GSTP1 methylation clearly distinguishes benign prostatic tissue and limited prostate adenocarcinoma. J Urol. 2003 Mar;169(3):1138-42.

49. Menigatti M, Di Gregorio C, Borghi F, Sala E, Scarselli A, Pedroni M, Foroni M, Benatti P, Roncucci L, Ponz de Leon M, Percesepe A. Methylation pattern of different regions of the MLH1 promoter and 
silencing of gene expression in hereditary and sporadic colorectal cancer. Genes Chromosomes Cancer. 2001 Aug;31(4):357-61.

50. Borssén M, Palmqvist L, Karrman K, Abrahamsson J, Behrendtz M, Heldrup J, Forestier E, Roos G, Degerman S. Promoter DNA methylation pattern identifies prognostic subgroups in childhood T-cell acute lymphoblastic leukemia. PloS one. 2013 Jun 6;8(6):e65373.

51. Borssén M, Nordlund J, Haider Z, Landfors M, Larsson P, Kanerva J, Schmiegelow K, Flaegstad T, Jónsson ÓG, Frost BM, Palle J. DNA methylation holds prognostic information in relapsed precursor B-cell acute lymphoblastic leukemia. Clinical epigenetics. 2018 Dec;10(1):31.

52. Nordlund J, Bäcklin CL, Wahlberg P, Busche S, Berglund EC, Eloranta ML, Flaegstad T, Forestier E, Frost BM, Harila-Saari A, Heyman M. Genome-wide signatures of differential DNA methylation in pediatric acute lymphoblastic leukemia. Genome biology. 2013 Sep;14(9):r105.

53. Milani L, Lundmark A, Kiialainen A, Nordlund J, Flaegstad T, Forestier E, Heyman M, Jonmundsson G, Kanerva J, Schmiegelow K, Söderhäll S. DNA methylation for subtype classification and prediction of treatment outcome in patients with childhood acute lymphoblastic leukemia. Blood. 2010 Feb 11;115(6):1214-25.

54. Sandoval J, Heyn H, Méndez-González J, Gomez A, Moran S, Baiget M, Melo M, Badell I, Nomdedéu JF, Esteller M. Genome-wide DNA methylation profiling predicts relapse in childhood B-cell acute 
lymphoblastic leukaemia. British journal of haematology. 2013 Feb;160(3):406.

55. Uyen TN, Sakashita K, Al-Kzayer LA, Nakazawa Y, Kurata T, Koike K. Aberrant methylation of protocadherin 17 and its prognostic value in pediatric acute lymphoblastic leukemia. Pediatric blood \& cancer. 2017 Mar;64(3):e26259.

56. Swerdlow SH, Campo E, Harris NL, Harris NL, Jaffe ES, Pileri SA, Stein $\mathrm{H}$, Thiele J, Vardiman JW, editors. WHO Classification of Tumours of Haehatopoietic and Lymphoid Tissues, Lyon, France, IARC, 2008.

57. Zachariadis V, Gauffin F, Kuchinskaya E, Heyman M, Schoumans J, Blennow E, Gustafsson B, Barbany G, Golovleva I, Ehrencrona H, Cavelier L. The frequency and prognostic impact of dic $(9 ; 20)(p 13.2 ; q 11$. 2) in childhood B-cell precursor acute lymphoblastic leukemia: results from the NOPHO ALL-2000 trial. Leukemia. 2011 Apr;25(4):622.

58. Nordlund J, Bäcklin CL, Zachariadis V, Cavelier L, Dahlberg J, Öfverholm I, Barbany G, Nordgren A, Övernäs E, Abrahamsson J, Flaegstad T. DNA methylation-based subtype prediction for pediatric acute lymphoblastic leukemia. Clinical epigenetics. 2015 Dec;7(1):11.

59. Milani L, Lundmark A, Nordlund J, Kiialainen A, Flaegstad T, Jonmundsson G, Kanerva J, Schmiegelow K, Gunderson KL, Lönnerholm G, Syvänen AC. Allele-specific gene expression patterns in primary leukemic cells reveal regulation of gene expression by $\mathrm{CpG}$ site methylation. Genome research. 2009 Jan 1;19(1):1-1. 
60. Figueroa ME, Chen SC, Andersson AK, Phillips LA, Li Y, Sotzen J, Kundu M, Downing JR, Melnick A, Mullighan CG. Integrated genetic and epigenetic analysis of childhood acute lymphoblastic leukemia. The Journal of clinical investigation. 2013 Jul 1;123(7):3099-111.

61. Busche S, Ge B, Vidal R, Spinella JF, Saillour V, Richer C, Healy J, Chen SH, Droit A, Sinnett D, Pastinen T. Integration of high-resolution methylome and transcriptome analyses to dissect epigenomic changes in childhood acute lymphoblastic leukemia. Cancer research. 2013 Jul $15 ; 73(14): 4323-36$

62. van Dongen JJ, van der Velden VH, Brüggemann M, Orfao A. Minimal residual disease diagnostics in acute lymphoblastic leukemia: need for sensitive, fast, and standardized technologies. Blood. 2015 Jun 25;125(26):3996-4009

63. Van der Velden VH, Cazzaniga G, Schrauder A, Hancock J, Bader P, Panzer-Grumayer ER, Flohr T, Sutton R, Cavé H, Madsen HO, Cayuela $\mathrm{JM}$. Analysis of minimal residual disease by $\mathrm{Ig} / \mathrm{TCR}$ gene rearrangements: guidelines for interpretation of real-time quantitative PCR data. Leukemia. 2007 Apr 1;21(4):604-11.

64. Szczepański T, Willemse MJ, Brinkhof B, van Wering ER, van der Burg M, van Dongen JJ. Comparative analysis of Ig and TCR gene rearrangements at diagnosis and at relapse of childhood precursor-B-ALL provides improved strategies for selection of stable PCR targets for monitoring of minimal residual disease. Blood. 2002 Apr 1;99(7):2315-23. 
65. Flores-Montero J, Sanoja-Flores L, Paiva B, Puig N, García-Sánchez O, Böttcher S, van der Velden VH, Perez-Moran JJ, Vidriales MB, GarcíaSanz R, Jiménez C. Next Generation Flow for highly sensitive and standardized detection of minimal residual disease in multiple myeloma. Leukemia. 2017 Oct;31(10):2094.

66. Nordlund J, Milani L, Lundmark A, Lönnerholm G, Syvänen AC. DNA methylation analysis of bone marrow cells at diagnosis of acute lymphoblastic leukemia and at remission. PloS one. $2012 \mathrm{Apr}$ 6;7(4):e34513.

67. Wong NC, Ashley D, Chatterton Z, Parkinson-Bates M, Ng HK, Halemba M, Kowalczyk A, Bedo J, Wang Q, Bell K, Algar E. A distinct DNA methylation signature defines pediatric pre-B cell acute lymphoblastic leukemia. Epigenetics. 2012 Jun 1;7(6):535-41.

68. Chatterton Z, Burke D, Emslie KR, Craig JM, Ng J, Ashley DM, Mechinaud F, Saffery R, Wong NC. Validation of DNA methylation biomarkers for diagnosis of acute lymphoblastic leukemia. Clinical chemistry. 2014 Jul 1;60(7):995-1003.

69. Coolen MW, Statham AL, Gardiner-Garden M, Clark SJ. Genomic profiling of $\mathrm{CpG}$ methylation and allelic specificity using quantitative highthroughput mass spectrometry: critical evaluation and improvements. Nucleic acids research. 2007 Sep 1;35(18):e119.

70. Wang MX, Wang HY, Zhao X, Srilatha N, Zheng D, Shi H, Ning J, Duff DJ, Taylor KH, Gruner BA, Caldwell CW. Molecular detection of B-cell 
neoplasms by specific DNA methylation biomarkers. International journal of clinical and experimental pathology. 2010;3(3):265.

71. Hogan LE, Meyer JA, Yang J, Wang J, Wong N, Yang W, Condos G, Hunger SP, Raetz E, Saffery R, Relling MV. Integrated genomic analysis of relapsed childhood acute lymphoblastic leukemia reveals therapeutic strategies. Blood. 2011 Nov 10;118(19):5218-26.

72. Staal FJ, de Ridder D, Szczepanski T, Schonewille T, Van Der Linden EC, Van Wering ER, Van Der Velden VH, Van Dongen JJ. Genome-wide expression analysis of paired diagnosis-relapse samples in ALL indicates involvement of pathways related to DNA replication, cell cycle and DNA repair, independent of immune phenotype. Leukemia. 2010 Mar 1;24(3):491-9.

73. Bhojwani D, Kang H, Moskowitz NP, Min DJ, Lee H, Potter JW, Davidson G, Willman CL, Borowitz MJ, Belitskaya-Levy I, Hunger SP. Biologic pathways associated with relapse in childhood acute lymphoblastic leukemia: a Children9s Oncology Group study. Blood. 2006 Jul $15 ; 108(2): 711-7$.

74. Chow YP, Alias H, Jamal R. Meta-analysis of gene expression in relapsed childhood B-acute lymphoblastic leukemia. BMC cancer. 2017 Feb 10;17(1):120.

75. Jain M, Zhang L, He M, Zhang YQ, Shen M, Kebebew E. TOP2A is overexpressed and is a therapeutic target for adrenocortical carcinoma. Endocrine-related cancer. 2013 Jun 1;20(3):361-70. 
76. De Resende MF, Vieira S, Chinen LT, Chiappelli F, da Fonseca FP, Guimarães GC, Soares FA, Neves I, Pagotty S, Pellionisz PA, Barkhordarian A. Prognostication of prostate cancer based on TOP2A protein and gene assessment: TOP2A in prostate cancer. Journal of translational medicine. 2013 Feb 11;11(1):36.

77. Bhatla T, Wang J, Morrison DJ, Raetz EA, Burke MJ, Brown P, Carroll WL. Epigenetic reprogramming reverses the relapse-specific gene expression signature and restores chemosensitivity in childhood Blymphoblastic leukemia. Blood. 2012 May 31;119(22):5201-10.

78. Bennett AL, Williams LE, Ferguson MW, Hauck ML, Suter SE, Lanier CB, Hess PR. Canine acute leukaemia: 50 cases (1989-2014). Veterinary and comparative oncology. 2017 Sep;15(3):1101-14.

79. Matus RE, Leifer CE, MacEwen EG. Acute lymphoblastic leukemia in the dog: a review of 30 cases. Journal of the American Veterinary Medical Association. 1983 Oct;183(8):859-62.

80. Tasca S, Carli E, Caldin M, Menegazzo L, Furlanello T, Gallego LS. Hematologic abnormalities and flow cytometric immunophenotyping results in dogs with hematopoietic neoplasia: 210 cases (2002-2006). Veterinary clinical pathology. 2009 Mar;38(1):2-12.

81. Williams MJ, Avery AC, Lana SE, Hillers KR, Bachand AM, Avery PR. Canine lymphoproliferative disease characterized by lymphocytosis: immunophenotypic markers of prognosis. Journal of Veterinary Internal Medicine. 2008;22(3):596-601. 
82. Han L, Zhao Z. Contrast features of CpG islands in the promoter and other regions in the dog genome. Genomics. 2009 Aug 31;94(2):117-24.

83. Smallwood TL, Small GW, Suter SE, Richards KL. Expression of asparagine synthetase predicts in vitro response to L-asparaginase in canine lymphoid cell lines. Leukemia \& lymphoma. 2014 Jun 1;55(6):1357-65.

84. Bronzini I, Aresu L, Paganin M, Marchioretto L, Comazzi S, Cian F, Riondato F, Marconato L, Martini V, Te Kronnie G. DNA methylation and targeted sequencing of methyltransferases family genes in canine acute myeloid leukaemia, modelling human myeloid leukaemia. Veterinary and comparative oncology. 2017 Sep;15(3):910-8.

85. Figueiredo JF, Culver S, Behling-Kelly E, Breen M, Friedrichs KR. Acute myeloblastic leukemia with associated BCR-ABL translocation in a dog. Veterinary clinical pathology. 2012 Sep;41(3):362-8. 


\section{CHAPTER 2: METHYLOME ANALYSIS OF RELAPSED PEDIATRIC PRE-B ACUTE LYMPHOBLASTIC LEUKEMIA}

\subsection{ABSTRACT}

Background: The chance of survival for relapsed pediatric pre-B cell acute lymphoblastic leukemia (ALL) patients is poor. Epigenetic alterations, involving DNA methylation may contribute in driving relapse events and have the potential to serve as biomarkers at diagnosis. In order to identify aberrant methylation associated with potential oncogenes, epidrivers, and prognostic biomarkers in ALL, genome-wide methylation profiles were constructed for diagnosis and relapse matched patient samples using the methylated $\mathrm{CpG}$ island recovery assay (MIRA), followed by next-generation Illumina sequencing. Results: First, paired samples at diagnosis and at relapse were compared to identify methylation changes that occur in patients at relapse. Approximately $99 \%$ of regions differentially methylated between paired patient samples at diagnosis and relapse were hypomethylated in the patients at relapse. 61 of these regions were present with regulatory elements of oncogenes. This is in contrast to previous studies that observed predominate hypermethylation at relapse.

Predominate hypomethylation may contribute to oncogenic activation and overall genomic instability in relapsed ALL patients. Next, to identify potential biomarkers that were aberrantly methylated in patient samples at both diagnosis and at relapse, differentially methylated regions (DMRs) were identified between patients at diagnosis and pre-B cells from healthy individuals and also between 
patients at relapse and pre-B cells from healthy individuals. Common DMRs identified in the patients at diagnosis and at relapse included those that were present in the promoter, 5' UTR, and first exon of 796 genes. This included potential epidriver genes associated with tumor suppression (PRUNE2, PTPRO, FRMD5, MLF1) and B-cell function (MCOLN2, IL7, SOCS2, BID). Lastly, to identify biomarkers present at diagnosis with the potential to identify patients that will relapse, DNA methylation profiles of patients that relapsed were compared to the methylation profiles of patients that did not relapse. A total of 130 hypermethlyated loci sustained from diagnosis to relapse were identified. These loci were not among the hypermethylated regions found in the non-relapse cohort when compared to normal controls. Conclusion: The study's results suggest that oncogenic activation and genomic instability may be consequences of regulatory aberrant hypomethylation, which may contribute to the drug resistant phenotype observed in relapsed ALL patients. In addition, potential epidriver genes consisting of tumor suppressors and oncogenes may provide a selective advantage for neoplastic pre-B cells at diagnosis and relapse. Lastly, the 130 loci identified as putative biomarkers represent regions with risk stratification potential, by which patients may be assigned to either low-moderate or high risk groups prior to treatment at diagnosis. A quantitative approach is necessary to further delineate the methylation disparities of individual $\mathrm{CpG}$ within these regions between patients at diagnosis who did or did not relapse. 


\subsection{INTRODUCTION}

Although the survival rate of pediatric pre-B cell acute lymphoblastic leukemia (ALL) has reached approximately $90 \%$, relapsed ALL is still the leading cause of cancer related deaths among children. According to the National Cancer Institute, approximately 3,100 children and adolescents under 20 are diagnosed each year in the United States. ${ }^{1}$ Patients at a higher risk of relapse are primarily associated with certain clinical features (white blood cell count $(\mathrm{WBC})>50,000$ cells $/ \mu \mathrm{L}$ ) and a few recurrent cytogenetic subtypes (Philadelphia translocation (BCR/ABL1), mixed-lineage leukemia (MLL), hypodiploidy). ${ }^{1,2}$ However, relapse also occurs in ALL patients belonging to favorable cytogenetic subtypes (hyperdiploidy [51> chromosomes $>46$ ], normal [chromosomes $=46]$ ), alluding to alternate contributing mechanisms, such as aberrant DNA methylation.

There have been two studies that have analyzed DNA methylation differences between diagnosis and relapsed matched patient samples using either the $27 \mathrm{k}$ or 450k methylation BeadChip platform. . $^{3,4}$ The two studies observed predominate gains of DNA methylation (hypermethylation) at relapse compared to diagnosis. Pathway analysis of hypermethylated genes from both studies found enrichment for Wnt/ß-catenin signaling. Hogan and colleagues confirmed several negative regulators, such as PTPRO and $s F R P 2$ of the $\mathrm{Wnt} / \beta$-catenin pathway that exhibited promoter hypermethlyation and downregulation at relapse. ${ }^{4}$ Other enriched pathways observed in either study, include the MAPK cascade and transcriptional regulatory network in embryonic stem cells. 
Unlike previous studies, the primary aim of this study was to better understand the ramifications of aberrant DNA methylation at relapse in individuals that relapsed despite a cytogenetic profile associated with a low risk for relapse. First, differentially methylated regions (DMRs) between 10 children with favorable cytogenetic subtypes (hyperdiploidy or normal) at diagnosis and upon relapse were identified utilizing the methylated $\mathrm{CpG}$ island recovery assay, followed by next-generation sequencing (MIRA-seq). Next, aberrant methylation within regulatory regions of oncogenes or tumor suppressors were identified at relapse, followed by describing their biological role in relation to cancer. In addition, aberrant methylation sustained from diagnosis to relapse was analyzed, which may be helpful in identifying driver genes of ALL that are regulated by epigenetic changes, termed epidrivers. Finally, a relapse associated methylation signature was sought by comparing hypermethlyated loci found in a cohort of patients at diagnosis that did not relapse to hypermethylated loci sustained from diagnosis to relapse.

\subsection{MATERIALS AND METHODS}

\subsubsection{Patient samples}

Bone marrow aspirates containing $>87 \%$ leukemic blasts from ALL patient samples were used under full ethical approval of the institution review board at the University of Missouri (Table 2.1). MIRA-seq libraries were created for A27, A59, A70, A101, and A121 patient samples at diagnosis that relapsed and for all 
ten matched relapsed samples in this study. These MIRA-seq profiles are accessible through the NCBI Sequence Read Archive (Accession PRJNA470682). Previously generated MIRA-seq libraries for A4, A15, A18-A26, A28-A31, A33, A36, A37 diagnosis patient samples and ten normal human umbilical blood (HCB1-HCB10) were used in one or more of the analyses in this study. ${ }^{5}$ The previously generated MIRA-seq profiles can be found in the NCBI Sequence Read Archive (Accession SRP058314).

\subsubsection{Genomic DNA isolation and MIRA-seq profile construction}

Using the QIAamp DNA Micro Kit (Qiagen cat. no. 56304), genomic DNA was extracted from ALL patient samples. Approximately $1 \mu \mathrm{g}$ of DNA in was used as the starting concentration in construction of each MIRA-seq library. The DNA was sonicated with the Diagenode Bioruptor (Diagenode; cat. no. B01010002) at $4^{\circ} \mathrm{C}$, creating a range of 200 to $700 \mathrm{bp}$ fragments. Sonicated DNA ( 150ng) was run on $1 \%$ agarose gel at $\sim 96 \mathrm{~V}$ for 45 minutes to verify the 200 to $700 \mathrm{bp}$ fragmented range. The sonicated DNA was purified using the MinElute PCR purification kit (Qiagen; cat. no. 28004) and eluted with $12 \mu \mathrm{L}$ nuclease-free water. End repair and $\mathrm{dA}$ tailing of the fragments was performed using the NEBNext DNA Library Prep Master Mix Set for Illumina kit (New England BioLabs; cat. no. E6040S) with a DNA purification step using Agencourt AMPure XP Beads (Beckman Coulter; cat. no. A63881). After End repair and dA tailing, NEB-Next Adaptors were added following another DNA purification step with 1x the concentration AMPure XP Beads and 10 $\mathrm{LL}$ nuclease-free water elution. For 
methylated DNA fragment enrichment, methylated $\mathrm{CpG}$ island recovery assay MIRA was performed with the Methyl Collector UltraTM kit (Active Motif; cat. no. 55005). This pull-down method involves a methyl binding protein complex (MBD2b/MBD3L1) conjugated with nickel beads that compartmentalize the methylated fragments towards the magnetic stand, where the supernatant is exposed and removed with subsequent wash steps in between using AMPure XP Beads. The MIRA product was run on $1 \%$ agarose gel for 45 minutes at $\sim 96 \mathrm{~V}$ and bands between 200 to $700 \mathrm{bps}$ were excised and purified using the MinElute Gel Extraction kit (Qiagen; cat no. 28604). These methylated fragments were PCR enriched with the NEBNext DNA Library Prep Master Mix Set for Illumina kit with multiplex oligos for 12 cycles. The DNA product was purified again with AMPure XP Beads and eluted with $15 \mu \mathrm{L}$ nuclease-free water. End-point PCR was performed for a known methylated region of gene (SLC25A37) and a known unmethylated region of gene (APC1) in the methylated DNA enriched library. After running the PCR samples on $1 \%$ agarose gel at $\sim 96 \mathrm{~V}$ for 45 minutes, there was a distinct band present at around $160 \mathrm{bp}$ representing the SLC25A37 gene product, but a slim to no band seen at the $160 \mathrm{bp}$ ladder mark for the APC1 gene product. SLC25A37: forward primer 5'-GGTGGCTCCCACTTTAAGGAA-3' and reverse primer 5'-ATCTCGGCTGTCCCCAT-3', (amplicon size $=158 \mathrm{bp})$. APC1: forwards primer 5'-ACTGCCATCAACTTCCTTGC-3' and reverse primer 5'GCGGATTACACAGCTGCTTC-3' (amplicon size $=162 \mathrm{bp}$ ). Fragment analysis and Qubit quantitation was performed for each library prior to sequencing. No more than 4 MIRA-seq libraries were multiplexed in 10nM concentrations with 
100bp single-end sequencing by the DNA Core facility at the University of Missouri on the HiSeq 2000.

\subsubsection{Sequence processing and annotation of patient sample libraries}

Quality control check of FASTQ file reads were done using FastQC v0.11.4 ${ }^{6}$, then adaptor sequences were removed, including reads $<50 \mathrm{bps}$, using cutadapt v1.7.1. ${ }^{7}$ Read alignment was performed using Bowtie 2 v2.2. ${ }^{8}$ to the human reference genome (hg19) with default settings and allowing no more than two mismatches. The output SAM files were then converted to BAM files and sorted accordingly using "view" and "sort" options with samtools version 1.2.1 ${ }^{9}$ Picardtools version 1.92 under "MarkDuplicates" option, removed duplicate reads. The final BAM output files were then indexed with samtools "index" option. Genomic coordinate BED files containing the differentially methylated regions DMRs were annotated using HOMERv4. $3^{10}$ (Hypergeometric Optimization of Motif EnRichment) with default settings. The $\mathrm{X}$ and $\mathrm{Y}$-chromosomes were excluded from this analysis.

\subsubsection{Identifying DMRs between diagnosis and relapse patients}

Differentially methylated regions DMRs between diagnosis and relapse matched patients was based off a computational method used by Chavez and colleagues. ${ }^{11}$ Sufficient coverage depth was observed in each sample file (BAM file) using a saturation analysis (saturation correlation $>0.90$ ). The reads were accumulated in $200 \mathrm{bp}$ windows along with a $200 \mathrm{bp}$ extension (average fragment 
size of $\sim 400 \mathrm{bp}$ ). These windows are regions of interest (ROls). ROls with a mean across all samples $<50$ counts were excluded to avoid bias and enhancing power, while reducing false discoveries. ${ }^{12}$ The remaining ROIs were tested with a modified version of MEDIPS package in R/Bioconductor, utilizing edgeR's generalized linear model function (appropriate for matched patient sample comparison) in determining if a $\mathrm{ROI}$ is a DMR, where the false discovery rate (Benjamini-Hochberg) is $<5 \%$ and a $\log _{2}$ fold change $\geq 1$. Normalized RPM values (Reads Per Million) were computed for each 200bp window and used to identify DMRs. DMRs were merged as separate entities in respect to hypomethylation and hypermethylation, if the adjacent 200bp window met the previously described criteria.

\subsubsection{Identifying common DMRs between diagnosis and relapse patients}

First, DMRs were identified between HCB and diagnosis, then HCB and relapse patients. ROls of $200 \mathrm{bp}$ were tested using the MEDIPS package with default parameters (classic edgeR). ROls with a mean across all samples $<50$ counts were excluded and DMRs were selected with a false discovery rate (BenjaminiHochberg) of $<5 \%$ and $a \log _{2}$ fold change $\geq 1$. DMRs were merged as hypermethylated or hypomethylated regions. Hypermethylated DMR coordinates

at diagnosis were intersected with hypermethylated DMRs at relapse, likewise for hypomethylated regions. This was accomplished using the intersectBed feature from bedtools v2.24.0. ${ }^{13}$ The output from this analysis were DMRs that were sustained from diagnosis to relapse, termed common DMRs. 


\subsection{6 mirPath v3 software analysis}

HOMER annotated microRNAs with common hypermethylation or

hypomethylation were submitted to mirPath $v 3^{14}$ using the software's default parameters of a $p$-value $<0.05$ and incorporating a false discovery rate correction option. The MicroT threshold default value was 0.8 , which is the standard for human pathway predictions. The TarBase v7.0 was utilized as the miRNA gene interaction database in finding potential target pathways.

\subsubsection{Identification of enriched biological processes of hypomethylated protein-coding genes}

Hypomethylated protein-coding genes were submitted to Gene Ontology Consortium for biological processes enrichment analysis $(p$-value $<0.05){ }^{15}$

\subsubsection{In silico analysis of $\mathbf{3 8}$ hypermethylated regions at relapse}

Publically available ENCODE Data Coordination Center at UCSC, provided ChIP-seq coordinates from the GM12878 lymphoblastoid cell line (LCL).

Genomic coordinates were extracted into BED format and then intersected with the 38 hypermethylated regions at relapse. Putative enhancers were defined as overlapping genomic coordinates of H3K4me1 (GSM733772) and H3K27ac (GSM733771) histone marks. ChIP-seq coordinates from DNase hypersensitivity sites (GSM816665) and 76 available transcription factors were also utilized. 


\subsubsection{Identification of relapse associated regions in patients at original diagnosis}

MEDIPS was utilized in finding 17,137 hypermethylated regions in 13 nonrelapse ALL patients compared to $10 \mathrm{HCB}$ normal control patients. Using intersectBed from bedtools v2.24.0, 130 regions were present within the 2,170 common hypermethylated regions found between diagnosis-relapse and absent among the 17,137 hypermethylated regions found within the 13 non-relapse patients. The 130 regions were then ranked based on odds ratios, where larger scores represented a greater presence of individuals with read counts $>50$ in the relapsed cohort in correlation with the absence of read counts $>50$ within the non-relapsed cohort. Odds ratio scores, including 95\% confidence intervals, and their respective $p$-values were calculated using MEDCALC software v 12.4 (MedCalc Software, Ostend, Belgium) based on $\%$ of reads $>50$ in the relapsed cohort $=\mathrm{P} 2$ and $\%$ of reads $>50$ in the 13 non-relapsed cohort $=\mathrm{P} 1$. Regions where read count values were $>50$ were labeled in red and regions $<50$ read counts were labeled in yellow for a given patient. Haldane-Anscombe correction was applied to the data for each region, where a constant equal to 0.5 was added to each cell.

\subsection{RESULTS}

\subsubsection{Patients with ALL lose methylation at relapse}

High quality sequence reads were generated for each sample, resulting in approximately 100 million unique mapped reads for each patient at diagnosis and 
140 million reads for each patient at relapse. The overall read alignment rate generated by Bowtie 2 ranged from 87.4 to $91.4 \%$. Unique mapped reads were used to identify differentially methylated regions between diagnosis and relapse samples using a false discovery rate of $\leq 5 \%$ and a $\log _{2}$ fold change $\geq 1$. Strikingly, 70,740 DMRs were identified with $99.9 \%$ of the DMRs losing methylation at relapse.

Importantly, a loss of methylation was observed in retrotransposable elements, satellite repeat sequences, and within the 5' regulatory region of protein coding genes, ncRNAs and pseudogenes (Figure 2.1). Further, among the top 20 DMRs with the largest $\log _{2}$ fold change, 12 resided within the 5' regulatory region of 8 genes. BedGraphs pertaining to genes exhibiting the largest $\log _{2}$ fold change within their 5 ' regulatory region, illustrate the distinct read count differences between diagnosis and relapsed patients (Figure 2.2).

In addition, two large stretches of hypomethylation were observed in patients with ALL at relapse. A 40kb hypomethylated region comprised of two $10.2 \mathrm{~kb}$ DMRs and 12 additional DMRs was observed (Figure 2.3). This region is located on chromosome 1 and harbors the protein-coding gene RHOU, the pseudogene DUSP5P1, and $175 S$ ribosomal RNA gene copies. The second region comprised of a large $692 \mathrm{~kb}$ hypomethylated region encompassing 3 protocadherin gene clusters on chromosome 5 (Figure 2.3). A total of 111 
DMRs were present within this region and correspond directly with $\mathrm{CpG}$ islands and the protocadherin genes.

To determine the biological processes associated with potential regulatory DMRs that lose methylation in patients with ALL at relapse, gene ontology (GO) enrichment analysis was performed. Enriched biological processes included cell adhesion, cell signaling, cell differentiation, and regulation of immune response. Next, DMRs associated with genes with oncogenic potential were identified and classified based on cellular function (Table 2.2). Genes with oncogenic potential were associated with processes and pathways pertaining to relapsed ALL, which include the MAP-kinase cascade, Wnt/ $\beta$-catenin signaling, and DNA replication. $^{4,16}$

Remarkably, only 38 regions of the total 70,740 DMRs found at relapse, gained methylation at relapse (Table 2.3). Three regions were located within the promoter or first exon of a protein coding gene and 4 regions were located within exon-intron junctions. To further determine the regulatory potential of the hypermethylated DMRs, publically available data for the GM12878 lymphoblastoid cell line was utilized to identify regions concomitant with active chromatin (DNase hypersensitivity), transcriptional enhancers (H3K4me1 and H3K27ac) and bound transcription factors. Half of the hypermethylated DMR were concomitant with at least one potential regulatory element. 


\subsubsection{Identification of DMRs present at diagnosis and relapse}

In order to identify putative regulatory DMRs that may contribute to the ALL phenotype, common DMRs observed in patients with ALL at diagnosis and relapse when compared to healthy precursor B-cells were identified using a false discovery rate of $\leq 5 \%$ and $\log _{2}$ fold change $\geq 1$. A total of 2,170 hypermethylated and 1,741 hypomethylated DMRs were present at both diagnosis and relapse (Figure 2.4). A predominance of hypermethylated DMRs were observed within promoters, 5' UTRs, and first exons of protein coding genes, non-coding RNAs, and within regions associated with CpG islands (CGI), whereas a predominance of hypomethylated DMRs were observed in retrotransposable elements and non-CGI regions of the genome (Figure 2.4).

Genes and miRNAs with aberrant regulatory methylation at diagnosis and at relapse were then characterized based on their potential to contribute to the overall pathogenesis of ALL. Common putative regulatory DMRs present in protein-coding genes and ncRNAs, included hypermethylation within genes involved in B-cell development (IL7, MCOLN2) ${ }^{17,18}$ and tumor suppression (FRMD5, MLF1, PRUNE2, PTPRO, LOC389332, miR-124-3, miR-129-2, miR375, LINC01018) ${ }^{19,20,21,22,23,24,25,26,27}$, whereas genes involved in hematopoietic stem cell (HSC) regulation (SOCS2, BID) ${ }^{28,29}$ exhibited hypomethylation (Table 2.4). Functional annotation clustering analysis of the 677 protein-coding genes that possessed a hypermethylated DMR within the 5'regulatory region revealed enrichment of genes associated with DNA binding homeodomain (Enrichment 
Score: 20.16), fork head transcription factor (Enrichment Score: 7.53), peptidase M12B ADAM-TS (Enrichment Score: 5.04), myc-type, basic helix-loop-helix domain (Enrichment Score: 4.87), cadherin conserved site (Enrichment Score: 3.70), ionotropic glutamate receptor (Enrichment Score: 3.38), and core promoter proximal region sequence specific DNA binding (Enrichment Score: 2.39). Functional annotation clustering of the 43 protein coding genes that possessed a hypomethylated DMR within the 5'regulatory region did not reach statistical significance.

In order to identify aberrantly methylated miRNAs associated with pathways and functional groups with undocumented but potential roles in the pathogenesis of ALL, miRNAs overlapping common DMRs were submitted to mirPath v3. Among the 14 miRNAs, the mirPath analysis identified an association between hypermethylated miR-375 with Hippo signaling, proteoglycans in cancer, cell cycle, and others. Further, hypomethylated miR-589 was associated with antigen processing/presentation, allograft rejection pathways, and others ( $p$ value $<0.05$ )

\subsubsection{Identification of relapse associated DMRs present at diagnosis}

To identify DMRs present at diagnosis exclusively in individuals that went on to relapse, data previously generated by Almamun and colleagues was utilized. ${ }^{5}$ When hypermethylated DMRs were sought in patients at diagnosis that had relapsed and patients that had not relapsed, compared to healthy patient 
samples, 130 regions were identified in the patients that had relapsed. Odds ratios were calculated to identify the strongest candidate biomarkers and ranged from 0.70 to 57.9 (Figure 2.5). A significance level ( $p$-value $<0.05$ ) was met for 23 regions. These regions lay within introns $(n=3)$ of protein-coding genes (WDR60, LOC100506990, NBPF1) and within intergenic sequences $(\mathrm{n}=20)$. DMRs within the intergenic regions did not overlap with any $\mathrm{CpG}$ island and varied in their distances to the nearest transcriptional start site (TSS) of a given gene $(4.2 \mathrm{~kb}$ to $1.7 \mathrm{mb})$.

\subsection{DISCUSSION}

This is the first study to implement Illumina next-generation sequencing technology to create methylome profiles for matched diagnosis and relapsed ALL patients. The selected patients in this study contain a favorable cytogenetic profile, which enables a better understanding of how aberrant DNA methylation may contribute to relapsed ALL. This study is also the first to analyze sustained aberrant DNA methylation patterns that exist at both diagnosis and relapsed stage of ALL. This allowed for a comparative analysis against aberrantly methylated loci from patients at diagnosis who did not relapse.

This study did not incorporate input control samples when identifying DMRs between patient samples. When performing differential coverage between the different patient cohorts, local CpG density biases would affect read coverage in the same way. There may be impacts due to certain genetic components like 
copy number alterations. However, these genetic alterations would need to occur within the same locus among many patients to have a sizable impact.

The differential methylation analysis between diagnosis and relapse patients revealed that losses of DNA methylation characterize the genomic landscape in patient samples at relapse. This finding may seemingly contradict past studies that have found predominate hypermethylation at relapse..$^{3,4}$ There are two main factors that may contribute to the outcome disparities between this study and pasts. First, this study's smaller sample size relative to past studies has a direct effect on statistical power, potentially resulting in fewer regions of hypermethylation observed at relapse. This notion may be supported by the fact that 457 out of 740 genes that exhibited sustained 5 ' regulatory hypermethylation from diagnosis to relapse in this study corresponded to genes with 5' regulatory hypermethylation observed at relapse from diagnosis from the $450 \mathrm{k}$ array study done by Nordlund and colleagues. ${ }^{3}$ Therefore, a larger sample size most likely results in many of sustained hypermethylated DMR findings to actually have increases in DNA methylation at relapse compared to diagnosis.

The second factor pertains to the different methodological approach of regional differences (DMR) and individual CpG differences (DMC). This study sought out $200 \mathrm{bp}$ regions of differential methylation (DMR) by comparing read count differences counted across intervals as opposed to past microarray studies, which are predicated on differential methylation at the single CpG level (DMC) in 
accordance to fluorescent signals ( $\beta$-values) of individual probes. Therefore, individual CpGs that are differentially methylated within this study may go unaccounted for due to the influence of high read counts affiliated with adjacent CpGs within the same 200bp. For example, this effect may be more profound in $\mathrm{CpG}$ islands, where higher read counts are observed, which may mask methylation differences of individual CpGs.

A noticeable observation among the hypomethylated regions detected at relapse is that the majority lay within retrotransposable elements. Losses of methylation within these regions have well documented associations with malignant progression and overall genomic destabilization. DNA hypomethylation also occurred within the 5' regulatory regions of genes that may contribute to relapse. Due to the limitations of patient samples, gene expression differences between diagnosis and relapse were not evaluated. However, Chow and colleagues performed a meta-analysis incorporating the data from 3 gene expression studies that evaluated differential expression between individuals at diagnosis and relapse. ${ }^{30}$ A total of 126 of the hypomethylated genes identified in this study were found to be upregulated at relapse in the meta-analysis. Functional annotation of these genes revealed an enrichment of genes involved in DNA replication and repair (TOP2A, PCNA, MCM6). One of the 126 hypomethylated genes that showed differential expression in the meta-study $(T O P 2 A)$, showed differential expression in each of the individual studies. ${ }^{4,16,31}$ In general, increased expression of DNA repair genes has been associated with relapse, 
where upregulation of TOP2A has been shown to be predictive of poor relapse free survival. ${ }^{32}$ While, others have also reported a role for TOP2A in relapsed ALL, this data supports a potential role for additional genes involved in DNA replication and repair including $P C N A$ and MCM6.

Markedly large stretches of hypomethylation have been reported in cancer. ${ }^{33,34}$ In this study, two large stretches of hypomethylation were observed in patients with $\mathrm{ALL}$ at relapse. Interestingly, the $692 \mathrm{~kb}$ region harboring the protocadherin gene clusters has been reported to be hypermethylated in numerous malignancies including pediatric ALL. $5,35,36,37$ This region lost methylation at relapse, thereby reverting to methylation profiles consistent with normal, healthy individuals. Therefore, it may be unlikely that methylation within the protocadherin clusters plays a causal role in the malignant phenotype. Conversely, the $40 \mathrm{~kb}$ region spanned a large $\mathrm{CpG}$ island that is comprised of 17 $5 S$ ribosomal RNA gene copies. 5S ribosomal RNA has been shown to function by negatively regulating the $\mathrm{p} 53$ tumor suppressor signaling pathway. ${ }^{38}$ Therefore, the loss of methylation in this region may have oncogenic potential in patients with ALL at relapse.

In this study, the identification of DMRs present in regulatory elements at diagnosis and at relapse unveiled promising candidate epidriver loci that are potentially emblematic of ALL. For the purposes of this discussion, an epidriver locus can be defined as a DMR that was present in individuals at both diagnosis 
and relapse and that was also associated with the aberrant expression of a gene with a potential role in the pathogenesis of ALL identified in our previous work. ${ }^{5}$ Specifically, potential epidrivers of ALL that were identified are involved in tumor suppression, B-cell development, and hematopoiesis. The most promising candidates include hypermethylated DMR that were associated with the down regulation of tumor suppressor genes (FRMD5, MLF1, PRUNE2, PTPRO) $)^{19,20,21,22}$ and B-cell development genes (IL7 and MCOLN2) $)^{17,18}$, and hypomethylated DMR that were associated with the upregulation of genes associated with aberrant hematopoiesis (SOCS2, BID). ${ }^{28,29}$ It is easy to envision that the aberrant epigenetic modifications identified in this study may be responsible for abnormal gene expression, thereby resulting in impaired B-cell development, a hallmark of ALL.

Methylation-mediated misregulation of these genes is hypothesized to play a role in the pathogenesis of pediatric ALL. Connections linking several of the potential driver genes to cancer and faulty hematopoiesis have previously been established. For example, PTPRO, a well-established tumor suppressor gene in the Wnt/ß-catenin pathway, has been shown to be hypermethylated and silenced in multiple cancers, including ALL. ${ }^{5,39,40,41}$ Further, IL7 has been shown to be a vital cytokine for normal B-cell differentiation and it has been shown that the expression of MCOLN2 is regulated by the B-cell related transcription factor, PAX5 $5^{17,18}$ Finally, the upregulation of SOCS2 has been shown to be linked to ineffective hematopoiesis resulting in increased expansion of immature precursor 
populations in ALL. ${ }^{28}$ Taken together, functional studies related to these genes in ALL is warranted.

Reliable relapse associated biomarkers are currently lacking in pediatric ALL. In this study, potential biomarkers were identified that were present in individuals that relapse and were absent in individuals that did not relapse. The 130hypermethylated regions exclusive to patients that relapsed may be helpful in appropriately stratifying patients with favorable karyotypes at diagnosis into their correct risk group. The potential biomarkers were not associated with alterations in gene expression; therefore, the utility lies solely in appropriately stratifying patient risk of relapse. Interestingly, only 21 of the regions are located within CpG islands, whereas the majority $(n=94)$ lay within intergenic sequences and outside of $\mathrm{CpG}$ islands. Milani and colleagues found that methylation levels outside of CpG islands had the highest variance among ALL patients and therefore served as the best classification markers in identifying recurrent subtypes of ALL. ${ }^{42}$ Hence, it is feasible that the CpGs identified outside of CpG islands have the potential to serve as predictive classifiers in the future for patients who relapse.

In conclusion, this study is the first to observe predominate hypomethylation in relapsed ALL. Genes involved in DNA replication and repair correlated with regulatory hypomethylation in this study at relapse and gene upregulation at relapse found in previous diagnosis and relapse paired studies. In addition, the 
identification of potential epidriver genes in ALL may provide insight into the mechanism(s) of how leukemic blasts in ALL resist chemotherapy and proliferate uncontrollably. Therefore, functional studies for those genes are an essential step in understanding their role in the tumorigenesis of ALL. Lastly, quantitating percent methylation differences of individual $\mathrm{CpGs}$ between the relapse and nonrelapse cohorts of loci exhibiting the highest odds ratio would be a good starting point in the process of identifying bonafide relapse associated biomarkers at diagnosis. 


\begin{tabular}{|c|c|c|c|c|c|c|}
\hline $\begin{array}{c}\text { Patient } \\
\text { ID }\end{array}$ & $\begin{array}{c}\text { Age } \\
\text { (months) }\end{array}$ & $\begin{array}{l}\text { WBC, } \\
10^{3} / \mu l\end{array}$ & Sex & Cytogenetics & $\begin{array}{l}\text { Relapse } \\
\text { Status }\end{array}$ & $\begin{array}{c}\text { Months to } \\
\text { Relapse }\end{array}$ \\
\hline A4 & 4 & 7.8 & M & hyperdiploidy & Yes & 86 \\
\hline A15 & 36 & 7.8 & $M$ & hyperdiploidy & Yes & 2 \\
\hline A18 & 17 & 4.3 & $\mathrm{~F}$ & $\begin{array}{c}46, \mathrm{XX}-15 \mathrm{der}(1) \\
\mathrm{t}(1 ; ?), \operatorname{del}(6)(q 21), \mathrm{t} \\
\text { mar }\end{array}$ & Yes & 39 \\
\hline A19 & 36 & 3.7 & $\mathrm{M}$ & hyperdiploidy & Yes & 56 \\
\hline A20 & 120 & 3.6 & $M$ & $46, X Y$ & No & - \\
\hline $\mathrm{A} 21$ & 36 & 6.6 & M & $\begin{array}{c}46, X Y \\
t(3 ; 19)(p 25 ; p 13)\end{array}$ & No & - \\
\hline A22 & 60 & 2.5 & $\mathrm{~F}$ & $47, X X+21 ; 48, X X$ & No & - \\
\hline A23 & 180 & 2.3 & $M$ & $\begin{array}{c}46, X Y \\
\operatorname{del}(6)(q 21 ; q 27)\end{array}$ & No & - \\
\hline A24 & 108 & 3.7 & M & $\begin{array}{l}45,-7-9+\operatorname{der}(9) \\
t(8 ; 9)(q 112 ; p 11)\end{array}$ & No & - \\
\hline A25 & 48 & 13.7 & $M$ & $46, X Y$ & No & - \\
\hline A26 & 48 & 4.3 & $M$ & $47, X Y$ & No & - \\
\hline A27 & 60 & 3.1 & $M$ & $46, X Y$ & Yes & 30 \\
\hline A28 & 36 & 1.5 & $M$ & none available & No & - \\
\hline A29 & 24 & 10.2 & $\mathrm{~F}$ & $46, X X$ & No & - \\
\hline $\mathrm{A} 30$ & 24 & 3.7 & $F$ & $46, X X$ & No & - \\
\hline A31 & 132 & 18.8 & $M$ & $45, X Y-7$ & No & - \\
\hline A33 & 180 & 4.5 & $M$ & $46, X Y$ & Yes & 31 \\
\hline A36 & 72 & 2.7 & $F$ & $46, X X$ & No & - \\
\hline $\mathrm{A} 37$ & 20 & 2.5 & $M$ & hyperdiploidy & No & - \\
\hline A59 & 18 & 6.3 & $M$ & $46, X Y$ & Yes & 8 \\
\hline A70 & 36 & 2.6 & $M$ & hyperdiploidy & Yes & 8 \\
\hline A101 & 113 & 5.8 & $F$ & $46, X X$ & Yes & 7 \\
\hline $\mathrm{A} 121$ & 10 & 1.3 & $M$ & $46, X Y$ & Yes & 28 \\
\hline
\end{tabular}

Table 2.1 Patient characteristics 


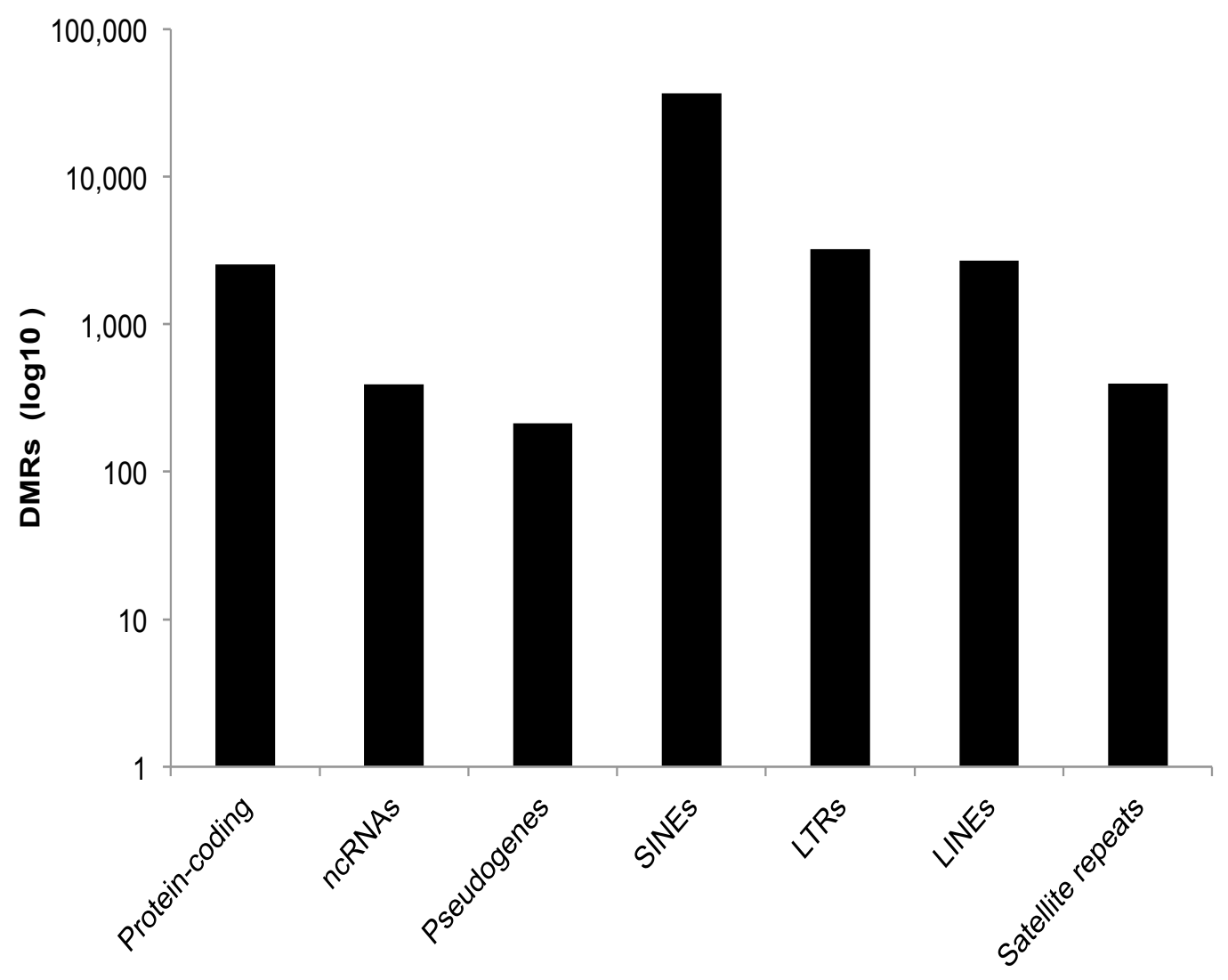

Figure 2.1. Genomic distribution of DMR that were hypomethylated in pediatric ALL patients at relapse. 


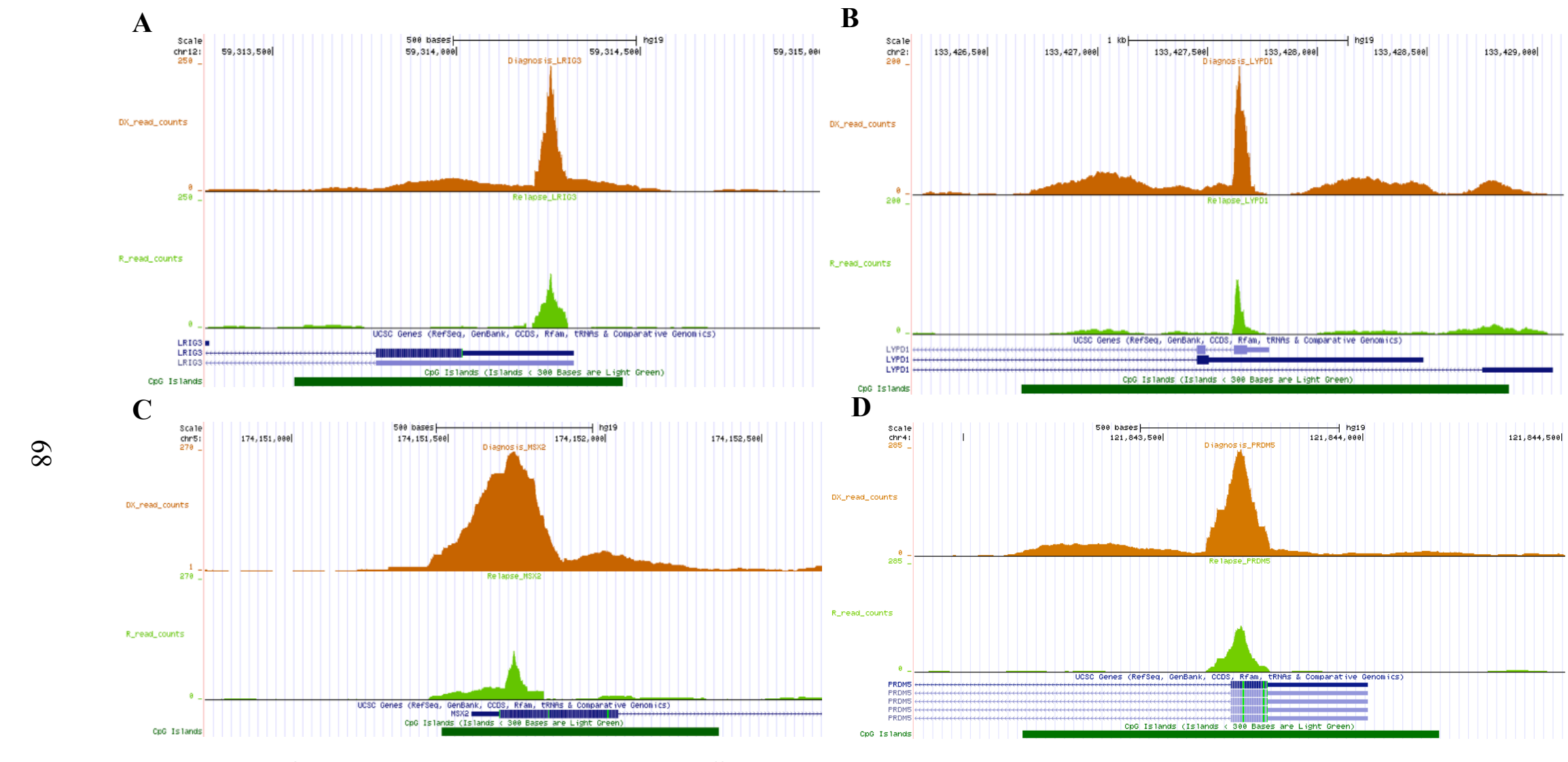

B

Figure 2.2 BedGraphs illustrating average read count differences between diagnosis (orange) and relapse (green) within the 5 'regulatory region of four genes (purple) with the largest $\log _{2}$ fold change: $\left[L R I G 3, \log _{2} f \mathrm{c}=2.64\right]^{\mathrm{A}},\left[L Y P D 1, \log _{2} \mathrm{fc}=2.63\right]^{\mathrm{B}},\left[M S X 2, \log _{2} \mathrm{fc}=2.61\right]^{\mathrm{C}}$, $\left[P R D M 5, \log _{2} f \mathrm{c}=2.58\right]^{\mathrm{D}}$ Note: $\mathrm{CpG}$ islands in dark green 

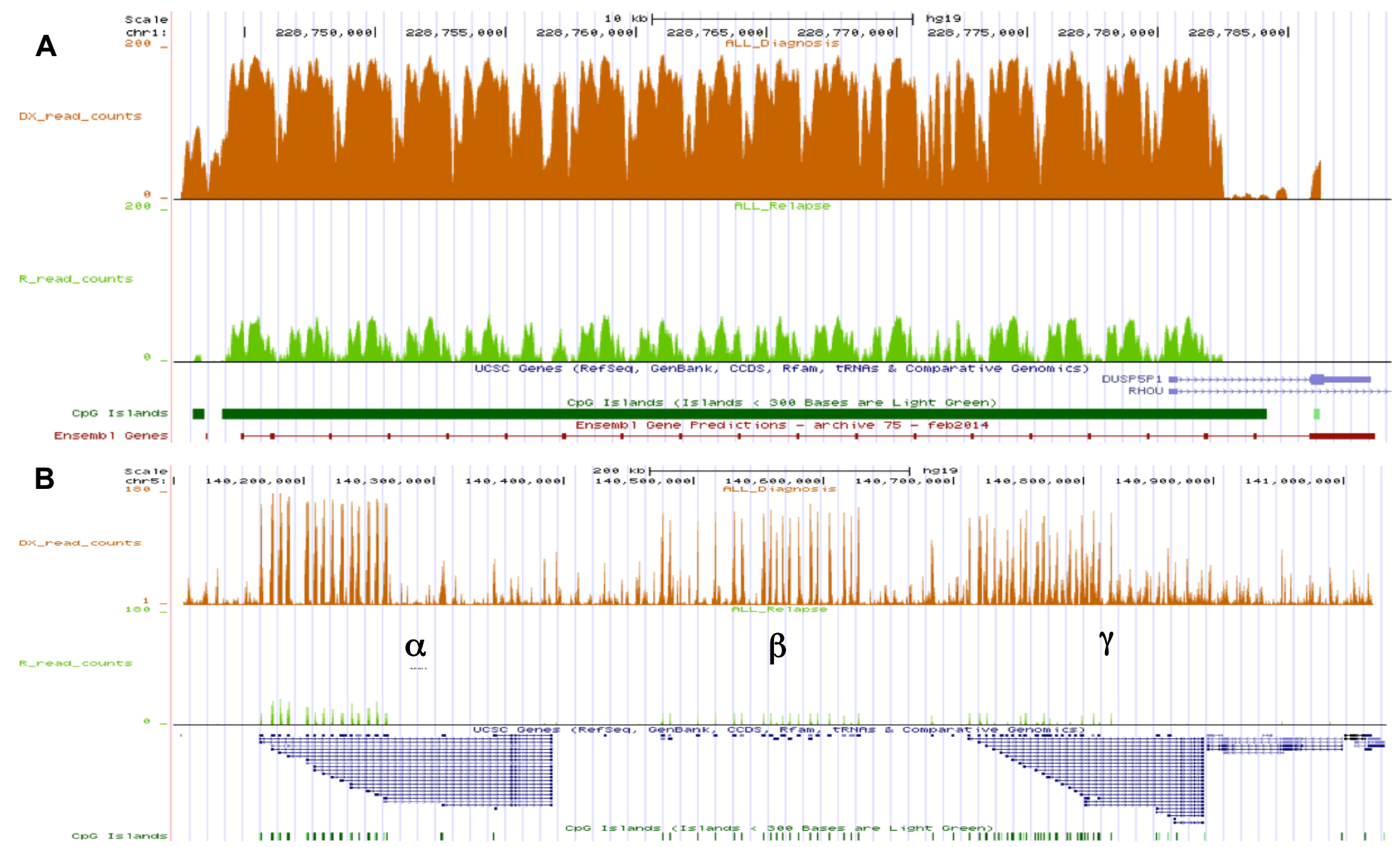

Figure 2.3 BedGraphs illustrating average read count differences between diagnosis (orange) and relapse (green) within a $40 \mathrm{~kb}$ stretch overlapping $5 \mathrm{~S}$ ribosomal RNAs (red), RHOU and DUSP5P1 (purple). B. Average read count differences within a $692 \mathrm{~kb}$ region overlapping the $\alpha \beta \gamma$ protocadherin cluster (purple). Note: $\mathrm{CpG}$ islands in dark green 


\begin{tabular}{|c|c|c|}
\hline \multicolumn{3}{|c|}{ Hypomethylated genes with oncogenic potential at relapse } \\
\hline & Gene name & Biotype \\
\hline \multirow[t]{4}{*}{ Histones } & H3F3C & Protein-coding \\
\hline & HIST3H3 & Protein-coding \\
\hline & HIST1H2AA & Protein-coding \\
\hline & HIST1H2BA & Protein-coding \\
\hline \multirow[t]{3}{*}{ p53-signaling } & MDM4 & Protein-coding \\
\hline & CUL5 & Protein-coding \\
\hline & $5 S$ rRNA & ncRNA \\
\hline \multirow[t]{7}{*}{ DNA replication/Cell-division } & TOP2A & Protein-coding \\
\hline & PCNA & Protein-coding \\
\hline & MCM6 & Protein-coding \\
\hline & PRIM1 & Protein-coding \\
\hline & CDC14C & Pseudogene \\
\hline & LINC00857 & ncRNA \\
\hline & LINC00668 & ncRNA \\
\hline \multirow[t]{5}{*}{ MAP-kinase signaling } & $M A P 2 K 6$ & Protein-coding \\
\hline & MAPK15 & Protein-coding \\
\hline & $p 38$ & Protein-coding \\
\hline & DUSP5P1 & Pseudogene \\
\hline & LOC407835 & Pseudogene \\
\hline Ras-signaling & MRAS & Protein-coding \\
\hline \multirow{2}{*}{$\begin{array}{l}\text { Fibroblast growth factor receptor } \\
\text { signaling }\end{array}$} & FGFR2 & Protein-coding \\
\hline & LOC100335030 & Pseudogene \\
\hline Inhibiting apoptosis & AKT1 & Protein-coding \\
\hline \multirow[t]{7}{*}{\begin{tabular}{|l|} 
Wnt/ $\beta$-catenin signaling \\
\end{tabular}} & FZD2 & Protein-coding \\
\hline & FZD7 & Protein-coding \\
\hline & FZD9 & Protein-coding \\
\hline & FZD10 & Protein-coding \\
\hline & WNT2 & Protein-coding \\
\hline & SOX10 & Protein-coding \\
\hline & SOX14 & Protein-coding \\
\hline \multirow[t]{2}{*}{ B-cell proliferation/differentiation } & CARD14 & Protein-coding \\
\hline & SOX11 & Protein-coding \\
\hline \multirow[t]{3}{*}{ miRNAs } & $m i R-543$ & ncRNA \\
\hline & $m i R-632$ & ncRNA \\
\hline & miR-922 & ncRNA \\
\hline \multirow[t]{2}{*}{ Stem cell proliferation/differentiation } & SOX2 & Protein-coding \\
\hline & SOX9 & Protein-coding \\
\hline
\end{tabular}

Table 2.2 Genes with oncogenic potential that were hypomethylated in pediatric ALL patients at relapse. 


\begin{tabular}{|c|c|c|c|}
\hline Chromosome:Start-End & Regulatory Regions & Genomic Region & Gene Name \\
\hline chr17:76130002-76130400 & $\mathrm{D}, \mathrm{TF}$ & Promoter & TMC8 \\
\hline chr3:194407802-194408200 & $\mathrm{TF}$ & First exon & FAM43A \\
\hline $\operatorname{chr} 21: 46117602-46117800$ & & First exon & KRTAP10-12 \\
\hline chr1:154988802-154989000 & $\mathrm{TF}$ & Exon & $Z B T B 7 B$ \\
\hline chr8:1900802-1901000 & & Exon & ARHGEF10 \\
\hline chr1:5006602-5006800 & & Intergenic & - \\
\hline chr2:239403202-239403400 & $\mathrm{E}, \mathrm{TF}$ & Intergenic & - \\
\hline chr5:133269802-133270000 & E,D & Intergenic & - \\
\hline chr7:403602-403800 & & Intergenic & - \\
\hline chr12:122444402-122444600 & & Intergenic & - \\
\hline chr12:132641402-132641800 & $\mathrm{TF}$ & Intergenic & - \\
\hline 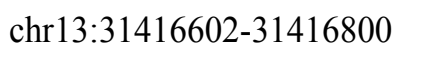 & & Intergenic & - \\
\hline chr13:39899002-39899200 & & Intergenic & - \\
\hline chr14:105122602-105122800 & $\mathrm{E}, \mathrm{D}, \mathrm{TF}$ & Intergenic & - \\
\hline $\operatorname{chr16:3002802-3003000~}$ & & Intergenic & - \\
\hline $\operatorname{chr} 17: 216802-217000$ & & Intergenic & - \\
\hline $\operatorname{chr} 21: 40361002-40361200$ & & Intergenic & - \\
\hline chr2:131734602-131734800 & & Intron & ARHGEF4 \\
\hline chr3:13113802-13114200 & $\mathrm{E}, \mathrm{D}, \mathrm{TF}$ & Intron & IQSEC1 \\
\hline chr3:195534802-195535000 & & Intron & MUC4 \\
\hline chr4:1835802-1836000 & $\mathrm{E}, \mathrm{D}, \mathrm{TF}$ & Intron & LETMI \\
\hline chr6:42007602-42007800 & $\mathrm{E}, \mathrm{TF}$ & Intron & CCND3 \\
\hline chr7:157462802-157463000 & & Intron & PTPRN2 \\
\hline $\operatorname{chr} 7: 2106002-2106200$ & $\mathrm{D}$ & Intron & MADILI \\
\hline chr7:2177802-2178200 & $\mathrm{E}, \mathrm{D}, \mathrm{TF}$ & Intron & MADIL1 \\
\hline chr8:144599002-144599200 & & Intron & $\mathrm{ZC} 3 \mathrm{H} 3$ \\
\hline chr10:126239002-126239200 & $\mathrm{TF}$ & Intron & $L H P P$ \\
\hline $\operatorname{chr} 12: 529202-529400$ & & Intron & CCDC77 \\
\hline chr16:1509202-1509400 & $\mathrm{E}, \mathrm{D}, \mathrm{TF}$ & Intron & CLCN7 \\
\hline $\operatorname{chr} 16: 21552402-21552800$ & $\mathrm{E}, \mathrm{D}, \mathrm{TF}$ & Intron & LOC23117 \\
\hline $\operatorname{chr} 17: 3807802-3808000$ & $\mathrm{TF}, \mathrm{D}$ & Intron & $P 2 R X 1$ \\
\hline chr19:1967002-1967200 & & Intron & CSNK1G2 \\
\hline $\operatorname{chr} 22: 36724802-36725000$ & $\mathrm{E}, \mathrm{D}, \mathrm{TF}$ & Intron & МҮН9 \\
\hline chr1:153744402-153744600 & $\mathrm{TF}$ & Exon-intron junction & INTS3 \\
\hline chr16:1588002-1588200 & & Exon-intron junction & TMEM204 \\
\hline $\operatorname{chr} 16: 87734602-87735000$ & $\mathrm{E}, \mathrm{TF}$ & Exon-Intron junction & FLJ00104 \\
\hline $\operatorname{chr} 17: 80866002-80866200$ & & Exon-intron junction & $T B C D$ \\
\hline $\operatorname{chr} 17: 74674602-74674800$ & & TTS & $M X R A 7$ \\
\hline
\end{tabular}

$\mathrm{E}=$ Enhancer region (H3K4me1 and H3K27ac overlap)

$\mathrm{D}=$ DNase I Hypersensitivity site

$\mathrm{TF}=$ Transcription factor bound site in the GM12878 lymphoblastoid cell line

TTS $=$ Transcription termination site 
A

Hypermethylation

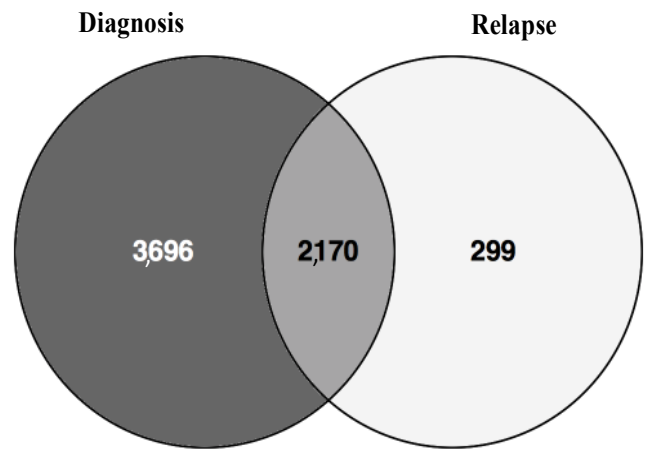

C

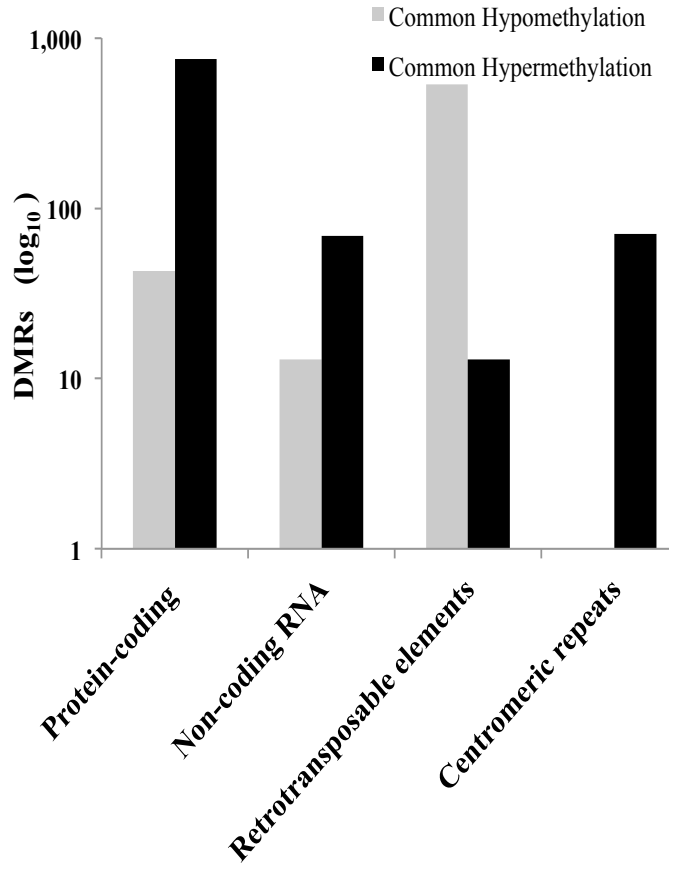

B Hypomethylation

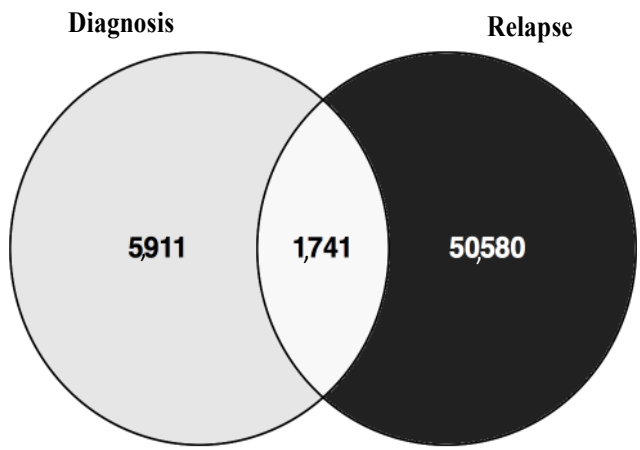

D

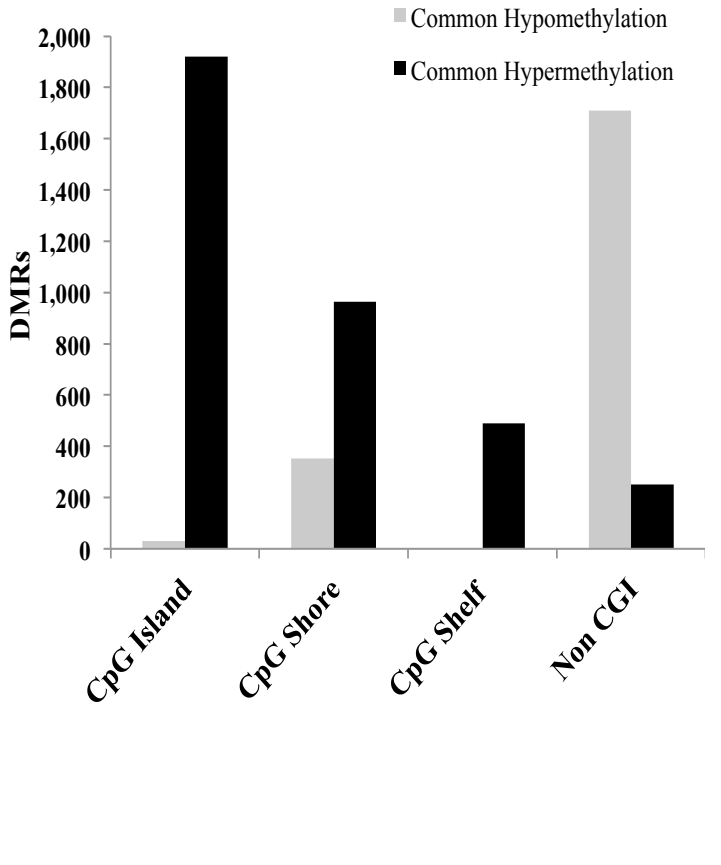

Figure 2.4 Hypermethylated DMRs present in pediatric patients with ALL at diagnosis and at relapse. B. Hypomethylated DMRs present in pediatric patients with ALL at diagnosis and at relapse. C. Genomic distribution of DMRs present in pediatric patients with ALL at diagnosis and at relapse. D. DMRs present in pediatric patients with ALL at diagnosis and at relapse in the context of $\mathrm{CpG}$ islands. 


\begin{tabular}{|c|c|c|c|c|}
\hline & Gene name & Methylation status & Function in cancer & Biotype \\
\hline Inhibition of Src signaling & $\overline{\text { FRMD }^{19}}$ & $\overline{\text { Hypermethylated }}$ & $\overline{\text { Tumor suppressor }}$ & Protein-coding \\
\hline Inhibition of p53 signaling & $M L F 1^{20}$ & Hypermethylated & Tumor suppressor & Protein-coding \\
\hline Inhibition of Ras-signaling & PRUNE2 $2 l$ & Hypermethylated & Tumor suppressor & Protein-coding \\
\hline Inhibition of cell proliferation & $\begin{array}{l}\text { LOC } 389332^{23} \\
\text { LINC01018 }\end{array}$ & $\begin{array}{l}\text { Hypermethylated } \\
\text { Hypermethylated }\end{array}$ & $\begin{array}{l}\text { Tumor suppressor } \\
\text { Tumor suppressor }\end{array}$ & $\begin{array}{c}\text { Protein-coding } \\
\text { ncRNA }\end{array}$ \\
\hline Wnt/B-catenin signaling & $P^{2} P R O^{22}$ & Hypermethylated & Tumor suppressor & Protein-coding \\
\hline \multirow[t]{2}{*}{ B-cell proliferation/differentiation } & $I L 7^{17}$ & Hypermethylated & $\begin{array}{c}\text { Arrested B-cell lineage } \\
\text { development }\end{array}$ & Protein-coding \\
\hline & MCOLN2 $2^{18}$ & Hypermethylated & $\begin{array}{c}\text { Arrested B-cell lineage } \\
\text { development }\end{array}$ & Protein-coding \\
\hline Cell-cycle regulator & SPDYE $8 P$ & Hypomethylated & Unknown & Pseudogene \\
\hline \multirow[t]{3}{*}{$\underline{\text { miRNAs }}$} & $m i R-124-3^{24}$ & Hypermethylated & Tumor suppressor & ncRNA \\
\hline & $m i R-129-2^{25}$ & Hypermethylated & Tumor suppressor & ncRNA \\
\hline & $m i R-375^{26}$ & Hypermethylated & Tumor suppressor & ncRNA \\
\hline Leukemic hematopoiesis & $\operatorname{SOCS} 2^{28}$ & Hypomethylated & Oncogene & Protein-coding \\
\hline Hematopoietic stem cell survival & $B I D^{29}$ & Hypomethylated & Oncogene & Protein-coding \\
\hline
\end{tabular}

Table 2.4 Classification of genes associated with aberrant methylation at diagnosis and at relapse 


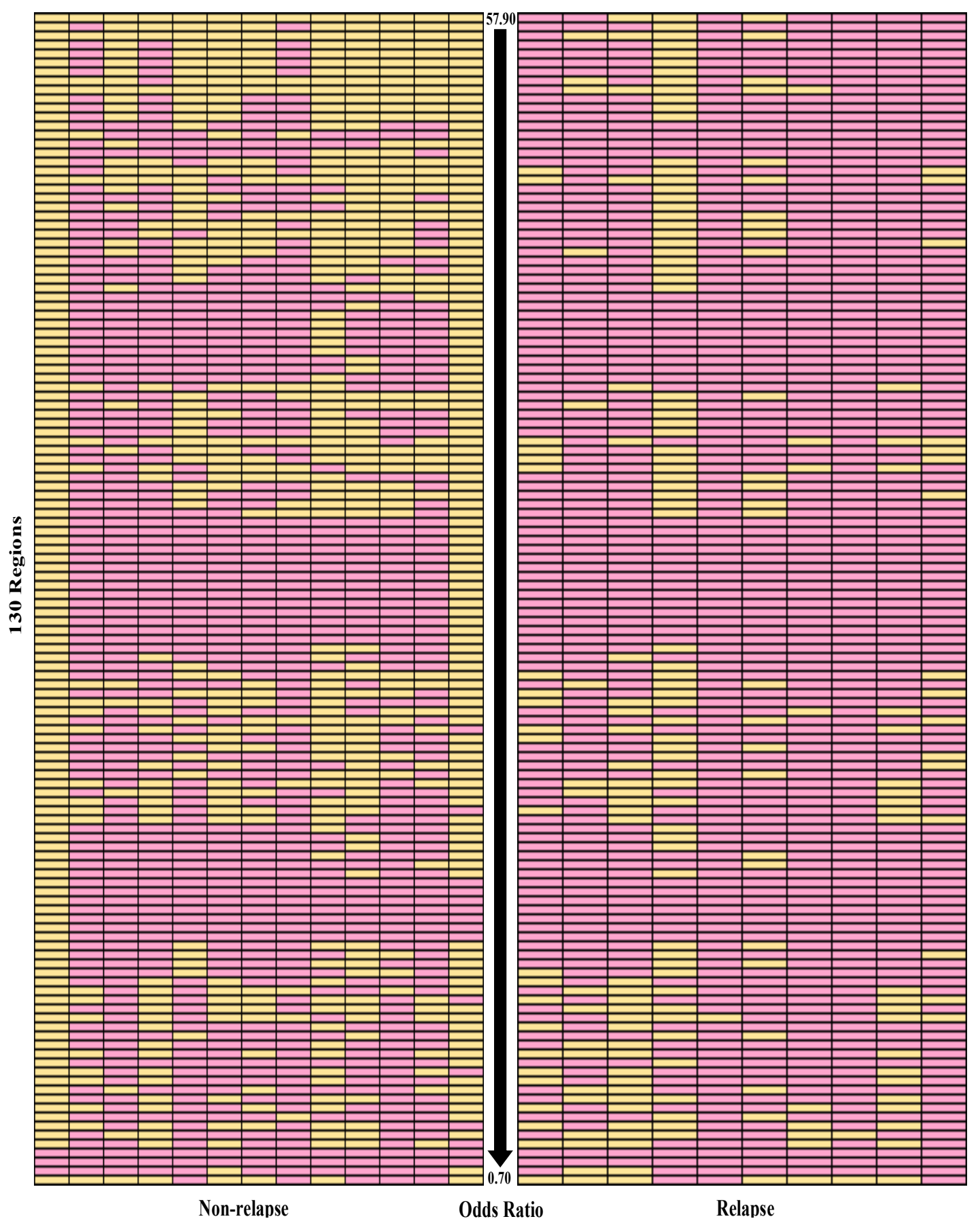

Figure 2.5 Differentially methylated loci between patients at diagnosis that did not relapse (left) and patients at diagnosis that did later relapse (right). Each row represents a DMR and each column represents at patient at original diagnosis. The regions were ranked based on odds ratio scores from largest (top) to smallest (bottom). Red cells represent read counts $>50$ and yellow cells 


\section{REFERENCES}

1. $P D Q \circledast$ Pediatric Treatment Editorial Board. PDQ Childhood Acute Lymphoblastic Leukemia Treatment. Bethesda, MD: National Cancer Institute;2017 Feb 3 [accessed 2017 Dec 15]. http://www.cancer.gov/types/leukemia/patient/child-all-treatment-pdq.

2. Pui $\mathrm{CH}$, Evans WE. Treatment of acute lymphoblastic leukemia. N Engl J Med 2006;354:166-178.

3. Nordlund J, Backlin CL, Wahlberg P, et al. Genome-wide signatures of differential DNA methylation in pediatric acute lymphoblastic leukemia. Genome Biol 2013;14:r105.

4. Hogan LE, Meyer JA, Yang J, et al. Integrated genomic analysis of relapsed childhood acute lymphoblastic leukemia reveals therapeutic strategies. Blood 2011;118:5218-5226.

5. Almamun M, Levinson BT, van Swaay AC, et al. Integrated methylome and transcriptome analysis reveals novel regulatory elements in pediatric acute lymphoblastic leukemia. Epigenetics 2015;10:882-890.

6. Andrew S. FastQC: a quality control tool for high throughput sequence data; 2010 [accessed 2017 Mar 15].

http://www.bioinformatics.babraham.ac.uk/projects/fastqc.

7. Martin M. Cutadapt removes adapter sequences from high-throughput sequencing reads. EMBnet.journal 2011.

8. Langmead B, Salzberg SL. Fast gapped-read alignment with Bowtie 2. Nat Methods 2012;9:357-359. 
9. Li H, Handsaker B, Wysoker A, et al. The Sequence Alignment/Map format and SAMtools. Bioinformatics 2009;25:2078-2079.

10. Heinz S, Benner C, Spann N, et al. Simple combinations of lineagedetermining transcription factors prime cis-regulatory elements required for macrophage and B cell identities. Mol Cell 2010;38:576-589.

11. Chavez L, Jozefczuk J, Grimm C, et al. Computational analysis of genomewide DNA methylation during the differentiation of human embryonic stem cells along the endodermal lineage. Genome Res 2010;20:1441-1450.

12. Bourgon R, Gentleman R, Huber W. Independent filtering increases detection power for high-throughput experiments. Proc Natl Acad Sci U S A 2010;107:9546-9551.

13. Quinlan AR, Hall IM. BEDTools: a flexible suite of utilities for comparing genomic features. Bioinformatics 2010;26:841-842.

14. Vlachos IS, Zagganas K, Paraskevopoulou MD, et al. DIANA-miRPath v3.0: deciphering microRNA function with experimental support. Nucleic Acids Res 2015;43:W460-466.

15. Ashburner M, Ball CA, Blake JA, et al. Gene ontology: tool for the unification of biology. The Gene Ontology Consortium. Nat Genet 2000;25:25-29.

16. Staal FJ, de Ridder D, Szczepanski T, et al. Genome-wide expression analysis of paired diagnosis-relapse samples in ALL indicates involvement of pathways related to DNA replication, cell cycle and DNA repair, independent of immune phenotype. Leukemia 2010;24:491-499. 
17. Dias S, Silva H, Jr., Cumano A, et al. Interleukin-7 is necessary to maintain the B cell potential in common lymphoid progenitors. J Exp Med 2005;201:971-979.

18. Valadez JA, Cuajungco MP. PAX5 is the transcriptional activator of mucolipin-2 (MCOLN2) gene. Gene 2015;555:194-202.

19. Hu J, Niu M, Li X, et al. FERM domain-containing protein FRMD5 regulates cell motility via binding to integrin beta5 subunit and ROCK1. FEBS Lett 2014;588:4348-4356.

20. Yoneda-Kato N, Tomoda K, Umehara M, et al. Myeloid leukemia factor 1 regulates p53 by suppressing COP1 via COP9 signalosome subunit 3. EMBO J 2005;24:17391749.

21. Salameh A, Lee AK, Cardo-Vila M, et al. PRUNE2 is a human prostate cancer suppressor regulated by the intronic long noncoding RNA PCA3. Proc Natl Acad Sci U S A 2015;112:8403-8408.

22. Motiwala T, Kutay H, Ghoshal K, et al. Protein tyrosine phosphatase receptor-type O (PTPRO) exhibits characteristics of a candidate tumor suppressor in human lung cancer. Proc Natl Acad Sci U S A 2004;101:13844-13849.

23. Jin P, Wang J, Liu Y. Downregulation of a novel long non-coding RNA, LOC389332, is associated with poor prognosis and tumor progression in clear cell renal cell carcinoma. Exp Ther Med 2017;13:1137-1142.

24. Shi XB, Xue L, Ma AH, et al. Tumor suppressive miR-124 targets androgen receptor and inhibits proliferation of prostate cancer cells. Oncogene 2013;32:4130-4138. 
25. Li M, Tian L, Wang L, et al. Down-regulation of miR-129-5p inhibits growth and induces apoptosis in laryngeal squamous cell carcinoma by targeting APC. PLoS One 2013;8:e77829.

26. Jung HM, Patel RS, Phillips BL, et al. Tumor suppressor miR-375 regulates MYC expression via repression of CIP2A coding sequence through multiple miRNAmRNA interactions. Mol Biol Cell 2013;24:1638-1648, S1631-1637.

27. Zibo W, Jibin L, Hongyan Z. Expression and significance of long chain non-coding RNA LINC01018 in non-small cell lung cancer. Journal of Modern Oncology 2017;18;2907-2910.

28. Vitali C, Bassani C, Chiodoni C, et al. SOCS2 Controls Proliferation and Stemness of Hematopoietic Cells under Stress Conditions and Its Deregulation Marks Unfavorable Acute Leukemias. Cancer Res 2015;75:2387-2399.

29. Maryanovich M, Oberkovitz G, Niv H, et al. The ATM-BID pathway regulates quiescence and survival of haematopoietic stem cells. Nat Cell Biol 2012;14:535-541.

30. Chow YP, Alias H, Jamal R. Meta-analysis of gene expression in relapsed childhood B-acute lymphoblastic leukemia. BMC Cancer 2017;17:120.

31. Bhojwani D, Kang H, Moskowitz NP, et al. Biologic pathways associated with relapse in childhood acute lymphoblastic leukemia: a Children's Oncology Group study. Blood 2006;108:711-717.

32. Jewell R, Conway C, Mitra A, et al. Patterns of expression of DNA repair genes and relapse from melanoma. Clin Cancer Res 2010;16:5211-5221. 
33. Rauch TA, Zhong X, Wu X, et al. High-resolution mapping of DNA hypermethylation and hypomethylation in lung cancer. Proc Natl Acad Sci U S A 2008;105:252-257.

34. Clark SJ. Action at a distance: epigenetic silencing of large chromosomal regions in carcinogenesis. Hum Mol Genet 2007;16 Spec No 1:R88-95.

35. Wang KH, Lin CJ, Liu CJ, et al. Global methylation silencing of clustered protocadherin genes in cervical cancer: serving as diagnostic markers comparable to HPV. Cancer Med 2015;4:43-55.

36. Dallosso AR, Oster B, Greenhough A, et al. Long-range epigenetic silencing of chromosome $5 \mathrm{q} 31$ protocadherins is involved in early and late stages of colorectal tumorigenesis through modulation of oncogenic pathways. Oncogene 2012;31:44094419.

37. Dallosso AR, Hancock AL, Szemes M, et al. Frequent long-range epigenetic silencing of protocadherin gene clusters on chromosome $5 \mathrm{q} 31$ in Wilms' tumor. PLoS Genet 2009;5:e1000745.

38. Li M, Gu W. A critical role for noncoding 5S rRNA in regulating Mdmx stability. Mol Cell 2011;43:1023-1032.

39. Stevenson WS, Best OG, Przybylla A, et al. DNA methylation of membrane-bound tyrosine phosphatase genes in acute lymphoblastic leukaemia. Leukemia 2014;28:787-793. 
40. Ming F, Sun Q. Epigenetically silenced PTPRO functions as a prognostic marker and tumor suppressor in human lung squamous cell carcinoma. Mol Med Rep 2017;16:746-754.

41. Hsu SH, Motiwala T, Roy S, et al. Methylation of the PTPRO gene in human hepatocellular carcinoma and identification of VCP as its substrate. J Cell Biochem $2013 ; 114: 1810-1818$.

42. Milani L, Lundmark A, Kiialainen A, et al. DNA methylation for subtype classification and prediction of treatment outcome in patients with childhood acute lymphoblastic leukemia. Blood 2010;115:121. 


\section{CHAPTER 3: COMPARATIVE METHYLOME ANALYSIS IN CANINE AND HUMAN ACUTE LEUKEMIA}

\subsection{ABSTRACT}

Background: Aberrant DNA methylation with resulting changes in expression that likely contribute to the pathogenesis of acute lymphoblastic leukemia have been identified in humans. Currently, the contribution of DNA methylation to disease phenotype remains unknown in canine acute leukemia (cAL). Therefore, identifying aberrant DNA methylation within regulatory regions of the same gene or intergenic loci in human ALL and cAL may aid in discovering novel therapeutic targets with the potential of also serving as functional or diagnostic biomarkers in human ALL. In order to identify aberrant DNA methylation, genome-wide methylation profiles were constructed for CAL and healthy dog using the methylated CpG island recovery assay (MIRA), followed by next-generation Illumina sequencing as previously performed in human ALL samples in our laboratory. A comparative methylome analysis between human ALL and canine AL was conducted. Results: First, the DNA methylation landscape in CAL was determined by comparing peaks against normal dog B lymphocytes, where 66,262 more peaks were present in CAL. Next, a differential methylation analysis was conducted between cAL and normal dog B lymphocytes, yielding 15,142 hypermethlated regions and 988 hypomethylated regions in CAL. Comparative analysis classified 409 genes exhibiting 5' regulatory hypermethylation in both human ALL and CAL. To identify potential functional biomarkers, we 
incorporated gene expression data from our previous human ALL analysis, which filtered the gene list down to 10 that were concomitant with lower expression at diagnosis compared to healthy patients, including 3 tumor suppressor genes (PRUNE2, PTPRO, RHOBTB1). Lastly, to identify potential biomarkers outside of genic regions, DMRs within intergenic regions were queried for sequence conservation between human and dog, where one intergenic region was identified. Conclusion: The genes PTPRO, PRUNE2, and RHOBTB1 are epigenetically misregulated in human ALL and CAL and therefore may serve critical biological function in human ALL. In addition, aberrant DNA methylation was identified in one conserved intergenic sequence between human and dog, where the regulatory potential in acute leukemia is unknown. Each of these may be valuable biomarkers.

\subsection{INTRODUCTION}

Canine acute leukemia (cAL) is a bone marrow malignancy of neoplastic hematopoietic cells in the bone marrow associated with poor responsiveness to treatment and is ultimately fatal in dogs. CAL can be of immature lymphoid or myeloid origin with white blood cell counts (WBC) greater than $5 \times 10^{9} / \mathrm{L}$ $(50,000 / \mu \mathrm{L})$, but in some cases a limited number of circulating cells at diagnosis is observed. ${ }^{1}$ Immunophenotyping is also a very important diagnostic tool used to identify lineage specific cell surface markers and is routinely practiced in both

dog and human acute leukemia. ${ }^{2}$ For example, immunophenotyping can help distinguish between chronic and acute canine leukemia by evaluating the 
presence of stem cell marker CD34+ blast populations, which are associated with acute leukemia. In canine acute lymphoblastic leukemia (ALL), B-lymphocytes display CD20, CD21 and/or CD79a, whereas T lymphocyte lineage shows CD3, CD5, and either CD4 or CD8 antigens. ${ }^{1,3}$ In human pre-B cell ALL pertinent surface markers for diagnosis and subclassification are CD19, CD20, CD22, CD24, and CD79a, while T-ALL surface markers present CD1a, CD2, CD3, CD4, CD5, CD7 and CD8 antigens. ${ }^{4}$ AML-M5a (monocytic) is the most common type in dog that lack MHCII- expression but display differential cell surface markers that contain stem cell antigens CD34/CD90 and monocyte antigen CD14. ${ }^{5} \mathrm{AML}$ in human can be defined based on expression of at least two of the following myeloid cell surface markers: CD13, CD15, CD33, CD65, and CD117. ${ }^{6}$

In human ALL, epigenetic alterations, such as DNA methylation have been extensively shown to play an instrumental role in regulating gene expression. This would entail mechanistic promoter specific hypermethylation of tumor suppressor and lineage dependent genes. ${ }^{7}$ Currently, there has been only one genome-wide DNA methylation study in canine AML that observed heterogeneity of either preferential hypomethylation, hypermethylation, or no difference in 5-mC compared to healthy dogs ${ }^{8}$ However, individual genes and functional groups affected by aberrant DNA methylation in CAL have not been investigated. Therefore a more complete DNA methylation analysis is warranted for canine AL. Utilizing the methylated $\mathrm{CpG}$ island recovery assay, followed by next-generation sequencing (MIRA-seq), methylome profiles were constructed for dogs 
diagnosed with $\mathrm{AL}$ and $\mathrm{CD} 21+$ healthy control dogs. Our first aim was to characterize the DNA methylation pattern observed in cAL by comparing the methylation peak signature in both the groups. The second aim of this study was to identify potential tumor suppressors, hematopoietic related genes, and functional groups displaying aberrant 5' regulatory methylation using MEDIPS R package to calculate differentially methylated regions (DMRs) between AL and healthy dog lymphocytes. Lastly, we conducted an epigenetic comparative analysis between human and dog to identify genes that exhibited aberrant regulatory DNA methylation in canine $\mathrm{AL}$ that was also present in our previous DNA methylation analysis in human acute lymphoblastic leukemia. ${ }^{9}$ In addition, aberrant methylation occurring within conserved intergenic sequences between canine $A L$ and human $A L L$ were investigated. This may provide insight into genes that are of functional relevance to acute lymphoblastic leukemia that may also serve as biomarkers in human ALL.

\subsection{MATERIALS AND METHODS}

\subsubsection{Patient samples}

Peripheral blood was extracted from $4 \mathrm{cAL}$ and 6 healthy dogs and was used in this study with Animal Care and Use Committee approval of the University of Missouri. Flow cytometry was conducted on 3 out of the $4 \mathrm{cAL}$ dogs at the University of Missouri Veterinary Health Center, in which all were positive for hematopoietic stem cell marker CD34+ (Table 3.1). Myeloid and leukoid lineages were undetermined from the flow cytometry. However, one dog had a 
subset of $\mathrm{CD} 14+/ \mathrm{MHCll}+$ cells, which may indicate a blast population of AML origin. All 4 dogs were euthanized within a two-week span after their diagnosis. CD21+ cells were isolated by flow cytometry from peripheral blood from 6 healthy dogs and were used as control samples. Previously generated DNA methylation (MIRA-seq) and gene expression (RNA-seq) data derived from 20 bone marrow aspirates from mostly cytogenetically normal and other subtypes of human ALL patients compared against ten healthy human umbilical blood (HCB) donor patients, where pre-BI/pre-BII (CD19+,CD34-,CD45 $\left.{ }^{\text {low/med }}\right)$ cells were used. ${ }^{9}$

\subsubsection{Genomic DNA isolation and MIRA-seq profile construction from patient samples}

Using the QIAamp DNA Micro Kit (Qiagen cat. no. 56304), genomic DNA was extracted from bone marrow aspirates in dog. Approximately $1 \mu \mathrm{g}$ of DNA in was used as the starting concentration in construction of each MIRA-seq library. The DNA was sonicated with the Diagenode Bioruptor (Diagenode; cat. no. B01010002) at $4^{\circ} \mathrm{C}$, creating a range of 200 to $700 \mathrm{bp}$ fragments. Sonicated DNA ( $150 \mathrm{ng}$ ) was run on $1 \%$ agarose gel at $\sim 96 \mathrm{~V}$ for 45 minutes to verify the 200 to $700 \mathrm{bp}$ fragmented range. The sonicated DNA was purified using the MinElute PCR purification kit (Qiagen; cat. no. 28004) and eluted with $12 \mu \mathrm{L}$ nuclease-free water. End repair and $\mathrm{dA}$ tailing of the fragments was performed using the NEBNext DNA Library Prep Master Mix Set for Illumina kit (New England BioLabs; cat. no. E6040S) with a DNA purification step using Agencourt AMPure XP Beads (Beckman Coulter; cat. no. A63881). After End repair and dA tailing, 
NEB-Next Adaptors were added following another DNA purification step with 1x the concentration AMPure XP Beads and 10 $\mathrm{LL}$ nuclease-free water elution. For methylated DNA fragment enrichment, methylated $\mathrm{CpG}$ island recovery assay MIRA was performed with the Methyl Collector UltraTM kit (Active Motif; cat. no. 55005). This pull-down method involves a methyl binding protein complex (MBD2b/MBD3L1) conjugated with nickel beads that compartmentalize the methylated fragments towards the magnetic stand, where the supernatant is exposed and removed with subsequent wash steps in between using AMPure XP Beads. The MIRA product was run on $1 \%$ agarose gel for 45 minutes at $\sim 96 \mathrm{~V}$ and bands between 200 to $700 \mathrm{bps}$ were excised and purified using the MinElute Gel Extraction kit (Qiagen; cat no. 28604). These methylated fragments were PCR enriched with the NEBNext DNA Library Prep Master Mix Set for Illumina kit with multiplex oligos for 12 cycles. The DNA product was purified again with AMPure XP Beads and eluted with $15 \mu \mathrm{L}$ nuclease-free water. Fragment analysis and Qubit quantitation was performed for each library prior to sequencing. MIRA-seq libraries were multiplexed in $10 \mathrm{nM}$ concentrations with $100 \mathrm{bp}$ singleend sequencing by the DNA Core facility at the University of Missouri on the HiSeq 2000. 


\subsubsection{Sequence processing and peak identification of dog MIRA-seq libraries}

Quality control check of FASTQ file reads were done using FastQC v0.11.4 ${ }^{10}$, then adaptor sequences were removed, including reads $<50 \mathrm{bps}$, using cutadapt v1.7.1. ${ }^{11}$ Read alignment was performed using Bowtie $2 \mathrm{v} 2.2^{12}$, mapping to the canine reference genome (canFam3) with default settings and allowing no more than two mismatches. The output SAM files were then converted to BAM files and sorted accordingly using "view" and "sort" options with samtools version 1.2.1. ${ }^{13}$ Picard-tools version 1.92 under "MarkDuplicates" option, removed duplicate reads. The final BAM output files were then indexed with samtools "index" option. Methylation peaks for each sample were created using MACS2 v2.0 $0^{14}$ "callpeak" function. A common methylation peak signature was identified in both the CAL and healthy dog cohorts using bedtools (version 2.17.0) ${ }^{15}$ "intersectBed" to find overlapping coordinates that were merged as one unified peak using "mergeBed." The peaks from the two cohorts were then compared against each other.

\subsubsection{Identifying DMRs between cAL and healthy dog}

Differentially methylated regions between CAL and healthy dogs were identified in the same manner as our previous human ALL study and are based off Chavez and colleagues' computational method. ${ }^{9,16}$ Sufficient coverage depth was observed in each sample file (BAM file) using a saturation analysis (saturation correlation $>0.90$ ). When performing differential coverage between the different 
dog cohorts, local CpG density biases would affect read coverage in the same way. We acknowledge that there may be impacts due to certain genetic components like copy number alterations. However, we reason that these genetic alterations would need to occur within the same locus among many dogs to have sizable impact. Therefore, input control samples were not needed when identifying DMRs. The reads were accumulated in $200 \mathrm{bp}$ windows along with a $200 \mathrm{bp}$ extension (average fragment size of $\sim 400 \mathrm{bp}$ ). These windows are termed regions of interest (ROIs). ROls with a mean read count across all samples $<20$ counts were excluded to avoid bias and enhancing power, while reducing false discoveries. ${ }^{17}$ In determining if a ROI is a DMR, the statistical parameters of a false discovery rate (Benjamini-Hochberg) $<5 \%$ and a $\log _{2}$ fold change $\geq 1$ had to be met. Normalized RPKM values (Reads Per Kilobase Per Million) were computed for each 200bp window and used to identify DMRs. DMRs were merged as separate entities in respect to hypomethylation and hypermethylation, if the adjacent $200 \mathrm{bp}$ window met the previously described criteria.

\subsubsection{Custom annotation of genomic coordinates in canine (canFam3)}

Annotating genomic coordinates in dog is partially challenging because many genes in the dog genome remain unclassified in sequence databases like RefSeq and Ensembl. In order to annotate genomic coordinate BED files containing either methylation peaks or DMRs in dog patients, HOMERv4. $3^{18}$ (Hypergeometric Optimization of Motif EnRichment) custom annotation option was implemented. To create a custom annotation for dog, a gene transfer format 
(GTF) file containing the Ensembl Genes track was created using the canFam3 assembly from the Table Browser tool in the UCSC Genome Browser platform. ${ }^{19}$ Ensembl ID's for each coordinate were then converted into gene names utilizing the database-to-database conversion tool from the biological DataBase network $^{20}$, in which many ensembl IDs lack a gene prediction in dog. The $X$ and Y-chromosomes were excluded from this analysis.

\subsubsection{Comparative DNA methylation analysis in human and dog and bedGraph illustration}

First, genes were filtered based on possession of DMR(s) within the 5' regulatory region (promoter/5'UTR/first exon) in canine AL and human ALL data. Next, in order to find a common gene signature with aberrant DNA methylation in canine $\mathrm{AL}$ and human $\mathrm{ALL}$, the compiled list of genes that contained hypermethylated or hypomethylated DMR(s) in each species was compared against each other, respectively. Lastly, the resulted list of shared genes between human and dog were filtered based on their expression in human ALL. Because shared hypomethylation was not observed, only hypermethylated genes were investigated for downregulated expression in human ALL. Using the "genomeCoverageBed" function from bedtools ${ }^{15}$, bedGraph illustrations were created for each candidate gene in the context of human ALL vs. HCB (control) and canine AL vs. healthy dog. Each bedGraph contains peaks representing average read counts per base coordinate across all patient samples in a given cohort within the 5' regulatory region of a gene. 


\subsubsection{Identifying conserved intergenic sequences with aberrant methylation}

between human $A L L$ and canine $A L$

The entire list of DMR coordinates in canine AL was uploaded to UCSC genome browser's LiftOver tool interface. ${ }^{21}$ Next, dog coordinates from the canFam3 assembly were converted to the human hg19 assembly under the strict parameter, where 0.95 minimum ratio of bases from the dog sequence must remap to the human sequence. A total of 421 regions were successfully converted into hg19 coordinates and then filtered upon their overlap of hyper or hypomethlyated regions found in our human ALL study. One hypermethylated intergenic region was identified in both canine AL and human ALL. Using CLC Sequence Viewer $8^{22}$ software, the respective dog and human sequence was aligned against each other to examine the degree of conservation. Transcription factor binding motif analysis was done using Tomtom Motif Comparison Tool under The MEME Suite v5.0.2 ${ }^{23}$ with default parameters.

\subsection{RESULTS}

\subsubsection{DNA methylation peak analysis in canine AL}

Methylome profiles were created for 10 dog samples, resulting in a total of 250 million reads for CAL samples and 272 million reads for healthy dog with an average alignment rate of $93 \%$. In order to characterize the methylation landscape of CAL and healthy canine, methylation peaks were identified in each sample derived from high quality reads. An overall genome-wide increase of 
DNA methylation was observed in AL with 136,758 methylation peaks present in cAL and 70,496 methylation peaks among healthy dog patients. The genomic distribution of peaks revealed methylation within intergenic and intronic loci for both cohorts (Figure 3.1). Further, 2,221 more peaks were identified within the 5 ' regulatory regions (promoter and first exon) in cAL compared to healthy dog. In the context of $\mathrm{CpG}$ islands (CGI), the majority of peaks were distributed outside CGI sequences (Figure 3.1). The distribution of peaks within CGls displayed 8,988 more peaks in cAL than healthy dog.

\subsubsection{Predominant hypermethylation in canine $A L$}

The methylation pattern specific to CAL was explored by identifying DMRs between CAL and healthy dog. Predominant hypermethylation was observed in CAL with 15,142 regions gaining methylation and only 988 regions losing methylation at diagnosis. While the majority of hypermethylated DMRs overlapped intergenic and intronic sequences, many DMRs coincided with 5' regulatory regions (promoter $n=1247$, first exon $n=655$ ) (Figure 3.2). Due to the significant role DNA methylation plays in the 5' regulatory region, we analyzed functional groups likely affected by aberrant methylation. Using DAVID's functional annotation clustering tool with a benjamini cutoff value $<0.05,1,106$ genes with 5' hypermethylation were analyzed. Among the functional groups identified, included genes with Homeodomains (Enrichment Score: 18.00, Gene count: 56), genes involved in the WNT pathway (Enrichment Score: 4.76, Gene count: 9), and histones (Enrichment Score: 2.70, Gene count: 8). Functional 
annotation clustering of the 20 genes in CAL coinciding with hypomethylated DMR within the 5' regulatory region did not reach statistical significance.

Next, individual genes were sought that exhibited regulatory hypermethylation in conjunction with functional involvement in hematopoiesis, epigenetics, apoptosis, acute leukemia or inhibition of pathway signaling. A total of 52 genes were identified, in which genes involved in hematopoiesis were the most represented $(n=14)$ (Table 3.2). Hematopoietic related genes include essential transcription factors such as IKZF1, PAX5, SOX2, ETV2 and cell surface markers CD19, $C D 40$, and $C D 79 B$. Genetic and epigenetic lesions within these genes are frequently observed in human acute leukemia. Among epigenetic associated genes were histones, where the majority of the variants belonged to the $\mathrm{H} 2 \mathrm{~A}$ and H2B family. Lastly, the Wnt/ $\beta$-Catenin pathway contributed to $\sim 44 \%$ of overall identified negative regulators of pathway signaling, which included genes SOX9, $P T P R O$, and DKK2. The remaining negative regulators included genes such as CDKN2B of cell cycle signaling and tumor suppressors PRUNE2 and RHOBTB1.

\subsubsection{Comparative DNA methylation analysis in canine AL and human ALL}

Comparative epigenetic analyses across species can aid in identify genes of pathological relevance to cancer and have the potential to serve as biomarkers. Therefore, we incorporated DNA methylation and gene expression data from our previous study in human acute lymphoblastic leukemia (ALL) patients and examined genes with aberrant methylation in the 5' regulatory that existed in both 
human ALL and canine AL. A total of 409 genes were hypermethylated in both human ALL and canine AL. Shared regulatory hypomethylation was not found between human and dog leukemia. The list of 409 hypermethylated genes was then filtered based on inverse correlation with gene expression found in human ALL, resulting in 10 genes concomitant with downregulation at diagnosis (Table 3.3). Among the 10 genes listed included 3 reported tumor suppressors: PTPRO, PRUNE2, and RHOBTB1. BedGraph illustrations highlight the distinct read count differences observed in the 5' regulatory region for each of the 3 candidate biomarker genes in both human ALL and canine AL (Figure 3.3). The read count peaks are much higher and are distributed across the 5' regulatory region in the leukemia groups for both species compared to their healthy counterparts, who exhibit very low read count peaks in all 3 genes.

In order to identify potential biomarkers outside of intragenic regions, DMR coordinates belonging to dog were converted into human coordinates with the objective of identifying conserved intergenic sequences that displayed aberrant DNA methylation in both species. Utilizing the LiftOver tool from the UCSC genome browser, 421 hypermethylated and 39 hypomethylated coordinates in canine (canFam3) were successfully converted to the human (hg19) assembly. These coordinates were intersected with hyper- and hypomethlyated DMR found in human ALL, where 77 hypermethylated loci were shared and no overlapping regions of hypomethylation were found. The 5 ' regulatory region $(n=47)$ made up most of the 77 hypermethylated DMR and only 1 intergenic region on 
chromosome 12 in human and chromosome 26 in dog was identified. The conservation of the intergenic region was investigated in human and dog by aligning the sequence from both assemblies against one another. Approximately $72 \%$ of the bases aligned between human and dog and 8 base pair gaps in intervals of no more than 3 were observed in the dog sequence (Figure 3.4). The intergenic sequences in both species lay in between transmembrane gene TMEM132B and a long intergenic noncoding RNA. Interestingly, the human intergenic sequence lies within a $\mathrm{CpG}$ shore, whereas the dog sequence is greater than $4 \mathrm{~kb}$ from the nearest $\mathrm{CpG}$ island.

Finally, the human DNA sequence was explored for any known transcription factor (TF) binding motifs using The MEME Suite. DNA motif analysis identified 4 transcription factors belonging to the ETS family (ETV2, ETV4, ETS1, ERG) and two within with zinc-finger family (GATA2, ERG) that were statistically significant ( $p$-value $<0.05)$. Hematopoietic transcription factor ETV2 was the most statistically significant motif finding $(p-v a l u e=5.31 e-04)$ with an optimal alignment sequence of 5'-TTCCTG-3'.

\subsection{DISCUSSION}

Methylation peak and DMR analysis from our previous human ALL study revealed global losses in DNA methylation in conjunction with regulatory hypermethylation. Using the same methodical approach (MIRA-seq) in human $A L L$, our canine $A L$ samples displayed gains of global DNA methylation with 
limited losses of methylation ${ }^{9}$. However, this observation is not representative of all dogs with acute leukemia as global hypomethylation has also been documented in AML. ${ }^{8}$ In most human ALL cases, the global methylation pattern can be attributed to specific cytogenetic aberrations. ${ }^{24,25}$ As for canine AL, cytogenetic analysis is not readily available for clinical application due to the difficulty of karyotyping 76 acrocentric autosomes of similar shape and size. Yet, cytogenetic alterations observed in human leukemia, such as BCR-ABL translocation, has been reported in individual AML cases. ${ }^{26}$ Thus, cytogenetic lesions may have an impact on the observed gains of DNA methylation in our canine AL samples, but are currently unknown.

The genomic distribution of $\mathrm{CpG}$ islands between dog and human differ considerably and may influence the number of genes affected by regulatory methylation. The DMR analysis in canine AL resulted in identifying 1,798 genes exhibiting 5' regulatory hypermethylation with 692 of the genes currently not annotated in the canFam3 assembly. In human ALL, hypermethylation was observed in 2,063 genes. Intriguingly, the dog genome has over 20,000 more $\mathrm{CpG}$ islands in their genome than the human genome. However, there are approximately 3,000 more promoter-associated $\mathrm{CpG}$ islands in human, which may contribute to the higher number of genes with $5^{\prime}$ regulatory hypermethylation detected in human ALL. ${ }^{27}$ 
We hypothesized that many genes involved in hematopoiesis and tumor suppression would possess regulatory hypermethylation in both canine $A L$ and human ALL. Moreover, a comparative analysis of the identified genes in dog and their functional groups may also be affected by aberrant methylation in human ALL. Functional annotation clustering of genes with regulatory hypermethylation in canine $A L$ and human ALL show similar affected groups and individual genes. Both species have enrichment in homeodomain (gene count: 82 human, 56 dog) and Wnt-signaling (gene count: 9 in human and dog) related genes. Aberrant hypermethylation of homeodomain genes is a well-known phenomenon in many cancers and has been linked to poorer outcomes in human ALL and breast cancer patients. ${ }^{28,29}$ In addition, methylation induced silencing of Wnt-signaling antagonist is a hallmark of human leukemia and has also been implicated in both relapsed ALL and AML. ${ }^{30,31,32}$

Further, the comparative analysis identified 3 candidate biomarker genes: PTPRO, PRUNE2, RHOBTB1, which may play a distinct functional role in human ALL pathogenesis that may be regulated by DNA methylation. Each gene has been reported as a functional tumor suppressor in cancer. For example, PTPRO has been identified as a novel receptor in the $\mathrm{Wnt} / \beta$-catenin signaling pathway and is epigenetically silenced by DNA methylation in esophageal, lung, and ALL cancers. ${ }^{9,33,34,35}$ Tumor suppressor activity of RHOBTB1 has also been described in breast and colon cancer, where a loss of function mutation leads to Golgi fragmentation. ${ }^{36,37}$ Although the function of PRUNE2 is unknown, induced 
expression resulted in decreased proliferation of prostate cancer cells. ${ }^{38}$ Therefore, the candidate genes represent potential biomarkers in terms of diagnostic and therapeutic intervention in human ALL.

Conserved intergenic sequences have previously been observed in mammals, specifically between human and murine. ${ }^{39}$ In the context of other potential biomarkers, the UCSC genome browser's LiftOver tool allowed for exploration of aberrant methylation occurring within conserved intergenic DNA sequences between human and dog. As one might expect, all but one of the dog to human converted genomic coordinates lay within a conserved genic loci, primarily the 5' regulatory region. Since genic regions had been investigated in terms of aberrant DNA methylation and gene expression between human and dog, intergenic regions were queried for sequence conservation. We found aberrant methylation within a homologous intergenic sequence between human and dog containing predominately ETS binding motifs in the human DNA sequence. In relation to hematopoiesis, ETV2 has been reported as a key player in hematopoietic progenitor development in murine through enhancer binding and subsequent activation of downstream target $L M O 2 .^{40,41}$ Therefore, further methylation in conjunction with TF binding studies may be warranted within this intergenic region. 
In conclusion, comparative methylome analysis between dog and human is a powerful tool in finding common functional groups and individual genes that likely contribute to acute leukemia. This is especially important in unraveling epigenetic lesions that are currently unknown and may lead to therapeutic targets, which are desperately needed in canine AL. In addition, conserved intergenic sequences in human and dog with aberrant methylation could unveil novel enhancer or repressor like regulatory regions. Moreover, this study has narrowed down potential epidrivers of human ALL in PTPRO, PRUNE2, and RHOBTB1 genes with tumor suppressing activity. Thus, validating the need for additional studies on their role in human ALL.

\begin{tabular}{|c|c|c|c|l|l|l|}
\hline ID & Breed & Age & Sex & \multicolumn{1}{c|}{ Diagnosis } & \multicolumn{1}{c|}{ Treatment } & \multicolumn{1}{c|}{ Outcome } \\
\hline 8151731 & $\begin{array}{l}\text { Labrador } \\
\text { Retriever }\end{array}$ & 9 yrs & Female & $\begin{array}{l}\text { Acute leukemia: } \\
\text { CD34+MHCll- } \\
\text { Flow cytometry did not } \\
\text { reveal markers for myeloid } \\
\text { or leukoid lineage. }\end{array}$ & $\begin{array}{l}\text { L-asparaginase, } \\
\text { steroids, } \\
\text { vincristine, } \\
\text { cytosine } \\
\text { arabinoside }\end{array}$ & $\begin{array}{l}\text { Euthanized 1 } \\
\text { week later due } \\
\text { to disease }\end{array}$ \\
\hline 7164929 & $\begin{array}{c}\text { Golden } \\
\text { Retriever }\end{array}$ & $\begin{array}{c}9 \\
\text { mths }\end{array}$ & Male & $\begin{array}{l}\text { Acute leukemia: } \\
\text { Flow cytometry not done. }\end{array}$ & None & $\begin{array}{l}\text { Euthanized at } \\
\text { diagnosis }\end{array}$ \\
\hline 7136328 & $\begin{array}{c}\text { Mixed } \\
\text { breed dog }\end{array}$ & $\begin{array}{c}8 \text { yrs } \\
7 \\
\text { mths }\end{array}$ & Female & $\begin{array}{l}\text { Acute leukemia: } \\
\text { CD34+ with population of } \\
\text { CD14+MHCll }\end{array}$ & Prednisone & $\begin{array}{l}\text { Euthanized 2 } \\
\text { weeks later } \\
\text { due to disease }\end{array}$ \\
\hline 7147625 & $\begin{array}{c}\text { German } \\
\text { Shepherd }\end{array}$ & 7 yrs & Female & $\begin{array}{l}\text { Acute leukemia } \\
\text { Poorly differentiated }\end{array}$ & None & $\begin{array}{l}\text { Euthanized at } \\
\text { diagnosis }\end{array}$ \\
\hline
\end{tabular}

Table 3.1 Clinical characteristics of 4 dogs diagnosed with acute leukemia. 


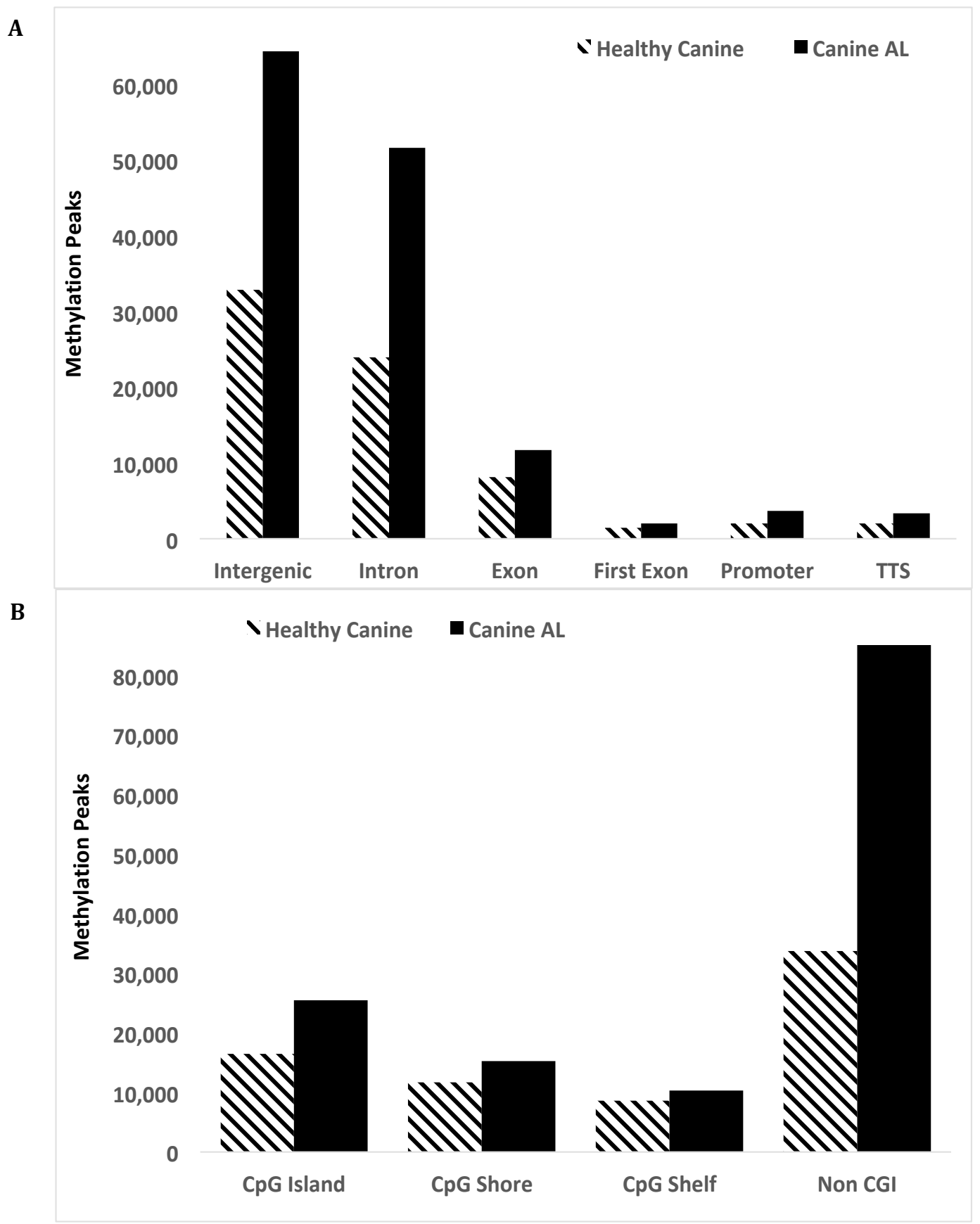

Figure 3.1 Genomic distribution of methylation peaks in canine that are healthy and diagnosed with acute leukemia. B. Peak distribution in the context of CpG islands, shores, and shelves of healthy and acute leukemic canine. 


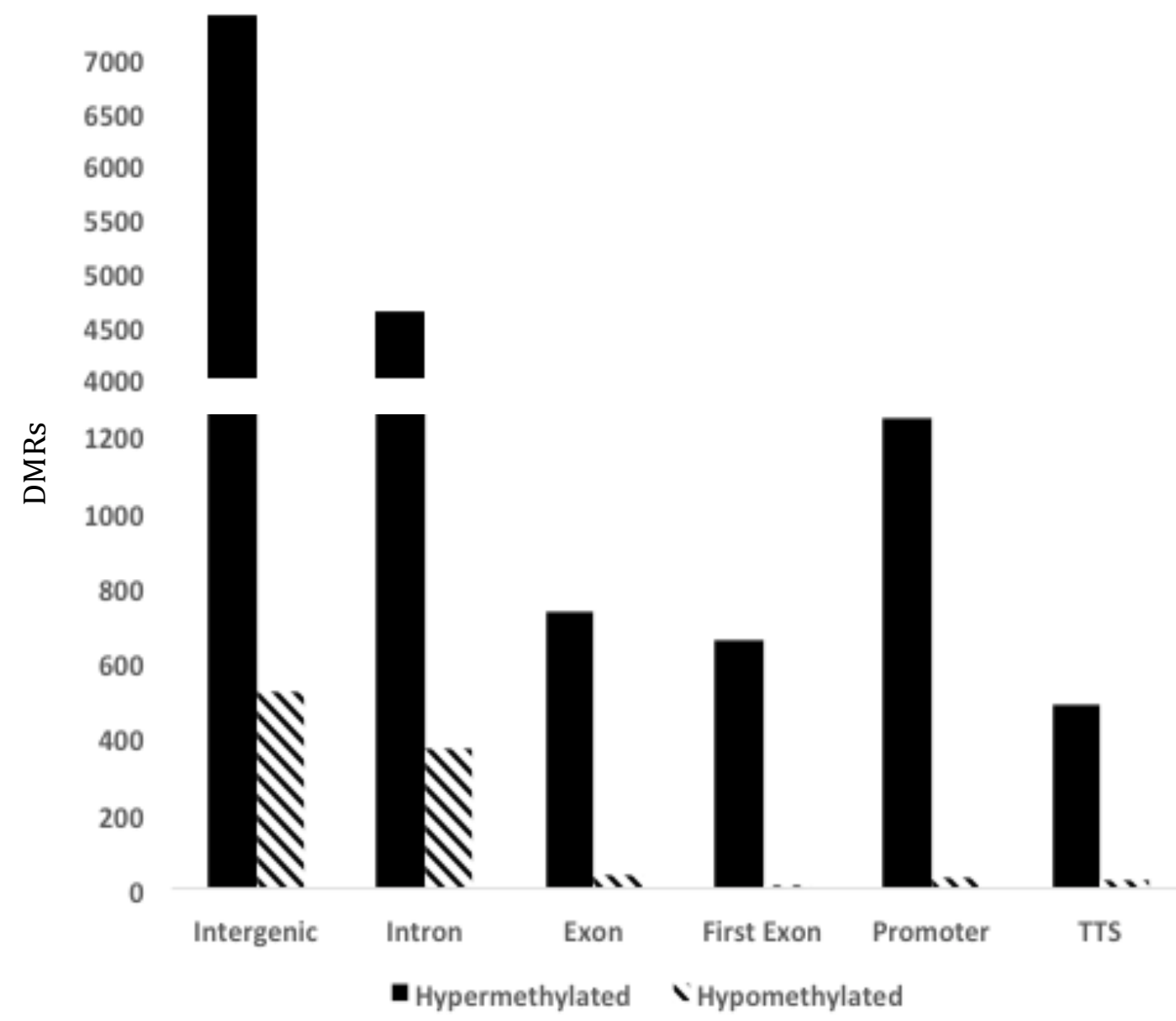

Figure 3.2 Genomic distribution of differentially methylated regions in canine acute leukemia patients. 


\begin{tabular}{|c|c|c|c|}
\hline Gene & Log2 fold change & Gene & Log2 fold change \\
\hline Hematopoiesis & & Pro-apoptotic & \\
\hline SOX2 & 4.53 & PERP & 5.58 \\
\hline PAX5 & 4.06 & NTN1 & 2.55 \\
\hline TNFRSF13B & 3.11 & Negative regulators & \\
\hline$C D 40$ & 2.83 & Wnt/ $\beta$-Catenin & \\
\hline$C D 79 B$ & 2.50 & soxg & 3.41 \\
\hline FCMR & 2.40 & WNT5A & 3.33 \\
\hline NODAL & 2.34 & SFRP4 & 3.03 \\
\hline SYK & 1.93 & PTPRO & 2.84 \\
\hline IKZF1 & 1.83 & $A P C D D 1$ & 2.10 \\
\hline CD19 & 1.63 & $D K K 2$ & 2.05 \\
\hline CTF1 & 1.36 & PCDH10 & 2.03 \\
\hline SEMA4D & 1.15 & WNT3 & 1.65 \\
\hline$A K N A$ & 1.12 & sox10 & 1.41 \\
\hline ETV2 & 1.06 & WNT11 & 1.27 \\
\hline Epigenetic regulators & & Cell-cycle signaling & \\
\hline Histones & & CCNA1 & 3.06 \\
\hline HIST1H2BJ & 3.44 & $C D K N 2 B$ & 2.78 \\
\hline HIST1H1A & 3.29 & PKMYT1 & 1.03 \\
\hline HIST1H3A & 1.99 & Tumor-suppressor & \\
\hline HIST1H2AC & 1.78 & PRUNE2 & 3.74 \\
\hline HIST1H2BB & 1.42 & RHOBTB1 & 3.22 \\
\hline HIST1H2AB & 1.78 & CDX1 & 2.94 \\
\hline HIST3H2A & 1.37 & FRMD3 & 2.69 \\
\hline HIST1HC & 1.23 & TWIST2 & 2.50 \\
\hline Methyltransferase & & $C C D C 8$ & 2.08 \\
\hline BHMT2 & 1.05 & CEACAM1 & 1.88 \\
\hline Histone methyltransferase & & $K L K 10$ & 1.80 \\
\hline PRDM14 & 4.62 & $D A B 2 I P$ & 1.72 \\
\hline SUV39H2 & 1.23 & CAV1 & 1.71 \\
\hline \multicolumn{4}{|l|}{ RNA methyltransferase } \\
\hline NSUN7 & 4.55 & & \\
\hline \multicolumn{4}{|l|}{ Kinetochore assembly } \\
\hline CENPW & 2.08 & & \\
\hline
\end{tabular}

Table 3.2 Classification of genes associated with 5' regulatory hypermethylation in canines with acute leukemia. 
Canine AL

Human ALL

Hypermethylated $\log _{2} f c$ Hypermethylated $\log _{2} f c$ Downregulated $\log _{2} f c$

\begin{tabular}{l|l|l|l|}
\cline { 2 - 3 } PKHD1L1 & 1.49 & 2.66 & -5.38 \\
KHDRBS2 & 2.64 & 2.84 & -4.83 \\
PTPRO & 2.83 & 3.65 & -4.65 \\
PDE4C & 1.45 & 3.43 & -3.82 \\
RHOBTB1 & 2.11 & 3.84 & -2.75 \\
OSMR & 6.01 & 3.96 & -2.38 \\
CDC42BPB & 2.64 & 4.12 & -1.98 \\
SLC13A5 & 1.96 & 3.34 & -1.71 \\
PRUNE2 & 3.74 & 4.56 & -1.47 \\
LMNA & 2.66 & 2.27 & -0.91 \\
\hline
\end{tabular}

Table 3.3 Downregulated genes in human ALL accompanied with $5^{\prime}$ regulatory hypermethylation in canine and human leukemia. ( $p$-value $<0.05)$ 

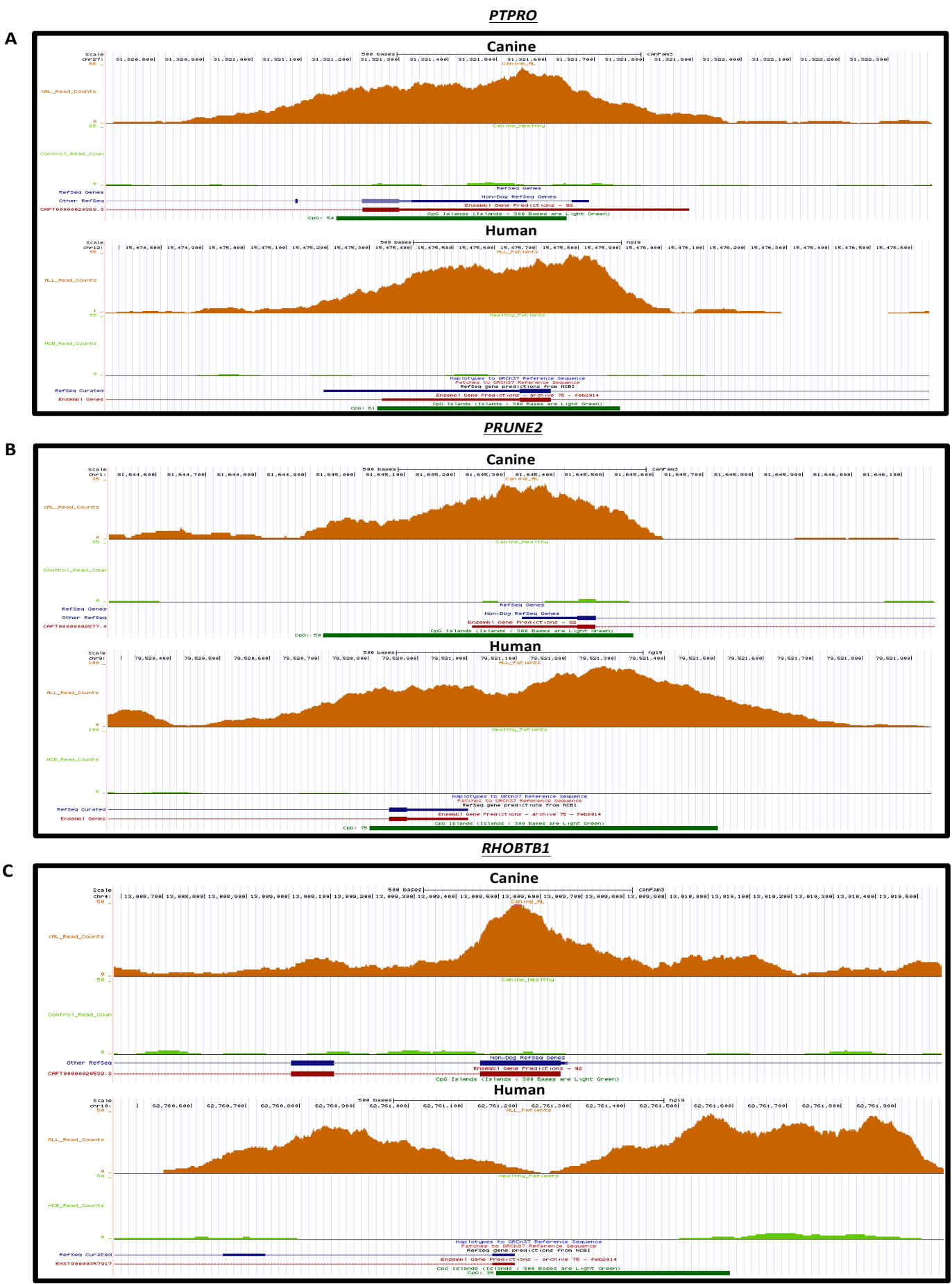

Figure 3.3 BedGraph illustrations showing differences in average read count peaks within the 5' regulatory region of A: PTPRO, B: PRUNE2, C: RHOBTB1 in both human ALL (orange) compared to healthy cord blood donor patients (HCB) (light green) and canine AL (orange) compared to healthy CD21+ canine (light green). The Y-axis contains the numeric scale of the max read count peak and the Xaxis represents the chromosomal coordinate given within the $\sim 1.5 \mathrm{~kb}$ window of each gene. The Ensembl (red) and RefSeq (purple) tracks are shown at the bottom along with the CpG islands in dark green. 


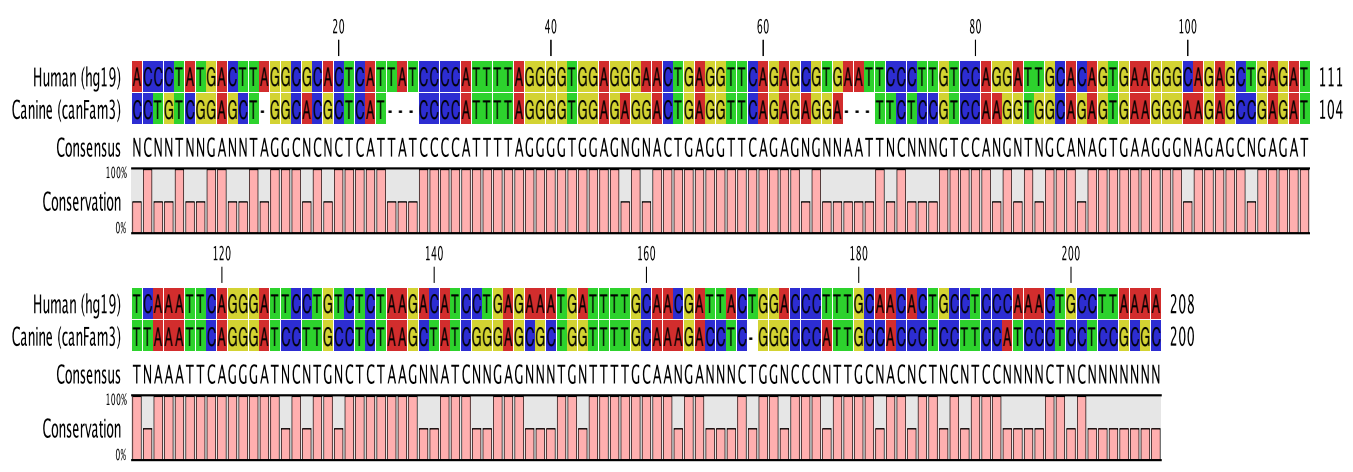

Figure 3.4 Sequence alignment of a hypermethylated intergenic region found in human ALL and canine AL. The 208 bases (chr12:12618099-

12618306 ) on the (+) strand from the human sequence were derived from the canFam3 to hg19 assembly conversion of 200 bases (chr26:4428401$4428600)$ on the (-) strand in canine, shown by 8 gaps created in the canine sequence. 


\section{REFERENCES}

1. Wellman ML. A PRACTICAL GUIDE TO LEUKEMIA IN DOGS AND CATS.

2. Tasca S, Carli E, Caldin M, Menegazzo L, Furlanello T, Gallego LS. Hematologic abnormalities and flow cytometric immunophenotyping results in dogs with hematopoietic neoplasia: 210 cases (2002-2006). Veterinary clinical pathology. 2009 Mar;38(1):2-12.

3. Weiss DJ. Flow cytometric and immunophenotypic evaluation of acute lymphocytic leukemia in dog bone marrow. Journal of veterinary internal medicine. 2001 Nov;15(6):589-94.

4. Chiaretti S, Zini G, Bassan R. Diagnosis and subclassification of acute lymphoblastic leukemia. Mediterranean journal of hematology and infectious diseases. 2014;6(1).

5. Stokol T, Nickerson GA, Shuman M, Belcher N. Dogs with acute myeloid leukemia have clonal rearrangements in T and B cell receptors. Frontiers in veterinary science. 2017 May 31;4:76.

6. Zhao F, Chen Y. Immunologic characteristics and prognosis of acute myeloid leukemia M1. 2007 Aug;15(4):687-91.

7. Rahmani M, Talebi M, Hagh MF, Feizi AA, Solali S. Aberrant DNA methylation of key genes and Acute Lymphoblastic Leukemia. Biomedicine \& Pharmacotherapy. 2018 Jan 31;97:1493-500.

8. Bronzini I, Aresu L, Paganin M, Marchioretto L, Comazzi S, Cian F, Riondato F, Marconato L, Martini V, Te Kronnie G. DNA methylation and 
targeted sequencing of methyltransferases family genes in canine acute myeloid leukaemia, modelling human myeloid leukaemia. Veterinary and comparative oncology. 2017 Sep;15(3):910-8.

9. Almamun M, Levinson BT, van Swaay AC, Johnson NT, McKay SD, Arthur GL, Davis JW, Taylor KH. Integrated methylome and transcriptome analysis reveals novel regulatory elements in pediatric acute lymphoblastic leukemia. Epigenetics. 2015 Sep 2;10(9):882-90.

10. Andrew S. FastQC: a quality control tool for high throughput sequence data; 2010 [accessed 2017 Mar 15]. http://www.bioinformatics.babraham.ac.uk/projects/fastqc.

11. Martin M. Cutadapt removes adapter sequences from high-throughput sequencing reads. EMBnet.journal 2011.

12. Langmead B, Salzberg SL. Fast gapped-read alignment with Bowtie 2 . Nat Methods 2012;9:357-359.

13. Li H, Handsaker B, Wysoker A, et al. The Sequence Alignment/Map format and SAMtools. Bioinformatics 2009;25:2078-2079.

14. Zhang Y, Liu T, Meyer CA, Eeckhoute J, Johnson DS, Bernstein BE, Nusb aum C, Myers RM, Brown M, Li W, et al. Model-based analysis of ChIPSeq (MACS). Genome Biol 2008; 9:R137.

15. Quinlan AR, Hall IM. BEDTools: a flexible suite of utilities for comparing genomic features. Bioinformatics 2010;26:841-842.

16. Chavez L, Jozefczuk J, Grimm C, et al. Computational analysis of genome-wide DNA methylation during the differentiation of human 
embryonic stem cells along the endodermal lineage. Genome Res 2010;20:1441-1450.

17. Bourgon R, Gentleman R, Huber W. Independent filtering increases detection power for high-throughput experiments. Proc Natl Acad Sci U S A 2010;107:9546-9551.

18. Heinz S, Benner C, Spann N, et al. Simple combinations of lineagedetermining transcription factors prime cis-regulatory elements required for macrophage and B cell identities. Mol Cell 2010;38:576-589.

19. Karolchik D, Hinrichs AS, Furey TS, Roskin KM, Sugnet CW, Haussler D, Kent WJ. The UCSC Table Browser data retrieval tool. Nucleic Acids Res. 2004 Jan 1;32(Database issue):D493-6.

20. Mudunuri,U., Che,A., Yi,M. and Stephens,R.M. (2009) bioDBnet: the biological database network. Bioinformatics, 25, 555-556.

21. Kent WJ, Sugnet CW, Furey TS, Roskin KM, Pringle TH, Zahler AM, Haussler D. The human genome browser at UCSC. Genome Res. 2002 Jun;12(6):996-1006.

22. CLC Genomics Workbench 9.5.3 (https://www.qiagenbioinformatics.com/)

23. Shobhit Gupta, JA Stamatoyannopolous, Timothy Bailey and William Stafford Noble, "Quantifying similarity between motifs", Genome Biology, 8(2):R24, 2007.

24. Nordlund J, Backlin CL, Wahlberg P, et al. Genome-wide signatures of differential DNA methylation in pediatric acute lymphoblastic leukemia. Genome Biol 2013;14:r105. 
25. Nordlund J, Bäcklin CL, Zachariadis V, Cavelier L, Dahlberg J, Öfverholm I, Barbany G, Nordgren A, Övernäs E, Abrahamsson J, Flaegstad T. DNA methylation-based subtype prediction for pediatric acute lymphoblastic leukemia. Clinical epigenetics. 2015 Dec;7(1):11.

26. Figueiredo JF, Culver S, Behling-Kelly E, Breen M, Friedrichs KR. Acute myeloblastic leukemia with associated BCR-ABL translocation in a dog. Veterinary clinical pathology. 2012 Sep;41(3):362-8.

27. Han L, Zhao Z. Contrast features of CpG islands in the promoter and other regions in the dog genome. Genomics. 2009 Aug 31;94(2):117-24.

28. Saraf AJ, Lau SF, He R, Issa JP, Jelinek J. Distinct DNA Methylation Patterns of HOX Genes in Leukemia.

29. Tommasi S, Karm DL, Wu X, Yen Y, Pfeifer GP. Methylation of homeobox genes is a frequent and early epigenetic event in breast cancer. Breast Cancer Research. 2009 Jun;11(1):R14.

30. Román-Gómez J, Cordeu L, Agirre X, Jiménez-Velasco A, San JoséEneriz E, Garate L, Calasanz MJ, Heiniger A, Torres A, Prosper F. Epigenetic regulation of Wnt-signaling pathway in acute lymphoblastic leukemia. Blood. 2007 Apr 15;109(8):3462-9.

31. Hogan LE, Meyer JA, Yang J, Wang J, Wong N, Yang W, Condos G, Hunger SP, Raetz E, Saffery R, Relling MV. Integrated genomic analysis of relapsed childhood acute lymphoblastic leukemia reveals therapeutic strategies. Blood. 2011 Jan 1:blood-2011. 
32. Valencia A, Roman-Gomez J, Cervera J, Such E, Barragan E, Bolufer P, Moscardo F, Sanz GF, Sanz MA. Wnt signaling pathway is epigenetically regulated by methylation of Wnt antagonists in acute myeloid leukemia. Leukemia. 2009 Sep;23(9):1658.

33. Kim M, Kim H, Jho EH. Identification of ptpro as a novel target gene of Wnt signaling and its potential role as a receptor for Wnt. FEBS letters. 2010 Sep 24;584(18):3923-8.

34. You YJ, Chen YP, Zheng XX, Meltzer SJ, Zhang H. Aberrant methylation of the PTPRO gene in peripheral blood as a potential biomarker in esophageal squamous cell carcinoma patients. Cancer Lett. 2012;315:138-144.

35. Motiwala T, Kutay H, Ghoshal K, Bai S, Seimiya H, Tsuruo T, Suster S, Morrison C, Jacob ST. Protein tyrosine phosphatase receptor-type O (PTPRO) exhibits characteristics of a candidate tumor suppressor in human lung cancer. Proceedings of the National Academy of Sciences. 2004 Sep 21;101(38):13844-9.

36. McKinnon CM, Mellor H. The tumor suppressor RhoBTB1 controls Golgi integrity and breast cancer cell invasion through METTL7B. BMC cancer. 2017 Dec;17(1):145.

37. Xu RS, Wu XD, Zhang SQ, Li CF, Yang L, Li DD, Zhang BG, Zhang Y, Jin JP, Zhang B. The tumor suppressor gene RhoBTB1 is a novel target of miR-31 in human colon cancer. International journal of oncology. 2013 Feb 1;42(2):676-82. 
38. Salameh A, Lee AK, Cardó-Vila M, Nunes DN, Efstathiou E, Staquicini FI, Dobroff AS, Marchiò S, Navone NM, Hosoya H, Lauer RC. PRUNE2 is a human prostate cancer suppressor regulated by the intronic long noncoding RNA PCA3. Proceedings of the National Academy of Sciences. 2015 Jul 7;112(27):8403-8.

39. Kondrashov AS, Shabalina SA. Classification of common conserved sequences in mammalian intergenic regions. Human molecular genetics. 2002 Mar 15;11(6):669-74.

40. Koyano-Nakagawa N, Kweon J, lacovino M, Shi X, Rasmussen TL, Borges L, Zirbes KM, Li T, Perlingeiro RC, Kyba M, Garry DJ. Etv2 is expressed in the yolk sac hematopoietic and endothelial progenitors and regulates Lmo2 gene expression. Stem Cells. 2012 Aug 1;30(8):1611-23.

41. Wang YJ, Huang J, Liu W, Kou X, Tang H, Wang H, Yu X, Gao S, Ouyang $\mathrm{K}$, Yang HT. IP3R-mediated Ca2+ signals govern hematopoietic and cardiac divergence of Flk1+ cells via the calcineurin-NFATc3-Etv2 pathway. Journal of molecular cell biology. 2017 May 10;9(4):274-88. 


\section{CHAPTER 4: RELAPSE ASSOCIATED BIOMARKERS IN ACUTE LYMPHOBLASTIC LEUKEMIA}

\subsection{Abstract}

Although the 5 year survival rate for ALL has broken the $90 \%$ mark, patients who relapse have a dismal outcome. Therefore patients at diagnosis would greatly benefit from relapse-associated biomarkers like DNA methylation so that an alternative therapeutic approach may be put in place and monitored closely through the course of treatment. Previously, we identified 130 loci (200bp) that were hypermethylated in a cohort of patients $(n=10)$ at diagnosis that went on to relapse compared to healthy controls. Hypermethlyation in these regions was absent in another cohort of patients $(n=13)$ at diagnosis who did not relapse. Odds ratio calculations for 3 read count cutoffs $(50,75,100)$ identified 38 statistically significant regions ( $p$-value $<0.05$ ) to quantitate individual $\mathrm{CpG}$ methylation differences between the two patient cohorts using pyrosequencing. Among the 4 regions tested in both cohorts by pyrosequencing, region \#1 contained $3 \mathrm{CpGs}$ that were hypermethylated in the relapse cohort $(n=10)$ compared to the non-relapse cohort $(n=8)$. In addition, the area under the curve (AUC) was greater than or equal to .925 for all 3 CpGs ( $p$-value< 0.05 ). 


\subsection{Introduction}

Risk stratification remains a significant problem for ALL patients. It is crucial that patients be categorized into their respective low-standard or high-risk group of relapsing prior to induction treatment. Failure in doing so vastly increases the likely-hood of failed response to treatment and subsequent relapse.

Consequences of inaccurate stratification include high risk patients treated under a less intensive treatment regimen or increased chemotoxicity exposure for patients misclassified as low-standard risk. Specifically, patients exhibiting favorable cytogenetic characteristics, such as diploidy (46 chromosomes) or high-hyperdiploidy ( $50<$ chromosomes) are placed into the low-standard risk treatment protocol. However, many of these patients have unidentified genetic and/or epigenetic characteristics that would qualify them as high-risk. Therefore, additional strategies implemented alongside primary stratification methods of cytogenetic testing, minimal residual disease (MRD) monitoring and white blood cell count (WBC) based stratification are needed at diagnosis and throughout treatment.

DNA methylation-based methods would be an attractive addition to patient stratification because of the robust nature and stability of DNA, which may also offer a non-invasive approach to monitoring patient treatment response via peripheral blood as opposed to bone marrow aspiration. For example, past studies have demonstrated the ability to assign patients into their correct cytogenetic subtype with high precision using a CpG panel developed from 450K 
microarray data. ${ }^{1-4}$ Furthermore, $\mathrm{CpG}$ island methylator phenotype (CIMP) classification is a method that has stratified ALL patients at diagnosis and relapse into low-standard and high-risk groups based on the bimodal distribution of methylation derived from a panel consisting of 1,293 individual CpG sites..$^{5,6}$

This study's objective was to identify CpG sites that could differentiate a small sample size of patients at diagnosis who either did or did not relapse. Using next-generation Illumina sequencing, our previous study identified 130 loci that were hypermethylated in normal and diploidy ALL patients at diagnosis that later went on to relapse $(n=10)$ compared to healthy patient controls $(n=10)$. Importantly, these 130 loci were not differentially methylated in a subset of normal or diploidy patients that had not gone on to relapse $(n=13)$ when compared to healthy patients. Based on odds ratio calculations applied to 3 different read count cutoffs $(50,75,100)$ for each region for a given patient, 38 regions reached statistical significance $(p<0.05)$ among the 130 . Given that read count data lack the quantitative means to measure individual $\mathrm{CpG}$ sites, pyrosequencing can overcome this shortcoming by producing percent methylation ratios $(\mathrm{C} / \mathrm{T})$ of individual $\mathrm{CpG}$ sites. In addition, pyrosequencing remains one of the most accurate technologies used in a clinical setting with minimal false-positive and false-negative results. ${ }^{7}$ Therefore, incorporating pyrosequencing technology provides a gold standard and optimal resolution for measuring differential methylation of individual CpG sites within our 38 loci of interest. 


\subsection{Methods}

\subsubsection{Patient samples}

Bone marrow aspirates containing $>87 \%$ leukemic blasts from ALL patient samples were used under full ethical approval of the Institutional Review Board at the University of Missouri (Table 4.1). MIRA-seq libraries were created for A27, A59, A70, A101, and A121 patient samples at diagnosis who relapsed and for all ten matched relapsed samples in this study. These MIRA-seq profiles (hg19 build) are accessible through the NCBI Sequence Read Archive (Accession PRJNA470682). Previously generated MIRA-seq libraries for A4, A15, A18-A26, A28-A31, A33, A36, A37 diagnosis patient samples and ten normal human umbilical blood (HCB1-HCB10) were used in this study. The previously generated MIRA-seq profiles can be found in the NCBI Sequence Read Archive (Accession SRP058314).

\subsubsection{Genomic DNA isolation and pyrosequencing experimentation}

Using the QIAamp DNA Micro Kit (Qiagen cat. no. 56304), genomic DNA was extracted from 18 ALL patients ( $n=8$, non-relapse cohort) $(n=10$, relapse cohort). Bisulfite conversion of genomic DNA (200 ng) was performed using the EZ DNA methylation kit (D5006, Zymo Research, Irvine, CA, USA) per the manufacturer's instructions. Bisulfite PCR was performed using PyroMark PCR Kit (Qiagen) using 20ng of bisulfite converted DNA under Qiagen's 
recommended HotStarTaq cycling conditions (45 cycles). All primer sequences designed were chosen based on a quality score of at least "Medium quality" using the PyroMark Assay design software 2.0 (Qiagen, Valencia, CA, USA) and can be found in (Table 4.2). Streptavidin-coated Sepharose beads (GE Healthcare) were used to purify biotin labeled PCR products. Subsequent purification, washing, and denaturing steps ( $\mathrm{NaOH}$ solution) were applied to the PCR products before sequencing. A pyrosequencing primer annealed to the single stranded PCR product and pyrosequencing was then performed on the PyroMark Q24 per manufacturer's instructions. Internal controls for bisulfite conversion were implemented by including non-CG sequence(s) into the target sequence. In addition, a water control was included as a negative control. The percent methylation within $\mathrm{CpG}$ sites of interest were calculated using instrumental software (Qiagen, PSQ24MA 2.1), resulting in pyrogram illustrations that provide a visual of peak heights representing nucleotide incorporation to the single stranded DNA and therefore a $\mathrm{C} / \mathrm{T}$ ratio at the $\mathrm{CG}$ site of interest could be calculated.

\subsubsection{Statistical analysis of pyrosequencing results}

Nonparametric statistical analysis of relative percent methylation differences between the relapse and non-relapse cohorts was performed with SPSS Statistics software (IBM Corp.). Wilcoxon rank-sum test and receiver operator characteristic (ROC) curve was applied to the percent of methylation values of 
each CpG site measured across 18 ALL patient samples. P-values $<0.05$ were considered statistically significant.

\subsubsection{Determining 38 loci of interest for pyrosequencing analysis}

The 130 regions of interest were identified as hypermethylated in the relapse cohort compared to normal healthy controls, but were not hypermethylated in the non-relapse cohort. The regions were then ranked based on odds ratios, where larger scores represented a greater presence of individuals with read counts of either $>50,75,100$ (cutoffs) in the relapsed cohort in correlation with the absence of read counts $>50,75,100$ within the non-relapsed cohort. Odds ratio scores, including 95\% confidence intervals, and their respective $p$-values were calculated using MEDCALC software v 12.4 (MedCalc Software, Ostend, Belgium). Regions where read count values were $>50,75,100$ were labeled in red and regions $<50,75,100$ read counts were labeled in yellow for a given patient. Haldane-Anscombe correction was applied to the data for each region, where a constant equal to 0.5 was added to each cell. P-values $<0.05$ were considered statistically significant.

\subsection{Results}

\subsubsection{8 loci are associated with relapse outcome in ALL patients}

In order to determine loci with statistical association to relapse outcome from the aforementioned list of 130 regions, odds ratio was applied to the sequencing data under three arbitrary read count cutoffs $(50,75,100)$. This resulted in identifying 
38 loci that reached statistical significance ( $p$-value $<0.05$ ), of which 16 had an overlap in at least two of the three read count cutoffs (Figure 4.1). The vast majority of the 38 loci were located in repetitive satellite intergenic elements of the genome $(n=34)$, where the remaining 4 loci overlapped intronic sequences within 4 separate genes. The most observed genes in proximity of the 38 loci included many pseudogenes: Actin-related pseudogenes ACTR3BP5 $(n=4)$ and ACTR3BP3 $(\mathrm{n}=3)$, zinc finger pseudogene $Z N F 733 P(\mathrm{n}=4)$, and ankyrin repeat pseudogene ANKRD26P1 ( $\mathrm{n}=3)$.

\subsubsection{CpG sites are hypermethylated in ALL patients who relapsed compared to ALL patients who did not relapse}

In order to quantitate methylation differences between relapse and non-relapse patients at diagnosis, individual CpGs within the 38 loci of interest were investigated for assaying compatibility (primer design and PCR product visibility) with pyrosequencing. A total of 4 loci: Region \#1(chr2: 9227240192272600(CpGs=3)). Region \#2(chr6: $58774601-58774800$ (CpGs=1)), Region \#3 (chr2: $92272401-92272600$ (CpGs=2)), Region \#4 (chr2: 92274801-92275000 $(C p G s=1))$ were tested. The $3 \mathrm{CpGs}$ tested in region \#1 were hypermethylated in the relapse cohort $(n=10)$ compared to the non-relapse cohort $(n=8)(p-$ value $<0.05$ ). In addition, ROC curve analysis of all $3 \mathrm{CpGs}$ demonstrated the ability to distinguish between the two cohorts based on methylation percentage with the area under the curve (AUC) being greater than at least 0.925 for all 3 CpGs tested ( $p$-value<0.05) (Figure 4.2). The distribution of percent methylation 
plotted across all 18 patients for the $3 \mathrm{CpGs}$, illustrates a clear separation between patients at diagnosis who did or did not relapse (Figure 4.3). Furthermore, the line graph highlights patient outliers for 1 or more CpGs: A19, A15 (relapse cohort in red) and A23, A28 (non-relapse cohort in blue).

\subsection{Discussion}

Considering only 1 of the 4 loci tested were statistically significant between relapse and non-relapse ALL patients, the remaining loci should also be assessed for methylation differences. The regions were prioritized based on primer constraints from Qiagen software where at least a medium quality score had to be met before proceeding. However, this does not exclude the possibility of lower quality or other custom designed primers from producing robust results. Moreover, alternative methods to measure $\mathrm{CpG}$ methylation within these regions may be used to circumvent the primer limitations of bisulfite specific PCR and subsequent pyrosequencing, such as quantitative methylation specific PCR (qMSP).

Many of our listed 130 loci $(n=103)$, including the 4 loci tested, contain novel CpG sites that have yet to be explored on an individual or genome-wide scale in ALL/relapsed ALL due to the absence of probes in $450 \mathrm{~K}$ methylation array experiments. This observation may also be attributed to the fact that primer development is difficult in these regions as many lay within repeat sequence motifs. 
The potential regulatory significance of region \#1 has yet to be determined. Although, according to ENCODE ChIP-seq data from the UCSC genome browser consortium, both enhancer histone markers (H3K4me1, H3K27ac) from lymphoblastoid cell line GM12878 overlap the region. ${ }^{8}$ Interestingly, the intergenic region lays between genes denoted as abparts (antibody various regions). In addition, methylation-mediated enhancer regulation of immunoglobulins and other elements such as eRNA has been shown to be an essential component to normal B cell function. ${ }^{9,10}$

A glaring limitation of this study includes a small sample size tested $(n=18)$ relative to most pyrosequencing studies used to find clinical significance between various treatment and diseased groups. ${ }^{10-13}$ In addition, the few patient outliers observed in region \#1 may increase as the sample size goes up. Nonetheless, region \#1 clearly distinguishes between relapse and non-relapse ALL at diagnosis in our sample set and therefore warrants further patient testing. Because the methylation pattern is specific to cytogenetic aberrations in ALL, a follow up study would include patients consistent with this study that present with either a normal karyotype or hyperdiploidy, then potentially branching out to the other predominate patient subtypes. ${ }^{14}$ 


\begin{tabular}{|c|c|c|c|c|c|c|c|}
\hline $\begin{array}{l}\text { Patient } \\
\text { ID }\end{array}$ & $\begin{array}{c}\text { Age } \\
\text { (months) }\end{array}$ & $\begin{array}{l}\text { WBC, } \\
10^{3} / \mu \mathrm{l}\end{array}$ & Sex & Cytogenetics & $\begin{array}{l}\text { Relapse } \\
\text { Status }\end{array}$ & $\begin{array}{c}\text { Months } \\
\text { to } \\
\text { Relapse }\end{array}$ & $\begin{array}{c}\text { Performed } \\
\text { Pyrosequencing }\end{array}$ \\
\hline A4 & 4 & 7.8 & $\mathrm{M}$ & hyperdiploidy & Yes & 86 & Yes \\
\hline A15 & 36 & 7.8 & $\mathrm{M}$ & hyperdiploidy & Yes & 2 & Yes \\
\hline A18 & 17 & 4.3 & $\mathrm{~F}$ & $\begin{array}{c}\text { 46, XX-15der(1) } \\
\mathrm{t}(1 ; ?), \operatorname{del}(6)(\mathrm{q} 21), \mathrm{t} \text { mar }\end{array}$ & Yes & 39 & Yes \\
\hline A19 & 36 & 3.7 & $\mathrm{M}$ & hyperdiploidy & Yes & 56 & Yes \\
\hline $\mathrm{A} 20$ & 120 & 3.6 & $\mathrm{M}$ & $46, X Y$ & No & - & No \\
\hline A21 & 36 & 6.6 & M & $\begin{array}{c}46, X Y \\
\mathrm{t}(3 ; 19)(\mathrm{p} 25 ; \mathrm{p} 13)\end{array}$ & No & - & No \\
\hline A22 & 60 & 2.5 & $\mathrm{~F}$ & $47, \mathrm{XX}+21 ; 48, \mathrm{XX}$ & No & - & Yes \\
\hline A23 & 180 & 2.3 & $\mathrm{M}$ & 46, XY del(6)(q21;q27) & No & - & Yes \\
\hline A24 & 108 & 3.7 & M & $\begin{array}{l}45,-7-9+\operatorname{der}(9) \\
\mathrm{t}(8 ; 9)(\mathrm{q} 112 ; \mathrm{p} 11)\end{array}$ & No & - & Yes \\
\hline $\mathrm{A} 25$ & 48 & 13.7 & $\mathrm{M}$ & $46, X Y$ & No & - & No \\
\hline $\mathrm{A} 26$ & 48 & 4.3 & $\mathrm{M}$ & $47, X Y$ & No & - & No \\
\hline $\mathrm{A} 27$ & 60 & 3.1 & $\mathrm{M}$ & $46, X Y$ & Yes & 30 & Yes \\
\hline A28 & 36 & 1.5 & $\mathrm{M}$ & none available & No & - & Yes \\
\hline A29 & 24 & 10.2 & $\mathrm{~F}$ & $46, \mathrm{XX}$ & No & - & \\
\hline A30 & 24 & 3.7 & $\mathrm{~F}$ & $46, X X$ & No & - & Yes \\
\hline $\mathrm{A} 31$ & 132 & 18.8 & $\mathrm{M}$ & $45, X Y-7$ & No & - & Yes \\
\hline A33 & 180 & 4.5 & $\mathrm{M}$ & $46, X Y$ & Yes & 31 & Yes \\
\hline A36 & 72 & 2.7 & $\mathrm{~F}$ & $46, X X$ & No & - & Yes \\
\hline A37 & 20 & 2.5 & $\mathrm{M}$ & hyperdiploidy & No & - & Yes \\
\hline A59 & 18 & 6.3 & $\mathrm{M}$ & $46, X Y$ & Yes & 8 & Yes \\
\hline A70 & 36 & 2.6 & $\mathrm{M}$ & hyperdiploidy & Yes & 8 & Yes \\
\hline A101 & 113 & 5.8 & $\mathrm{~F}$ & $46, \mathrm{XX}$ & Yes & 7 & Yes \\
\hline A121 & 10 & 1.3 & $\mathrm{M}$ & $46, X Y$ & Yes & 28 & Yes \\
\hline
\end{tabular}

Table 4.1 Patient characteristics 


\begin{tabular}{|c|c|c|c|c|c|c|}
\hline Region\# & Genomic coordinate (hg19) & Forward Primer $\left(5^{\prime} \rightarrow 3^{\prime}\right)$ & Reverse Primer $\left(5^{\prime} \rightarrow 3^{\prime}\right)$ & Pyrosequencing Primer $\left(\mathbf{5}^{\prime} \rightarrow 3^{\prime}\right)$ & CpGs analyzed & Quality score \\
\hline$T$ & Chr2: $89844201-889844400$ & AGGGAATTAAATGGAATAAATGTTAAATTG & CTATTCATACCCATTAAATTATTTCACAC & GAATGTAATGGAATGGAAA & 3 & 73 \\
\hline 2 & Chr6: 58774601-858774800 & AGAAATATTTTTTGTAGAATTTGGAAGTGT & CAAAAAAATCCAAATATCCACTAACAT & TTTCTACCATAAATCTCAAAAC & 1 & 63 \\
\hline 3 & Chr2: 92272401-92272600 & TGATGATGATTTGGTTTGGTTTAA & АТTCCCCTTTCTTAAAAAATCCTCCAACTA & ATGATTTGGTTTGGTTTAAT & 2 & 68 \\
\hline 4 & Chr2: 92274801-92275000 & TGGATTATATGGAGGTTTAATTGTGA & CTTТAССТAAATACTAACATCCCAAAAT & ATTTGGATAGATTTGAGGAT & 1 & 76 \\
\hline
\end{tabular}

Table 4.2 Bisulfite specific primer sequences.

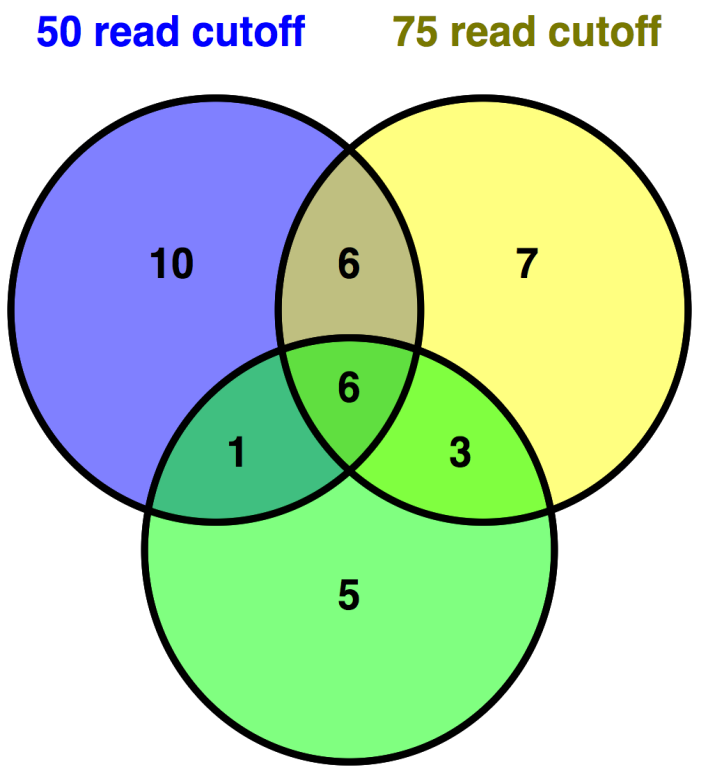

\section{0 read cutoff}

Figure 4.1 Venn diagram of 38 statistically significant loci based on odds ratio ( $p$-value $<0.05)$ applied to 130 regions of different read count cutoffs $(50,75,100)$. 


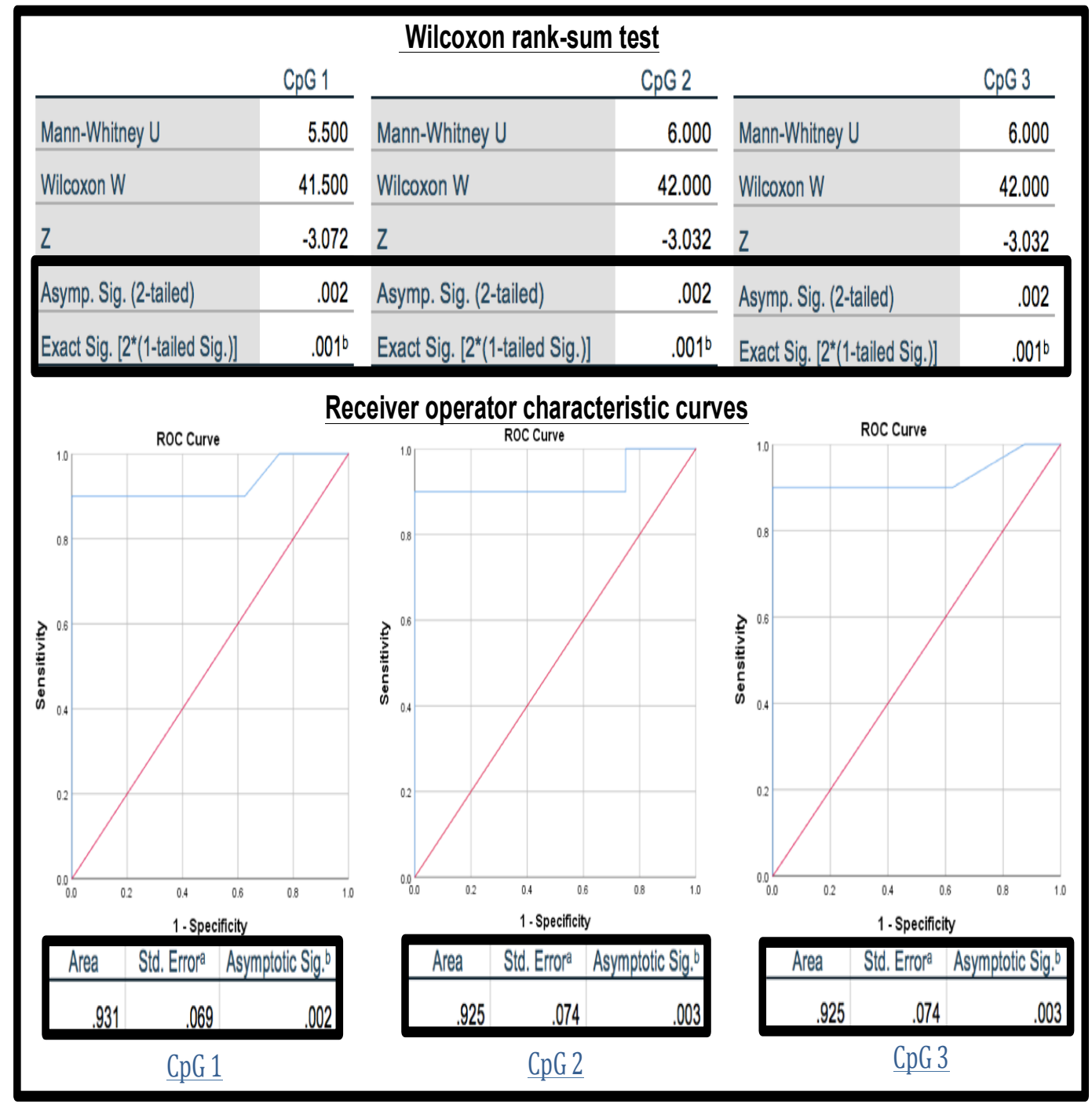

Figure 4.2 Statistical analysis of $3 \mathrm{CpGs}$ tested in region \#1. Median value differences of DNA methylation were observed between relapse and non-relapse cohorts using Wilcoxon rank-sum test (p-value < 0.05 ). The ROC curve analysis found the ability of the experimental test of $3 \mathrm{CpGs}$ to distinguish between ALL patients at diagnosis who did or did not go on to relapse (AUC >.925) (p-value $<0.05)$. 


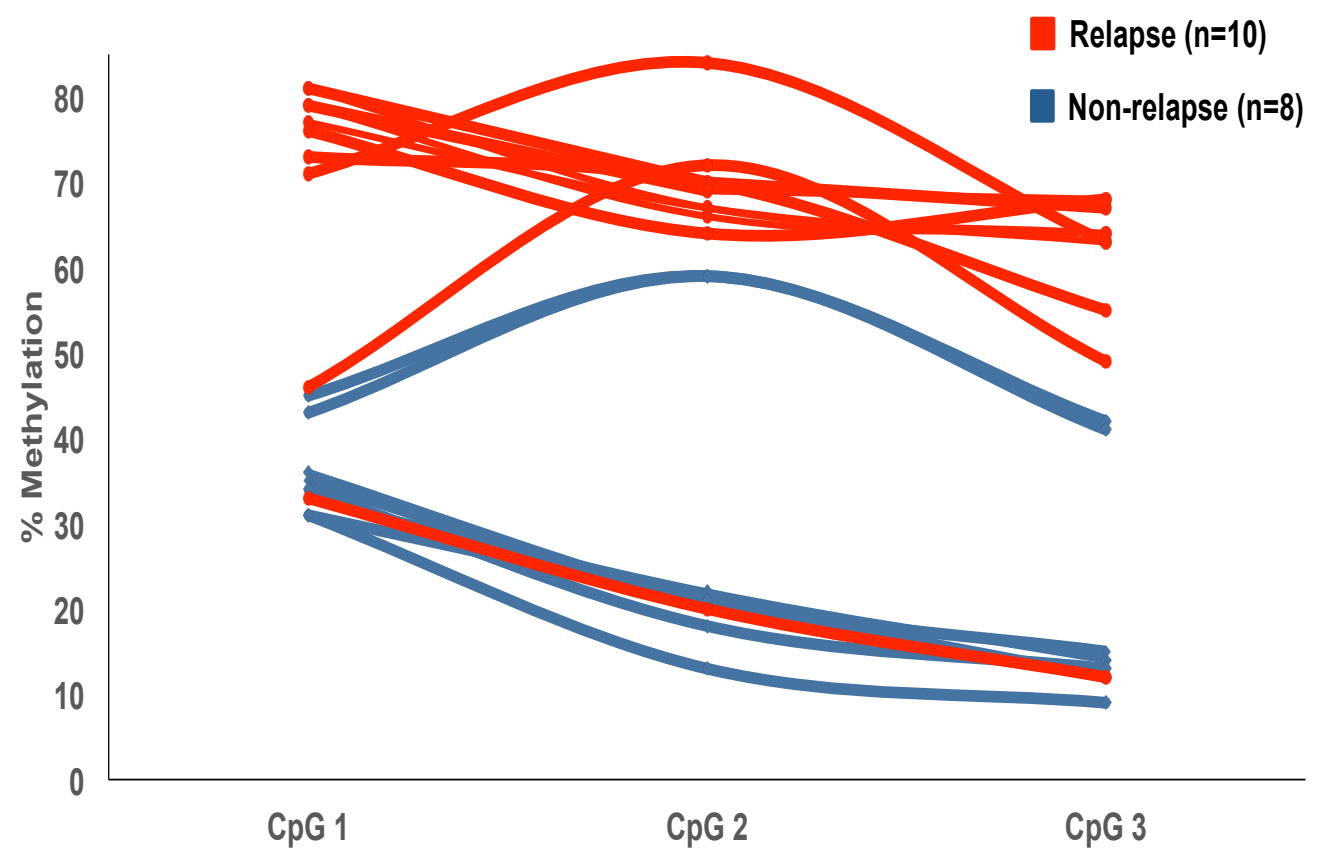

Figure 4.3 Line graph representing the percent methylation of $3 \mathrm{CpGs}$ observed across ALL patients at diagnosis who relapsed $(n=10)$ or did not relapse $(n=8)$. Outliers observed in 2 patient from the relapse cohort $(A 15, A 19)$ and 2 patients from the non-relapse cohort (A23, A28). 


\section{REFERENCES}

1) Nordlund J, Bäcklin CL, Zachariadis V, Cavelier L, Dahlberg J, Öfverholm I, Barbany G, Nordgren A, Övernäs E, Abrahamsson J, Flaegstad T. DNA methylation-based subtype prediction for pediatric acute lymphoblastic leukemia. Clinical epigenetics. 2015 Feb 17;7(1):11.

2) Milani L, Lundmark A, Kiialainen A, Nordlund J, Flaegstad T, Forestier E, Heyman M, Jonmundsson G, Kanerva J, Schmiegelow K, Söderhäll S. DNA methylation for subtype classification and prediction of treatment outcome in patients with childhood acute lymphoblastic leukemia. Blood. 2010 Feb 11;115(6):1214-25.

3) Busche S, Ge B, Vidal R, Spinella JF, Saillour V, Richer C, Healy J, Chen $\mathrm{SH}$, Droit A, Sinnett D, Pastinen T. Integration of high-resolution methylome and transcriptome analyses to dissect epigenomic changes in childhood acute lymphoblastic leukemia. Cancer research. $2013 \mathrm{Jul}$ $15 ; 73(14): 4323-36$.

4) Figueroa ME, Chen SC, Andersson AK, Phillips LA, Li Y, Sotzen J, Kundu M, Downing JR, Melnick A, Mullighan CG. Integrated genetic and epigenetic analysis of childhood acute lymphoblastic leukemia. The Journal of clinical investigation. 2013 Jul 1;123(7):3099.

5) Borssén M, Haider Z, Landfors M, Norén-Nyström U, Schmiegelow K, Åsberg AE, Kanerva J, Madsen HO, Marquart H, Heyman M, Hultdin M. DNA Methylation Adds Prognostic Value to Minimal Residual Disease 
Status in Pediatric T-Cell Acute Lymphoblastic Leukemia. Pediatric blood \& cancer. 2016 Jul;63(7):1185-92.

6) Borssén M, Nordlund J, Haider Z, Landfors M, Larsson P, Kanerva J, Schmiegelow K, Flaegstad T, Jónsson ÓG, Frost BM, Palle J. DNA methylation holds prognostic information in relapsed precursor B-cell acute lymphoblastic leukemia. Clinical epigenetics. 2018 Dec;10(1):31.

7) Quillien V, Lavenu A, Karayan-Tapon L, Carpentier C, Labussière M, Lesimple T, Chinot O, Wager M, Honnorat J, Saikali S, Fina F. Comparative assessment of 5 methods (methylation-specific polymerase chain reaction, methylight, pyrosequencing, methylation-sensitive highresolution melting, and immunohistochemistry) to analyze O6methylguanine-DNA-methyltranferase in a series of 100 glioblastoma patients. Cancer. 2012 Sep 1;118(17):4201-11.

8) Rosenbloom KR, Sloan CA, Malladi VS, Dreszer TR, Learned K, Kirkup VM, Wong MC, Maddren M, Fang R, Heitner SG, Lee BT, Barber GP, Harte RA, Diekhans M, Long JC, Wilder SP, Zweig AS, Karolchik D, Kuhn RM, Haussler D, Kent WJ. ENCODE data in the UCSC Genome Browser: year 5 update. Nucleic Acids Res. 2013 Jan;41(Database issue):D56-63

9) Inlay MA, Lin T, Gao HH, Xu Y. Critical roles of the immunoglobulin intronic enhancers in maintaining the sequential rearrangement of $\operatorname{lgH}$ and Igk loci. Journal of Experimental Medicine. 2006 Jul 10;203(7):1721-32.

10)Almamun M, Kholod O, Stuckel AJ, Levinson BT, Johnson NT, Arthur GL, Davis JW, Taylor KH. Inferring a role for methylation of intergenic DNA in 
the regulation of genes aberrantly expressed in precursor B-cell acute lymphoblastic leukemia. Leukemia \& lymphoma. 2017 Sep 2;58(9):215664.

11)Christians A, Hartmann C, Benner A, Meyer J, von Deimling A, Weller M, Wick W, Weiler M. Prognostic value of three different methods of MGMT promoter methylation analysis in a prospective trial on newly diagnosed glioblastoma. PloS one. 2012 Mar 13;7(3):e33449.

12)Dunn J, Baborie A, Alam F, Joyce K, Moxham M, Sibson R, Crooks D, Husband D, Shenoy A, Brodbelt A, Wong H. Extent of MGMT promoter methylation correlates with outcome in glioblastomas given temozolomide and radiotherapy. British journal of cancer. 2009 Jul;101(1):124.

13) Everhard S, Tost J, El Abdalaoui H, Crinière E, Busato F, Marie Y, Gut IG, Sanson M, Mokhtari K, Laigle-Donadey F, Hoang-Xuan K. Identification of regions correlating MGMT promoter methylation and gene expression in glioblastomas. Neuro-oncology. 2009 Aug 1;11(4):348-56.

14)Nordlund J, Bäcklin CL, Wahlberg $P$, Busche S, Berglund EC, Eloranta ML, Flaegstad T, Forestier E, Frost BM, Harila-Saari A, Heyman M. Genome-wide signatures of differential DNA methylation in pediatric acute lymphoblastic leukemia. Genome biology. 2013 Sep;14(9):r105. 


\section{CHAPTER 5: SUMMARY AND FUTURE DIRECTIONS}

The main objectives of this study were to 1) characterize the DNA methylation landscape of relapsed ALL and 2) identify potential epidriver genes and 3) biomarkers associated with relapse ALL within a mostly cytogenetically homogenous cohort (diploidy or hyperdiploidy). Our first experiment characterized the genomic landscape as predominantly hypomethylated at relapse. It is imperative to point out the differences between the technique that was used in this study (MIRA-seq) and past microarray studies that also evaluated matched diagnosis/relapse patients methylation differences and found predominate hypermethylation. ${ }^{1,2}$ The $450 \mathrm{~K}$ and $27 \mathrm{~K}$ arrays were designed to contain probes mostly within a CpG island context. Theoretically, the affinitybased approach (MIRA-seq) pulls down double stranded DNA fragments ( 250500bp) that contain at least 2 methylated CpGs. ${ }^{3}$ This notion is consistent with our results that observed 70,702 hypomethylated DMRs at relapse, where 30,208 DMRs were found in regions that did not overlap an existing probe within the $450 \mathrm{~K}$ cassette. Furthermore, the majority of the 30,208 DMRs are located within non-CpG island intergenic sequences where the $\mathrm{CpG}$ density is lower and therefore the $\mathrm{CpG}$ proximity to one another is farther. Our results add an element to relapsed ALL that suggests a global demethylation event that may have implications for retrotransposable element activation and genomic instability in ALL patients and should be further examined. It is also important to stress the fact that the cytogenetic subtype strongly influences the methylation landscape of 
ALL and therefore this phenomenon may be observed to a greater or lesser extent in other patient subtypes not tested in this study. Further, predominant global hypomethylation was the trend observed in our patients at diagnosis compared to pre-B cells from healthy individuals with $61 \%$ of 25,282 identified DMRs labeled as hypomethylated. ${ }^{4}$

Our second objective was to identify potential epidriver genes related to relapsed ALL. This was accomplished by comparing diagnosis and relapse samples to healthy patients $(\mathrm{HCB})$, respectively and identifying common DMRs located in 5' regulatory sequences between [diagnosis vs. $\mathrm{HCB}$ ] and [relapse vs. HCB]. A large portion of the common hypermethylated regions $(n=818 / 2170)$ was indeed in either a promoter, 5' UTR, or first exon region. The decision to include those three regions was made based on studies that correlated first exon methylation with transcriptional silencing and our own observation which found many genes exhibiting promoter hypermethylation that extended up to the first exon. ${ }^{5}$ The epidriver genes identified highlight tumor suppressor genes FRMD5, MLF1, PRUNE2, PTPRO and B-cell development related gene MCOLN2. These genes are putative epidriver genes in that they exhibit regulatory hypermethylation and were downregulated at diagnosis when compared to healthy patients. Importantly, only PTPRO has been documented as a potential epidriver of ALL. Further, its leukemogenic properties have been revealed in decitabine treated ALL cell line studies that linked activation of PTPRO to increased apoptosis. ${ }^{6}$ 
Hence, the remaining four putative epidriver genes should also be explored as potential targets of relapsed ALL.

In addition, analyzing DNA methylation changes in canine acute leukemia (cAL) reinforced the notion that leukemia is an epigenetically related disease as much as it is a genetic one. Around $13 \%$ of the hypermethylated regions found in $\mathrm{CAL}$ lay within the 5' regulatory region. We have identified numerous genes pertaining to hematopoiesis, epigenetics, and negative regulation of pathways that are hallmarks of ALL. Filtering of hypermethylated genes found in CAL that were concordant between hypermethylation and downregulation in our human ALL study, resulted in identifying a total of 10 genes in common between the two species: PKHD1L1, KHDRBS2, PTPRO, PDE4C, RHOBTB1, OSMR, CDC42BPB, SLC13A5, PRUNE2, LMNA. Besides PTPRO, the other nine genes have not been identified or tested for tumor suppressor or B cell function in ALL. Moreover, these results support the existence of a common epigenetic signature that may be essential in establishing ALL pathogenesis. In addition, this strengthens the potential functional significance of PTPRO and PRUNE2 as it pertains to relapsed ALL.

Our third objective utilized MIRA-seq profiles from human ALL patients at diagnosis who either did or did not relapse later on. 130 regions were hypermethylated in the relapse cohort compared to healthy patients. However no statistical differences were identified in the non-relapse cohort. The question 
remains, whether or not these regions were differentially methylated between the two patient cohorts themselves. Odds ratio calculations were applied to read counts, which narrowed down 38 regions that were most likely hypermethylated in the relapse cohort compared to the non-relapse cohort. One 200bp region containing $3 \mathrm{CpGs}$ was hypermethylated in the relapse group ( $p$-value $<0.05$ ). Given that the sample size was low for this experiment, the results should be interpreted as preliminary. Moreover, methylation data for ALL patients is absent within this region and likely variable between different subtypes. However, all 38 regions should be investigated considering only 4 regions were tested due to theoretical primer constraints on regions composed predominately of intergenic loci and also in part due to limited resources. Pyrosequencing remains an attractive option in forthcoming methylation studies in ALL and has been an instrumental method as shown in clinical trial studies used to identify chemoresistant patients by quantitating $\mathrm{CpG}$ sites within the promoter of MGMT. Further, one study compared pyrosequencing among 4 other methods in analyzing the promoter methylation status of $M G M T$ in glioma patients: Methylation-specific polymerase chain reaction (MSP), MethylLight (quantitativeMSP), methylation-sensitive high-resolution melting (MS-HRM), and immunohistochemistry. ${ }^{7}$ The study concluded that pyrosequencing was superior in that it displayed the highest reproducibility and sensitivity among the other methods and was further validated in additional frozen or FFPE glioma patient samples $(n=139)$ from 8 independent clinical centers. 
Future work should also include designing functional assays to investigate the role of potential relapse associated epidrivers identified in this study. Because of the scarcity of treatment options for relapsed ALL patients, new targets are desperately needed. These experiments may include transfection assays delivering a vector carrying the transcriptionally active form of the gene of interest to ALL cell lines or primary patient cells. Successful lentiviral-mediated transfections has been demonstrated in lymphoblastoid cell lines and may offer an effective way to express a gene of interest that may otherwise be epigenetically silenced. ${ }^{8}$ One would then evaluate gene expression changes and determine if there is any correlation with tumor suppressor function by measuring apoptotic activity, cell morphology, and cell viability. In addition, genes involved in proper B cell development such as methylation-induced downregulation of MCOLN2 should be further explored. Other than the fact that B cell transcription factor PAX5 binds to the promoter and regulates MCOLN2 in some fashion, very little is known about the regulation and function of MCOLN2 in the context of B cell development. ${ }^{9}$ With the improvement of cellular delivery and stability, next generation hypomethylating agents such as guadecitabine may allow researchers to better understand epidrivers in a more ideal sense. ${ }^{10}$ Further, low dosage of next-generation hypomethylated drugs could be an essential component to combined therapy options in the future.

In conclusion, DNA methylation has the future potential to serve as a biomarker to identify new gene targets and aid in ALL patient risk stratification at diagnosis 
and relapse stages. The implications of bonafide methylation-based biomarkers can be envisaged as a noninvasive approach to risk stratification that is compatible within a clinical setting. At initial ALL diagnosis, DNA methylation has been utilized to subtype patients with higher accuracy when coupled with standard cytogenetic testing. In addition, CpG panels may help identify patients at greater risk for relapse prior to and throughout the course of treatment as demonstrated by the several individual CpGs correlating with relapse and poorer overall survival. Future studies should scrutinize previously identified loci in ALL and novel loci that were observed in this study as well.

\section{REFERENCES}

1. Hogan LE, Meyer JA, Yang J, Wang J, Wong N, Yang W, Condos G, Hunger SP, Raetz E, Saffery R, Relling MV. Integrated genomic analysis of relapsed childhood acute lymphoblastic leukemia reveals therapeutic strategies. Blood. 2011 Nov 10;118(19):5218-26.

2. Nordlund J, Bäcklin CL, Wahlberg P, Busche S, Berglund EC, Eloranta ML, Flaegstad T, Forestier E, Frost BM, Harila-Saari A, Heyman M. Genome-wide signatures of differential DNA methylation in pediatric acute lymphoblastic leukemia. Genome biology. 2013 Sep;14(9):r105.

3. Benjamin AL, Green BB, Crooker BA, McKay SD, Kerr DE. Differential responsiveness of Holstein and Angus dermal fibroblasts to LPS challenge occurs without major differences in the methylome. BMC genomics. 2016 Dec;17(1):258. 
4. Almamun M, Levinson BT, van Swaay AC, et al. Integrated methylome and transcriptome analysis reveals novel regulatory elements in pediatric acute lymphoblastic leukemia. Epigenetics 2015;10:882-890.

5. Brenet F, Moh M, Funk P, Feierstein E, Viale AJ, Socci ND, Scandura JM. DNA methylation of the first exon is tightly linked to transcriptional silencing. PloS one. 2011 Jan 18;6(1):e14524.

6. Bhatla T, Wang J, Morrison DJ, Raetz EA, Burke MJ, Brown P, Carroll WL. Epigenetic reprogramming reverses the relapse-specific gene expression signature and restores chemosensitivity in childhood Blymphoblastic leukemia. Blood. 2012 May 31;119(22):5201-10.

7. Quillien V, Lavenu A, Karayan-Tapon L, Carpentier C, Labussière M, Lesimple T, Chinot O, Wager M, Honnorat J, Saikali S, Fina F. Comparative assessment of 5 methods (methylation-specific polymerase chain reaction, methylight, pyrosequencing, methylation-sensitive highresolution melting, and immunohistochemistry) to analyze O6methylguanine-DNA-methyltranferase in a series of 100 glioblastoma patients. Cancer. 2012 Sep 1;118(17):4201-11.

8. Ding W, Feng X, Li C. Transfection CXCR3 Gene into Lymphocytic Leukemia Cell Lines By Lentiviral Vector.

9. Valadez JA, Cuajungco MP. PAX5 is the transcriptional activator of mucolipin-2 (MCOLN2) gene. Gene 2015;555:194-202.

10. Jueliger S, Lyons J, Cannito S, Pata I, Pata P, Shkolnaya M, Lo Re O, Peyrou M, Villarroya F, Pazienza V, Rappa F. Efficacy and epigenetic 
interactions of novel DNA hypomethylating agent guadecitabine (SGI-110) in preclinical models of hepatocellular carcinoma. Epigenetics. 2016 Oct 2;11(10):709-20. 


\section{VITA}

Alexei Stuckel was born in Moscow, Russia in 1991. Alex started his college education in Biology and Chemistry in 2009 at the University of Missouri in Columbia, Missouri. After receiving his undergraduate degree in 2013, he was accepted into the Genetics Area PhD Program (GAP) at the University of Missouri. There he joined his past PI Dr. Kristen Taylor in the department of Pathology and Anatomical Sciences and began studying DNA methylation in relapsed pediatric acute lymphoblastic leukemia patients. In November of 2015, Alex was one of two graduate students chosen to speak at the national Epigenetics Symposium, hosted by Mizzou. During his graduate studies, he has served as a lab mentor for many undergraduate students. In 2018, Dr. Jeffrey Bryan took Alex in as his new advisor upon his former advisor's resignation. After receiving his $\mathrm{PhD}$ in genetics, he will begin his post-doctoral research in colorectal cancer at Harry S. Truman Memorial Veterans' Hospital. 